\title{
Synthesis and structure-activity relationships of C-glycosylated oxadiazoles as inhibitors of glycogen phosphorylase
}

\author{
Marietta Tóth ${ }^{\text {a }}$, Sándor Kun a , Éva Bokor a , Mahmoud Benltifa b,c,d,e , Gaylord Tallec b,c,d,e, \\ Sébastien Vidal ${ }^{\text {b,c,d,e, }}$, Tibor Docsa ${ }^{f}$, Pál Gergely ${ }^{g}$, László Somsák ${ }^{a, *}$, Jean-Pierre Praly b,c,d,e,* \\ ${ }^{a}$ Department of Organic Chemistry, University of Debrecen, POB 20, H-4010 Debrecen, Hungary \\ ${ }^{\mathrm{b}}$ Université de Lyon, Institut de Chimie et Biochimie Moléculaires et Supramoléculaires associé au CNRS, UMR 5246, Laboratoire de Chimie Organique 2, Bâtiment Curien, \\ 43 boulevard du 11 Novembre 1918, F-69622 Villeurbanne, France \\ ${ }^{\mathrm{c}}$ Université Lyon 1, F-69622 Villeurbanne, France \\ 10 d CNRS, UMR5246, Institut de Chimie et Biochimie Moléculaires et Supramoléculaires (ICBMS), Laboratoire de Chimie Organique 2, Bâtiment Curien, \\ 43 boulevard du 11 Novembre 1918, F-69622 Villeurbanne, France \\ ${ }^{\mathrm{e}}$ CPE-Lyon, F-69616 Villeurbanne, France \\ ${ }^{\mathrm{f}}$ Cell Biology and Signaling Research Group of the Hungarian Academy of Sciences at the Department of Medical Chemistry, Medical and Health Science Centre, \\ University of Debrecen, Egyetem tér 1, H-4032 Debrecen, Hungary \\ ${ }^{\mathrm{g}}$ Department of Medical Chemistry, Medical and Health Science Centre, University of Debrecen, Egyetem tér 1, H-4032 Debrecen, Hungary
}

\section{A R T I C L E I N F O}

\section{$20 \quad$ Article history:}

Received 8 January 2009

Revised 15 April 2009

Accepted 17 April 2009

Available online $\mathrm{xxxx}$

\section{Keywords:}

C-Glycosyl compounds

1,3,4-Oxadiazoles

1,2,4-Oxadiazoles

Glycogen phosphorylase

Inhibitors

\begin{abstract}
A B S T R A C T
A series of per-O-benzoylated 5- $\beta$-D-glucopyranosyl-2-substituted-1,3,4-oxadiazoles was prepared by acylation of the corresponding 5-( $\beta$-D-glucopyranosyl)tetrazole. As an alternative, oxidation of 2,6-anhydro-aldose benzoylhydrazones by iodobenzene I,I-diacetate afforded the same oxadiazoles. 1,3-Dipolar cycloaddition of nitrile oxides to per-O-benzoylated $\beta$-D-glucopyranosyl cyanide gave the corresponding 5 - $\beta$-D-glucopyranosyl-3-substituted-1,2,4-oxadiazoles. The $O$-benzoyl protecting groups were removed by base-catalyzed transesterification. The 1,3,4-oxadiazoles were practically inefficient as inhibitors of rabbit muscle glycogen phosphorylase $b$ while the 1,2,4-oxadiazoles displayed inhibitory activities in the micromolar range. The best inhibitors were the 5- $\beta$-D-glucopyranosyl-3-(4-methylphenyl- and -2naphthyl)-1,2,4-oxadiazoles ( $K_{\mathrm{i}}=8.8$ and $11.6 \mu \mathrm{M}$, respectively). A detailed analysis of the structureactivity relationships is presented.
\end{abstract}

() 2009 Published by Elsevier Ltd.

\section{Introduction}

The worldwide increasing prevalence of Type 2 Diabetes Mellitus (T2DM) has become a major health problem for most of the world's population. ${ }^{1}$ Several oral hypoglycemic agents ${ }^{2-4}$ (sulfonylureas, biguanides, thiazolidinediones, $\alpha$-glucosidase inhibitors ${ }^{5}$ ) are now being used to help diabetic patients to reduce hyperglycemia. Such symptomatic treatments are intended to reach normal physiological blood glucose levels. However, they have several undesirable side effects and may also cause hypoglycemia. ${ }^{6}$ These drugs are inadequate for $30-40 \%$ of patients. ${ }^{7}$ Due to the appearance and spreading of T2DM âmong young adults as well as children, the coming decades must face severe economic and health service burdens. ${ }^{8-10}$ Fuelled by all these facts, several new therapeutic possibilities are under investigation. ${ }^{11-13}$ Among them, liver glycogen phosphory-

\footnotetext{
* Corresponding authors. Tel.: +36 52512 900; fax: +36 52453836 (L.S.); fax: +334 78898914 (J.-P.P.).

E-mail addresses: somsak@tigris.unideb.hu, somsak@tigris.klte.hu (L. Somsák), jean-pierre.praly@univ-lyon1.fr (J.-P. Praly).
}

tion of glycogen, has been shown to be a target for the treatment of T2DM. ${ }^{14,15}$ Since GP appears as the rate limiting enzyme of glycogen degradation, its inhibition may offer a means for regulating blood sugar levels.

A number of inhibitors have been discovered and designed in recent years targeting the different binding sites identified for GP. ${ }^{20,25}$ Among these inhibitors, a large array of glucose derivatives binds at the catalytic site of the enzyme. ${ }^{20,25}$ Among the first efficient glucose analogs were the $\mathrm{N}$-acyl-glucopyranosylamines, for example, 1a,b,h,i (Chart 1), and further inhibitor design led to the discovery of more potent $N$-acyl- $N^{\prime}-\beta$-D-glucopyranosyl-ureas like 2a,b,h,i. As another class of efficient molecules, we developed several inhibitors having $C$-glucosyl heterocyclic structural elements such as tetrazole $\mathbf{3}$, benzimidazole $\mathbf{4}$, benzothiazole $\mathbf{5}$, 1,3,4-oxadiazole ${ }^{21,22} \mathbf{6 a}$ and 1,2,4-oxadiazoles $\mathbf{7 a , b , \mathbf { i }}$ and $\mathbf{8 b},{ }^{23,24}$ as well as hydroquinone derivatives. ${ }^{26}$ Several of these compounds displayed an inhibition against rabbit muscle glycogen phosphorylase $b$ (RMGPb) in the low micromolar range.

In the 3- $\beta$-D-glucopyranosyl-5-substituted 1,2,4-oxadiazole series, the 2-naphthyl derivative $7 \mathbf{i}$ was shown to be the best 


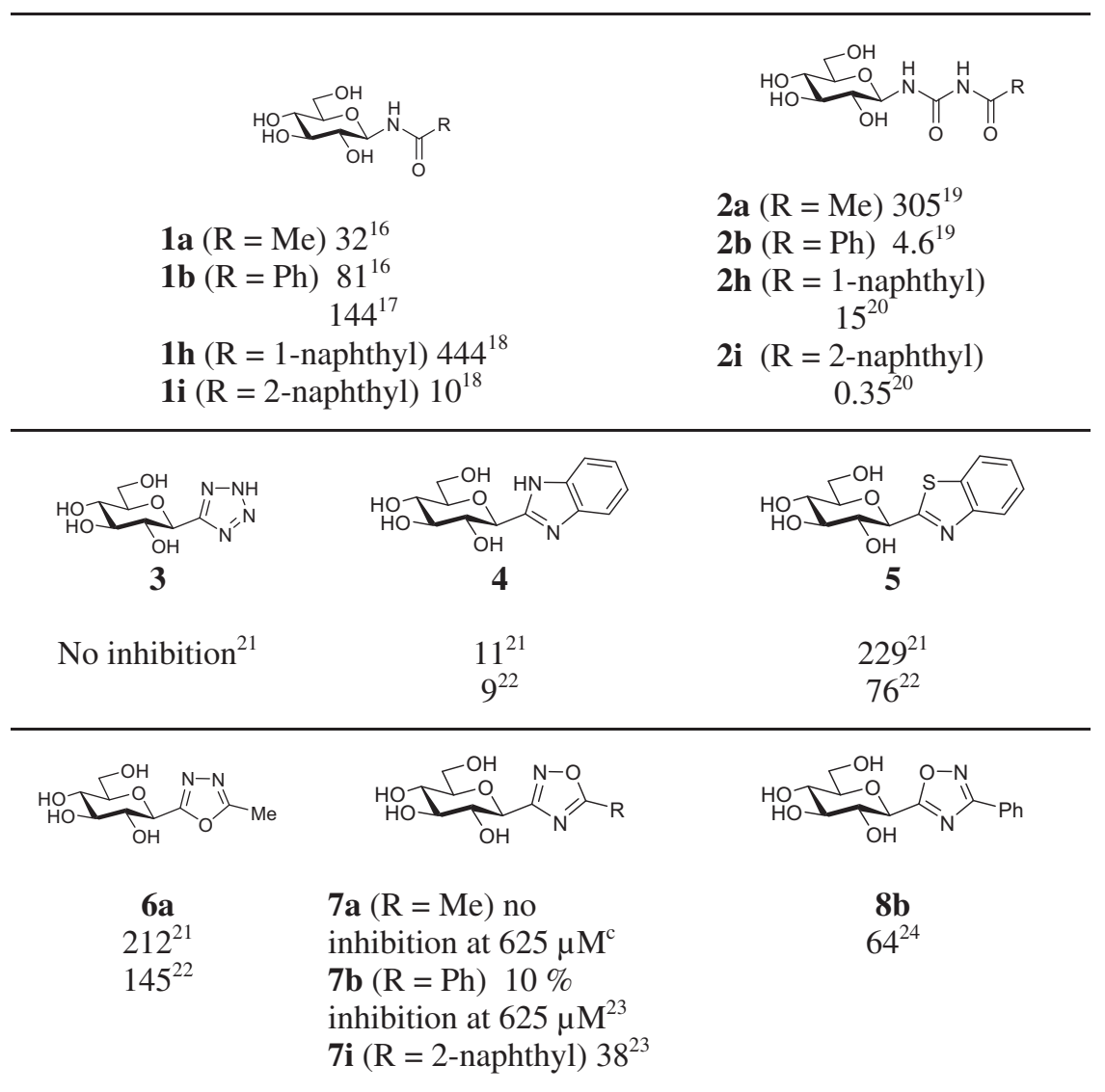

Q3 Chart 1. Inhibition of rabbit muscle glycogen phosphorylase ${ }^{\mathrm{a}}$ (RMGP) $b\left(K_{\mathrm{i}}[\mu \mathrm{M}]\right)$ by selected glucose-based derivatives ${ }^{\mathrm{b}}$.

aBecause of a $\sim 80 \%$ homology between the liver and muscle isoforms of GP, it is a general practice to use the more readily available RMGP for kinetic studies.

${ }^{\mathrm{b}}$ Numbering of molecules is based on the complete set of molecules presented in Table 1.'Unpublished results.

inhibitor. ${ }^{23}$ This finding was similar to the observations made with the $N$-acyl- $\beta$-D-glucopyranosylamines ${ }^{18} \mathbf{1 a}, \mathbf{b}, \mathbf{h}, \mathbf{i}$ and $N$-acyl- $N^{\prime}-\beta$-Dglucopyranosyl-ureas ${ }^{19,20} \mathbf{2 a , b}, \mathbf{h}, \mathbf{i}$. Especially in the latter series of compounds, the presence of a hydrophobic aromatic appendage properly oriented (comparing $\mathbf{2 h}$ to $\mathbf{2} \mathbf{i}$ ) proved beneficial for the strong binding to GP. This result was explained by the favorable interactions of the inhibitor in the so-called $\beta$-channel ${ }^{19}$ in the vicinity of GP's catalytic site which is an empty space surrounded by amino-acid residues of mixed character. ${ }^{14,20}$

Since the preliminary results obtained with the two other isomeric oxadiazoles (6a and $\mathbf{8 b}$ ) were encouraging with respect to GP inhibition, we planned a broader study of structure-activity relationships of $\mathrm{C}$-glucosylated oxadiazoles. We present herein the synthesis of $5-(\hat{\beta}$-D-glycopyranosyl) derivatives of 2 -substituted1,3,4- and 3-substituted-1,2,4-oxadiazoles with a diverse set of aromatic residues as well as a detailed comparative analysis of structure-activity relationships of the different isomeric oxadiazole derivatives.

\section{Results and discussion}

The nature of the aryl substituent of the oxadiazole ring is influencing the binding to the enzyme's catalytic site. We therefore prepared a series of molecules incorporating either basic ( $p$-amino), acidic ( $p$-hydroxy) or neutral ( $p$-methyl, $p$-methoxy, $p$-nitro) substituents on the phenyl residues as well as larger aromatic moieties (1- and 2-naphthyl). The syntheses of the target oxadiazoles were achieved using per-O-benzoylated $\beta$-D-glucopyranosyl cyanide $\mathbf{9}$ as a common starting material.

\subsection{Synthesis of 2-aryl-5-(D-glycopyranosyl)-1,3,4-oxadiazoles}

C-Glycosyl-1,3,4-oxadiazoles were prepared earlier in various sugar configurations by acylation of 5-(D-glycosyl)tetrazoles with an excess of acid chlorides or anhydrides, ${ }^{27-29}$ compound $\mathbf{6 a}$ being the only $\beta$-D-glucopyranosyl derivative among them. ${ }^{21}$ In the present study, we have investigated the use of acyl chlorides in pyridine or toluene, and also applied a DCC-mediated acylation by the corresponding carboxylic acid ${ }^{30}$ (Scheme 1 ). The yields for the acylation of tetrazole $\mathbf{1 0}$, obtained from $\mathbf{9}$ as earlier, ${ }^{21}$ were slightly higher in pyridine than in toluene, and the DCC coupling proved less satisfactory to get oxadiazoles $\mathbf{1 1}$.

A widely used method for the preparation of unsymmetrically 2,5-disubstituted-1,3,4-oxadiazoles is the oxidation of acylhydrazones by using a variety of oxidizing agents. ${ }^{31-36}$ This method was extended to anhydro-aldose benzoylhydrazone 12 which was obtained from 9 by our recently published method ${ }^{37}$ and oxidized by iodobenzene I,I-diacetate (PIDA) to give oxadiazole $\mathbf{1 1 b}$ in excellent yield (Scheme 1). The two alternative methods for getting 11b are similar in the number of synthetic steps as well as technical difficulties. However, route e-f gave higher overall yield as compared to route $\mathrm{a}-\mathrm{b}$ or $\mathrm{a}-\mathrm{d}$ (Scheme 1 ). To show the applicability of this oxidative method, anhydro-aldose benzoylhydrazones $\mathbf{1 4 a}-\mathbf{c}^{41}$ were also converted to the corresponding oxadiazoles 15 a-c in good yields (Scheme 2 ). Removal of the $O$-acyl protecting groups from oxadiazoles $\mathbf{1 1}$ was achieved by the Zemplén protocol to give glucopyranosyl oxadiazoles $\mathbf{6}$ (Scheme 1). Raney-nickel catalyzed reduction of the nitro group in $\mathbf{6 e}$ afforded amino compound $6 \mathbf{f}$. 


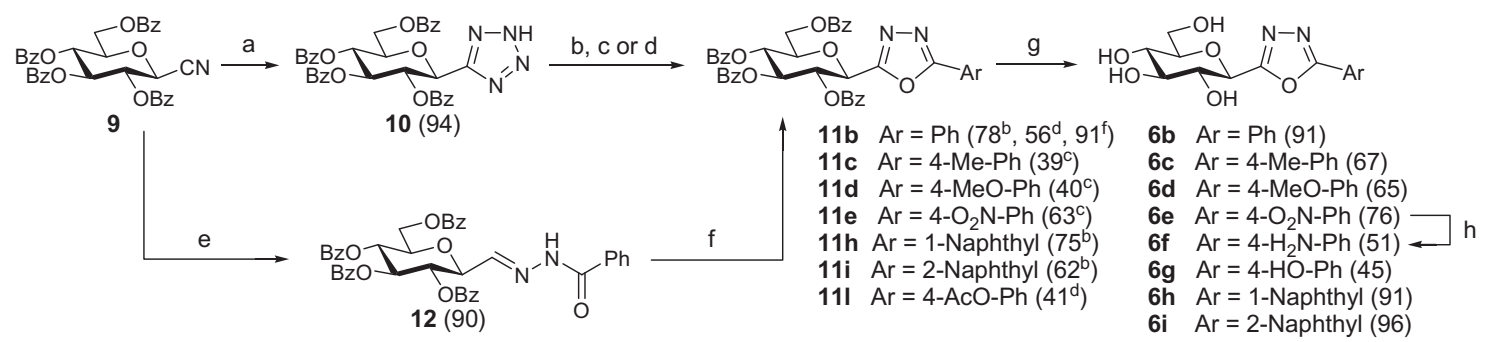

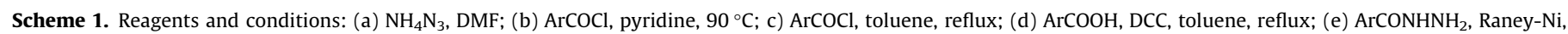
$\mathrm{NaH}_{2} \mathrm{PO}_{2}, \mathrm{AcOH}, \mathrm{H}_{2} \mathrm{O}$, pyridine, $40{ }^{\circ} \mathrm{C}$; (f) $\mathrm{PhI}(\mathrm{OAc})_{2}, \mathrm{CH}_{2} \mathrm{Cl}_{2}$, rt; (g) NaOMe, MeOH, rt; (h) Raney-Ni, $\mathrm{H}_{2}$, MeOH, $60{ }^{\circ} \mathrm{C}$. Yields $(\%)$ are indicated in parentheses.

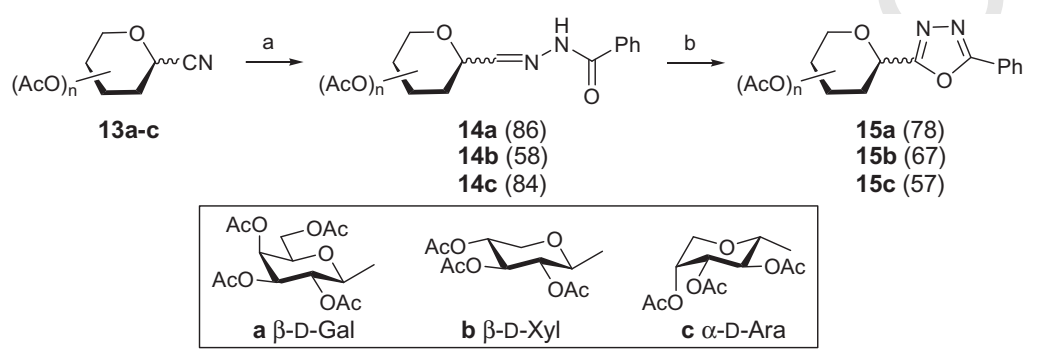

Scheme 2. Reagents and conditions: (a) $\mathrm{ArCONHNH}_{2}$, Raney-Ni, $\mathrm{NaH}_{2} \mathrm{PO}_{2}, \mathrm{AcOH}, \mathrm{H}_{2} \mathrm{O}$, pyridine, $40{ }^{\circ} \mathrm{C}$; b) $\mathrm{PhI}(\mathrm{OAc})_{2}$, $\mathrm{CH}_{2} \mathrm{Cl} \mathrm{Cl}_{2}, \mathrm{rt}$. Yields $(\%)$ are indicated in parentheses.

\subsection{Synthesis of 3-aryl-5-( $\beta$-D-glucopyranosyl)-1,2,4- oxadiazoles $^{24}$}

1,3-Dipolar cycloaddition of nitrile oxides to nitriles provides an efficient and short route to diversely substituted 1,2,4-oxadiazoles. The nitrile oxides can be easily obtained from the corresponding hydroximoyl chloride precursors $\mathbf{1 6}$ which will undergo a dehydrohalogenation in the presence of a base. The addition of the base must occur in the presence of the dipolarophile in order to avoid the formation of nitrile oxide dimers. Hydroximoyl chlorides are therefore synthesized in a two-step process from the corresponding aldehydes by a reaction with hydroxylamine hydrochloride to afford the oxime intermediates which are then treated with $\mathrm{N}$-chlorosuccinimide to afford the desired hydroximoyl chlorides $\mathbf{1 6}$ (Scheme 3). The purification of the oxime intermediates was required in order to obtain reproducible results and also to reach high purity of the hydroximoyl chlorides since their purification by standard column chromatography was usually not successful due to their poor stability. Glucosyl cyanide 9 was then reacted with the hydroximoyl chlorides $\mathbf{1 6}$ in the presence of $\mathrm{Et}_{3} \mathrm{~N}$ at low concentration in refluxing toluene to afford the desired 1,2,4-oxadiazoles 17 . The addition of the base was achieved at a slow rate with a syringe pump. Subsequent transesterification of the benzoate esters under Zemplén conditions afforded the expected 1,2,4-oxadiazoles 8 in high yields. A small proportion $(4-8 \%)$ of 1,2 -endo-glycals $\mathbf{1 8 b}$-e,i were also isolated while their formation could not be detected for other aryl substituents. We previously observed that a substituent at the 5-position of the 1,2,4-oxadiazole ring possessing an acid-labile $\alpha$-proton would be susceptible of deprotonation or even $\beta$-elimination if a leaving group is present at the $\beta$-position. ${ }^{22}$ Similar observations were made with other ester protected carbohydrate derivatives such as glycosyl cyanides ${ }^{29,38-40} C$-glycosyl thiadiazole ${ }^{41}$ or benzothiazole. $^{29}$ Interestingly, this elimination was not observed in the 1,3,4-oxadiazole series 11. Finally, the reduction of the $p$-nitrophenyl-substituted derivative 8 e to the corresponding $p$-aminophenyl oxadiazole 8 f was achieved under standard hydrogenation conditions ( $\left.\mathrm{Pd}-\mathrm{C} 10 \%, \mathrm{H}_{2}, 1 \mathrm{~atm}\right)$.

The $p$-benzyloxy-phenyl derivative $\mathbf{8 j}$ was initially prepared in order to obtain the $p$-hydroxy-phenyl substituted oxadiazole $\mathbf{8 g}$ through hydrogenolysis of the benzyl group. But, since the direct
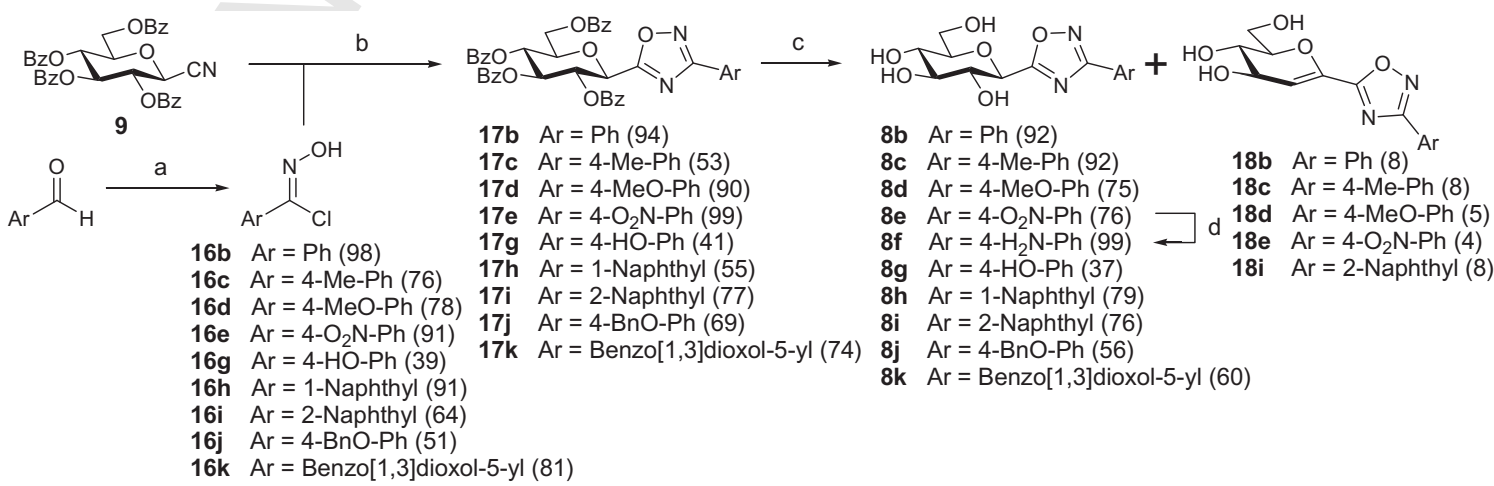

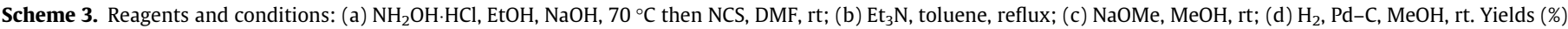
are indicated in parentheses. 
access to $\mathbf{8 g}$ could be achieved using the general synthetic route from $\alpha$-chloroarylaldoxime $\mathbf{1 6 g}$, we therefore considered the $p$-benzyloxy-phenyl derivative $\mathbf{8 j}$ as an additional candidate for the inhibition of GP. The benzo[1,3]dioxol-5-yl substituted 1,2,4oxadiazole 8k was synthesized in order to evaluate its inhibition towards the enzyme since the hydrophobic aromatic residue could interact with the $\beta$-channel of GP and also since this aromatic residue can be found as a pharmacophore in a series of natural products and synthetic drugs.

\subsection{Enzymatic evaluation of oxadiazoles as GP inhibitors}

The kinetic parameters of the synthesized molecules were then determined according to our previously described enzymatic protocol. ${ }^{26}$ We compared the inhibition properties of C-glucosylated 1,3,4-oxadiazoles 6 and 1,2,4-oxadiazoles 8 with the activity of regioisomeric 1,2,4-oxadiazoles $7, \mathrm{~N}$-acyl- $\beta$-D-glucopyranosylamines 1 and $N$-acyl- $N^{\prime}-\beta$-D-glucopyranosyl ureas $\mathbf{2}$ (Table 1 ).

In the $N$-acyl- $N^{\prime}-\beta$-D-glucopyranosyl urea series $\mathbf{2}$, an overall equivalent inhibition in the micromolar range was observed for the benzoyl analogs ( $2 \mathbf{b}-\mathbf{g} \mathrm{R}=(\mathrm{p}$-substituted)phenyl). The 1-naphthoyl derivative $\mathbf{2 h}$ was a somewhat worse inhibitor of GP. A simple change to the 2-naphthoyl moiety (2i) remarkably improved the inhibition compared to $\mathbf{2 h}$ (43-fold increase) and more moderately in comparison to the benzoyl derivative $\mathbf{2 b}$ (13-fold increase). The 2-naphthoyl derivative $\mathbf{2 i}$ was the first glucose-based inhibitor with sub-micromolar activity against GP. In the series $N$-acyl- $\beta$-D-glucopyranosylamines $\mathbf{1}$, a similar observation could be made since the 2-naphthoyl derivative $1 \mathbf{i}$ was the best inhibitor, found much more effective (44-fold) than $\mathbf{1 h}$, with a regioisomeric 1-naphthoyl residue. Other members of this family displayed usually weak inhibition with the exception of the acetyl derivative $1 \mathrm{a}$ with a $K_{\mathrm{i}}$ value of $32 \mu \mathrm{M}$. The methyl substituted oxadiazoles 6a and 7a and acetyl urea 2a showed poor (6a, 2a) or no detectable (7a) inhibition.

The 3-C-glucosylated 1,2,4-oxadiazoles 7 with a large series of aromatic substituents displayed the same inhibition pattern with the 2-naphthyl derivative $\mathbf{7 i}$ as the best inhibitor in the series. The phenyl substituted oxadiazole $\mathbf{7 b}$ was a poor inhibitor and the $p$-nitrophenyl derivative $7 \mathbf{e}$ displayed the worst inhibition in the series. This detrimental effect exerted by the nitro group was not observed in the acyl urea series (compare 7e and 2e). Nevertheless, the biological activity of these 3-C-glucosylated

Table 1

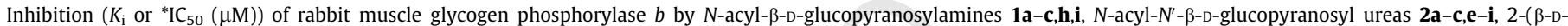

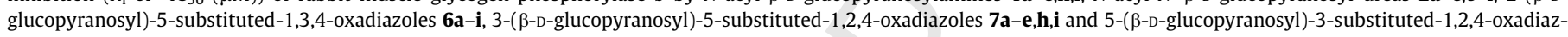
oles $\mathbf{8 b}-\mathbf{k}$

\begin{tabular}{|c|c|c|c|c|c|c|c|c|c|c|}
\hline $\mathrm{R}$ & & & & $\prod_{0}^{\mathrm{H}} \prod_{\mathrm{O}}^{\mathrm{H}}$ & & $\mathrm{HO}_{\mathrm{O}}^{\mathrm{N}-\mathrm{N}}$ & & $\stackrel{N}{N}_{N}^{\mathrm{N}-O}$ & & H \\
\hline \multirow[t]{11}{*}{$-\mathrm{CH}_{3}$} & 1a & $32^{16}$ & $2 \mathbf{a}$ & $305^{19}$ & $6 a$ & $\begin{array}{l}212^{21} \\
145^{22}\end{array}$ & $7 \mathbf{a}$ & No inhibition at $625 \mu \mathrm{M}$ & & - \\
\hline & 1b & $\begin{array}{l}81^{16} \\
144^{17}\end{array}$ & $\mathbf{2 b}$ & $4.6^{19}$ & $6 \mathbf{b}$ & $10 \%$ at $625 \mu \mathrm{M}$ & $7 \mathbf{b}$ & $10 \%$ at $625 \mu \mathrm{M}^{23}$ & $\mathbf{8 b}$ & 64 \\
\hline & 1c & $4500^{* 18}$ & $2 c$ & $2.3^{20}$ & $6 c$ & No inhibition at $625 \mu \mathrm{M}$ & 7c & $350^{* 23}$ & $8 c$ & 8.8 \\
\hline & & - & & - & 6d & No inhibition at $625 \mu \mathrm{M}$ & 7d & $550^{* 23}$ & 8d & 20.4 \\
\hline & & - & $2 e$ & $3.3^{20}$ & $6 e$ & No inhibition at $625 \mu \mathrm{M}$ & 7e & No inhibition at $625 \mu \mathrm{M}$ & $8 e$ & $650^{*}$ \\
\hline & & - & $2 f$ & $6.0^{20}$ & $6 f$ & No inhibition at $625 \mu \mathrm{M}$ & & - & $8 f$ & $20 \%$ at $625 \mu \mathrm{M}$ \\
\hline & & & $2 \mathrm{~g}$ & $6.3^{20}$ & $6 g$ & No inhibition at $625 \mu \mathrm{M}$ & & - & $8 g$ & 19.4 \\
\hline & 1h & $444^{18}$ & $2 \mathbf{h}$ & $15^{20}$ & $6 h$ & $10 \%$ at $625 \mu \mathrm{M}$ & 7h & No inhibition at $625 \mu \mathrm{M}$ & $8 h$ & 19.0 \\
\hline & $\mathbf{1 i}$ & $10^{18}$ & $\mathbf{2 i}$ & $0.35^{20}$ & $6 \mathbf{i}$ & $10 \%$ at $625 \mu \mathrm{M}$ & $7 \mathbf{i}$ & $38^{23}$ & $\mathbf{8 i}$ & $11.6^{\mathrm{a}}$ \\
\hline & & - & & & & - & & - & $8 \mathbf{j}$ & No inhibition at $625 \mu \mathrm{M}$ \\
\hline & & - & & & & - & & - & $\mathbf{8 k}$ & $>625^{*}$ \\
\hline
\end{tabular}

${ }^{\text {a }}$ A $K_{\mathrm{i}}$ value of $2.4 \mu \mathrm{M}$ was measured independently by N. G. Oikonomakos and co-workers (unpublished results). 


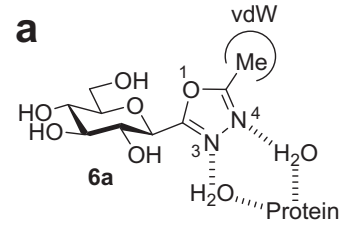

b

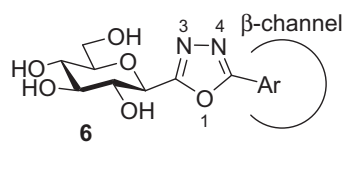

C

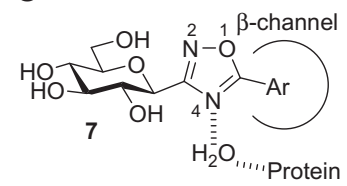

d

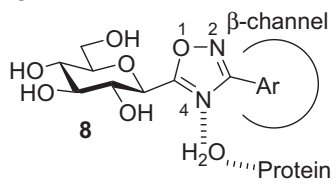

Figure 1. Observed and probable orientations of the heterocyclic moieties of C-glucosyl oxadiazole type inhibitors upon binding to the catalytic site of GP.

1,2,4-oxadiazoles 7 was always weaker than the corresponding $N$-acyl- $N^{\prime}-\beta$-D-glucopyranosyl ureas 2 .

The 5-C-glucosylated 1,2,4-oxadiazoles $\mathbf{8}$ are generally better inhibitors than the corresponding 3 -C-glucosylated counterparts $\mathbf{7}$ and followed a similar trend with the 2-naphthyl derivative $\mathbf{8 i}$ being among the best (displaying a value very close to the strongest inhibitor 8c ) and the $p$-nitrophenyl $\mathbf{8 e}$ the worst in the series. The weak inhibition observed for the $p$-benzyloxy-phenyl derivative $\mathbf{8 j}$ might be attributed to the steric hindrance of the benzyl moiety in comparison to the naphthyl residue and also to the rotation around the methylene benzylic group creating an entropy loss for the binding process.

Very surprisingly, the 1,3,4-oxadiazoles $\mathbf{6}$ with a substituent larger than methyl did not display any meaningful inhibition against RMGP $b$. To explain this unexpected result, we propose to consider the binding peculiarities of these molecules to the active site of GP as revealed by X-ray crystallography. Because of the lack of binding of the 1,3,4-oxadiazoles one has to go back to the structure of the enzyme-inhibitor complex obtained with the methylated analogue $\mathbf{6 a}$, while an X-ray structure is available for the enzyme-complex of the 2-naphthyl substituted $\mathbf{8 i}$. $^{25}$

There are no direct $\mathrm{H}$-bonds between the heterocycle of $\mathbf{6 a}$ and the protein, however, an extensive $\mathrm{H}$-bond network involving nitrogen atoms $\mathrm{N}-3$ and $\mathrm{N}-4$ exists with the participation of water molecules. ${ }^{22}$ As a result, 6a binds in the orientation shown in Figure 1a. The compound can be accommodated at the catalytic site with essentially no disturbance of the protein structure. The relatively small methyl group makes 6 van der Waals interactions while the $\beta$-channel remains unoccupied.

Similarly, no direct H-bonds could be observed between the heterocycle of 5-glucosyl-1,2,4-oxadiazole $8 \mathbf{i}$ and the protein. ${ }^{25}$ The nitrogen atom N-4 takes part in a H-bond network mediated by water molecules. Due to the isomeric constitution of the heterocyclic part of this molecule as compared to $\mathbf{6 a}$, the 3-substituent is in a favorable position to make interactions with residues surrounding the $\beta$-channel. The aromatic moiety makes 11 van der Waals contacts in the $\beta$-channel for the 2-naphthyl derivative $\mathbf{8 i}$. These interactions result in a strong binding with the orientation of 8i represented by Figure 1d. For the isomeric oxadiazoles 7 (Fig. 1c), a similar interaction pattern and orientation can be postulated. In the case of the 1,3,4-oxadiazole series with large aromatic substituents (6), interactions in the $\beta$-channel would require a rotameric orientation of the heterocycle as shown in Figure 1b. However, this conformation would ultimately result in a loss of participation of $\mathrm{N}-3$ and $\mathrm{N}-4$ in the H-bond network. In the other orientation (like in Fig. 1a), the accommodation of large substituents in the vicinity of the catalytic site would most probably significantly disturb the protein structure. These factors together prevent compounds $\mathbf{6}$ from strong binding to GP.

\section{Conclusion}

The synthesis of three series of C-glycosylated oxadiazoles could be achieved from per-O-benzoylated $\beta$-D-glucopyranosyl cyanide as a common starting material. Its transformation either into the corresponding 5-( $\beta$-D-glucopyranosyl)tetrazole and subsequent acylation or into anhydro-aldose acylhydrazones followed by oxidation furnished 2-( $\beta$-D-glucopyranosyl)-5-substituted1,3,4-oxadiazoles. 1,3-Dipolar cycloaddition of nitrile oxides to the cyanide moiety afforded 5-( $\beta$-D-glucopyranosyl)-3-substituted-1,2,4-oxadiazoles. The regioisomeric 3-( $\beta$-D-glucopyranosyl)-5-substituted-1,2,4-oxadiazoles were prepared previously by ring closure of intermediate $\mathrm{O}$-acyl-amidoximes.

Enzyme kinetic evaluation of these inhibitors showed that the nature of the oxadiazole ring attached to C -1 of glucopyranose is strongly influencing the inhibitory activity towards RMGP $b$. While the 1,3,4-oxadiazoles proved practically inactive, the 1,2,4-oxadiazole series displayed inhibition in the micromolar range with the 5 glucosylated derivatives being superior to their 3-glucosylated regioisomers. The nature of the $p$-substituent of the phenyl moiety exhibited a similar influence on the inhibition of GP in each series. In addition, the size and orientation of the aromatic substituent of the oxadiazole strongly modulated the activity. The 2-naphthyl derivatives in both 1,2,4-oxadiazole series were among the best inhibitors. A possible explanation was proposed to understand the differences in the inhibitory strengths of the isomeric oxadiazoles.

\section{Experimental}

\subsection{General methods}

Thin-layer chromatography (TLC) was carried out on aluminum sheets coated with Silica Gel $60 \mathrm{~F}_{254}$ (Merck). TLC plates were inspected by UV light $(\lambda=254 \mathrm{~nm})$ and developed by treatment with a mixture of $10 \% \mathrm{H}_{2} \mathrm{SO}_{4}$ in EtOH/H $\mathrm{H}_{2} \mathrm{O}(1 / 1 \mathrm{v} / \mathrm{v})$ followed by heating. Silica gel column chromatography was performed with Geduran ${ }^{\circledR}$ Silica Gel Si $60(40-63 \mu \mathrm{m})$ purchased from Merck (Darmstadt, Germany). Reversed-phase silica gel column chromatography was performed on a Varian Bond Elut C18 $(20 \mathrm{~mm}$, $15 \mathrm{~mm}$ diameter). ${ }^{1} \mathrm{H}$ and ${ }^{13} \mathrm{C}$ NMR spectra were recorded at $23{ }^{\circ} \mathrm{C}$ using Bruker AC200, DRX300, WP 360 SY, or DRX500 spectrometers with TMS or the residual solvent as the internal standard. The following abbreviations are used to explain the observed multiplicities: s, singlet; d, doublet; dd, doublet of doublet; ddd, doublet of doublet of doublet; $t$, triplet; td, triplet of doublet; q, quadruplet; m, multiplet; br, broad; p, pseudo. Structure elucidation was deduced from 1D and 2D NMR spectroscopy which allowed, in most cases, complete signal assignments based on COSY, HSQC and HMBC correlations. Atoms in the pyranosyl rings are numbered by primed figures and the aryl substituents with double-primed figures while those of the oxadiazole ring have the oxa suffix. NMR solvents were purchased from Euriso-Top (Saint Aubin, France) or Sigma-Aldrich. HRMS (LSIMS) mass spectra were recorded in the positive mode using a Thermo Finnigan Mat 95 XL spectrometer. MS (ESI) mass spectra were recorded in the positive mode using a Thermo Finnigan LCQ spectrometer. Optical rotations were measured using a Perkin Elmer polarimeter. Elemental analyses were performed at the Service Central d'Analyses du CNRS (Vernaison, France).

Method A: To a solution of tetrazole $10(700 \mathrm{mg}, 1.08 \mathrm{mmol})$ in abs. pyridine $(10 \mathrm{~mL})$ the corresponding acid chloride $(5.40 \mathrm{mmol})$ 
was added. The reaction mixture was stirred at $90{ }^{\circ} \mathrm{C}$ for $\lambda \mathrm{h}$. It was then cooled to $\mathrm{xt}$, water was added, and extracted with $\mathrm{CH}_{2} \mathrm{Cl}_{2}$ $(3 \times 40 \mathrm{~mL})$. The combined organic phase was washed with saturated aqueous $\mathrm{NaHCO}_{3}$ solution and water. The organic phase was dried $\left(\mathrm{MgSO}_{4}\right)$, concentrated under diminished pressure and the crude product was purified by column chromatography (hexane-EtOAc 3:1) and then crystallized from EtOH.

Method R: Perbenzoylated glucopyranosyl-tetrazole 10 was dissolved in abs. toluene $(100 \mathrm{mg} / \mathrm{mL})$ then acid chloride $(1.2-$ 2 equiv) was added in one portion. The mixture was refluxed and monitored by TLC. After disappearance of the starting material the solvent was removed under diminished pressure, the residue was purified by column chromatography if necessary and c्रrystallized from EtOH.

Method $C$ : An anhydro-aldose benzoylhydrazone (12 or 14, $0.25 \mathrm{mmol})$ was dissolved in $\mathrm{CH}_{2} \mathrm{Cl}_{2}(2.4 \mathrm{~mL})$ and PIDA $(159 \mathrm{mg}, 0.50 \mathrm{mmol})$ was added. The reaction mixture was stirred at $\mathrm{rt}$. When the reaction was complete (TLC: EtOAc/hexane, $1: 1)$, the solution was diluted with $\mathrm{CH}_{2} \mathrm{Cl}_{2}(4 \mathrm{~mL})$ and water $(2 \mathrm{~mL})$. The aqueous layer was extracted with $\mathrm{CH}_{2} \mathrm{Cl}_{2}$ $(3 \times 4 \mathrm{~mL})$, then the combined organic layers were washed with cold saturated $\mathrm{NaHCO}_{3}$ solution $(1 \times 5 \mathrm{~mL})$, dried $\left(\mathrm{Na}_{2} \mathrm{SO}_{4}\right)$ and filtered. The solvent was removed by evaporation under diminished pressure and the residue purified by column chromatography (EtOAc/hexane, 1:2).

Method D: A solution of arylaldehyde ( $40 \mathrm{mmol})$, hydroxylamine hydrochloride ( $80 \mathrm{mmol}, 2$ equiv) and sodium hydroxide ( $80 \mathrm{mmol}, 2$ equiv) in EtOH $(50 \mathrm{~mL})$ was stirred at $78^{\circ} \mathrm{C}$ for $2 \mathrm{~h}$. The suspension was filtered and the solid washed with EtOH $(2 \times 20 \mathrm{~mL})$. The filtrate was evaporated and the residue dissolved in EtOAc $(150 \mathrm{~mL})$. The organic layer was washed with water $(3 \times 70 \mathrm{~mL})$, dried $\left(\mathrm{Na}_{2} \mathrm{SO}_{4}\right)$, filtered and evaporated to dryness. A portion of the crude arylaldoxime $(7 \mathrm{mmol})$ was then dissolved in DMF (10 mL) and NCS (7 mmol, 1 equiv) was added in 8-10 portions. The reaction was slightly exothermic and NCS portions were added slowly in order to maintain the temperature at $35-40^{\circ} \mathrm{C}$. If no heat was generated after the first two additions of NCS, a stream of $\mathrm{HCl}$ (generated ex situ from $\mathrm{NaCl}$ and $\mathrm{H}_{2} \mathrm{SO}_{4}$ ) was bubbled through the solution in order to start the reaction then stopped when the temperature reached $35-40{ }^{\circ} \mathrm{C}$. The reaction was then stirred for $3 \mathrm{~h}$ at $\mathrm{rt}$ and poured into EtOAc $(100 \mathrm{~mL})$. The organic layer was washed with water $(3 \times 50 \mathrm{~mL})$, dried $\left(\mathrm{Na}_{2} \mathrm{SO}_{4}\right)$, filtered and evaporated to dryness. The hydroximoyl chlorides $\mathbf{1 6} \mathbf{b}-\mathbf{e}, \mathbf{g}-\mathbf{k}$ were used for cycloadditions without further purification.

Method E: A solution of glucosyl cyanide $9(0.5 \mathrm{mmol})$ and a hydroximoyl chloride $(2.5 \mathrm{mmol}, 5$ equiv) in toluene $(5 \mathrm{~mL})$ was stirred at $110{ }^{\circ} \mathrm{C}$ under argon. ${ }^{\wedge}$ Triethylamine $(3.75 \mathrm{mmol}$, 7.5 equiv) was dissolved in toluene $(5 \mathrm{~mL})$ and slowly added in $12 \hat{\mathrm{h}}$ with a syringe pump. The reaction was stirred at $110^{\circ} \mathrm{C}$ for an additional $12 \mathrm{~h}$ then the solvent was evaporated under diminished pressure. The residue was purified by flash silica gel column chromatography to afford the desired 1,2,4-oxadiazoles 17.

Method F: A solution of the acyl-protected carbohydrate derivatives $17(0.15 \mathrm{mmol})$ and $\mathrm{NaOMe}(50 \mu \mathrm{L}, 1 \mathrm{M}$ in $\mathrm{MeOH})$ in $\mathrm{MeOH}$ $(3 \mathrm{~mL})$ was stirred at $\mathrm{rt}$ for $3 \mathrm{~h}$. The solution was then neutralized to $\mathrm{pH} 5$ with a cation exchange resin (DOWEX 50WX2, $\mathrm{H}^{+}$form). The resin was filtered off and washed with $\mathrm{MeOH}(3 \times 10 \mathrm{~mL})$ then the filtrate was evaporated under diminished pressure. The residue was purified by flash silica gel column chromatography to afford the desired carbohydrate derivatives $\mathbf{8}$.

Method G: The benzoylated compounds $\mathbf{1 1}$ were dissolved in a mixture of abs. $\mathrm{MeOH}$ and abs. $\mathrm{CHCl}_{3}$ and $1 \mathrm{M}$ methanolic sodium methoxide solution was added to the solutions in catalytic amount. The reaction mixture was kept at room temperature for a given time and then neutralized with a cation exchange resin Amberlyst
$15\left(\mathrm{H}^{+}\right.$form $)$. After filtration and removal of the solvent under diminished pressure, the crude product was purified by crystallization from $\mathrm{Et}_{2} \mathrm{O}$ or by column chromatography to afford the deprotected carbohydrate derivatives $\mathbf{6}$.

\subsection{Synthesis of 5-aryl-2-(2,3,4,6-tetra-O-benzoyl- $\beta$-D- glucopyranosyl)-1,3,4-oxadiazoles}

\subsubsection{5-( $\beta$-D-Glucopyranosyl)-2-phenyl-1,3,4-oxadiazole (6b)}

Prepared according to method G. Yield: 91\% (white crystals). $\mathrm{Mp}=165-167^{\circ} \mathrm{C} .[\alpha]_{\mathrm{D}}^{20}=+33$ (c 0.2, MeOH). ${ }^{1} \mathrm{H}$ NMR $(360 \mathrm{MHz}$, $\left.\mathrm{CD}_{3} \mathrm{OD}\right): \delta=8.04-7.52(\mathrm{~m}, 5 \mathrm{H}, \mathrm{H}-\mathrm{ar}) 4.61(\mathrm{~d}, 1 \mathrm{H}, J=10.6 \mathrm{~Hz}, \mathrm{H}-$ $1^{\prime}$ ), 3.87 (pdd, $\left.1 \mathrm{H}, J<1 \mathrm{~Hz}, J=11.9 \mathrm{~Hz}, \mathrm{H}-6^{\prime} \mathrm{a}\right), 3.78$ (t, $1 \mathrm{H}$, $J=9.3 \mathrm{~Hz}, \mathrm{H}-2^{\prime}$ or $\mathrm{H}-3^{\prime}$ or $\left.\mathrm{H}-4^{\prime}\right), 3.68$ (dd, $1 \mathrm{H}, J=5.3 \mathrm{~Hz}$, $\left.J=11.9 \mathrm{~Hz}, \mathrm{H}-6^{\prime} \mathrm{b}\right), 3.53-3.40\left(\mathrm{~m}, 3 \mathrm{H}, \mathrm{H}-2^{\prime}\right.$ or $\mathrm{H}^{-} 3^{\prime}$ or $\mathrm{H}-4^{\prime}$ and $\mathrm{H}-$ $\left.5^{\prime}\right) .{ }^{13} \mathrm{C}$ NMR $\left(90 \mathrm{MHz}, \mathrm{CD}_{3} \mathrm{OD}\right): \delta=166.9,165.6$ (C-2oxa, C-5oxa), $133.5,130.5,130.5,128.1,128.1,124.7,82.9\left(C^{\prime}-1^{\prime}\right), 79.1,74.7$, 73.5, $71.3\left(\mathrm{C}-2^{\prime}, \mathrm{C}-3^{\prime}, \mathrm{C}-4^{\prime}, \mathrm{C}-5^{\prime}\right), 62.7\left(\mathrm{C}-6^{\prime}\right)$. Anal. Calcd for $\mathrm{C}_{14} \mathrm{H}_{16} \mathrm{~N}_{2} \mathrm{O}_{6}$ (308.29): C, 54.54; H, 5.23; N, 9.09. Found: C, 54.27; H, 5.30; N, 8.94.

\subsubsection{5-( $\beta$-D-Glucopyranosyl)-2-(4-methylphenyl)-1,3,4- oxadiazole $(6 c)$}

Prepared according to method G. Yield: $83 \mathrm{mg}, 67 \%$ (white crystals). $\mathrm{Mp}=185-188^{\circ} \mathrm{C} . \quad[\alpha]_{\mathrm{D}}^{20}=+19 \quad\left(\mathrm{c} \quad 0.14, \quad \mathrm{H}_{2} \mathrm{O}\right) .{ }^{1} \mathrm{H} \quad \mathrm{NMR}$ $\left(360 \mathrm{MHz}, \mathrm{D}_{2} \mathrm{O}\right): \delta=7.77(\mathrm{~d}, 2 \mathrm{H}, J=7.9 \mathrm{~Hz}, \mathrm{H}-\mathrm{ar}), 7.31$ (d, $2 \mathrm{H}$, $J=7.9 \mathrm{~Hz}, \mathrm{H}-\mathrm{ar}), 4.72$ (d, $\left.1 \mathrm{H}, J=10.6 \mathrm{~Hz}, \mathrm{H}-1^{\prime}\right), 3.92$ (pdd, $1 \mathrm{H}$, $J<1 \mathrm{~Hz}, J=11.9$, H-6'a), 3.86-3.55 (m, 5H, H-2', H-3', H-4', H-5', $\left.\mathrm{H}-6^{\prime} \mathrm{b}\right), 2.34\left(\mathrm{~s}, 3 \mathrm{H}, \mathrm{PhCH}_{3}\right) .{ }^{13} \mathrm{C}$ NMR $\left(90 \mathrm{MHz}, \mathrm{D}_{2} \mathrm{O}\right): \delta=166.8$, 164.0 (C-2oxa, C-5oxa), 144.7, 130.5, 127.5, 119.9, $81.2\left(\mathrm{C}-1^{\prime}\right)$, 77.3, 73.2, 72.2, 69.9 (C-2', C-3', C-4', C-5'), $61.3\left(\mathrm{C}-6^{\prime}\right), 21.4$ $\left(\mathrm{PhCH}_{3}\right)$. Anal. Calcd for $\mathrm{C}_{15} \mathrm{H}_{18} \mathrm{~N}_{2} \mathrm{O}_{6}$ (322.32): C, 55.90; H, 5.63; N, 8.69. Found: C, 55.82; H, 5.55; N, 8.61.

\subsubsection{5-( $\beta$-D-Glucopyranosyl)-2-(4-methoxyphenyl)-1,3,4- oxadiazole (6d)}

Prepared according to method G. Yield: 65\% (yellowish amorphous solid). $[\alpha]_{\mathrm{D}}^{20}=+15\left(\right.$ c $\left.0.16, \mathrm{H}_{2} \mathrm{O}\right) .{ }^{1} \mathrm{H}$ NMR $\left(360 \mathrm{MHz}, \mathrm{D}_{2} \mathrm{O}\right)$ : $\delta=7.68$ (d, 2H, $J=7.9 \mathrm{~Hz}, \mathrm{H}-\mathrm{ar}$ ), 6.89 (d, 2H, $J=7.9 \mathrm{~Hz}, \mathrm{H}-\mathrm{ar}), 4.71$ (d, $1 \mathrm{H}, J=9.2 \mathrm{~Hz}, \mathrm{H}-1^{\prime}$ ), 3.95 (pdd, $1 \mathrm{H}, J<1 \mathrm{~Hz}, J=11.9 \mathrm{~Hz}, \mathrm{H}-6^{\prime} \mathrm{a}$ ), 3.86-3.81 (m, 5H, H-2', H-6'b, OMe), 3.69-3.64 (m, 2H, H-3', H$\left.5^{\prime}\right), 3.57\left(\mathrm{t}, 1 \mathrm{H}, J=9.2 \mathrm{~Hz}, \mathrm{H}-4^{\prime}\right) .{ }^{13} \mathrm{C} \mathrm{NMR}\left(90 \mathrm{MHz}, \mathrm{D}_{2} \mathrm{O}\right)$ : $\delta=166.3,163.8$ (C-2oxa, C-5oxa), 129.4-115.1 (CH-ar, $\left.\mathrm{C}^{\mathrm{IV}}-\mathrm{ar}\right)$, $81.2\left(\mathrm{C}-1^{\prime}\right), 77.5,73.2,72.3,69.9\left(\mathrm{C}-2^{\prime}, \mathrm{C}-3^{\prime}, \mathrm{C}-4^{\prime}, \mathrm{C}-5^{\prime}\right), 61.4(\mathrm{C}-$ 6'), 56.1 (OMe). Anal. Calcd for $\mathrm{C}_{15} \mathrm{H}_{18} \mathrm{~N}_{2} \mathrm{O}_{7}$ (338.32): $\mathrm{C}, 53.25 ; \mathrm{H}$, 5.36; N, 8.28. Found: C, 53.19; H, 5.30; N, 8.35.

\subsubsection{5-( $\beta$-D-Glucopyranosyl)-2-(4-nitrophenyl)-1,3,4- oxadiazole (6e)}

Prepared according to method G. Purified by column chromatography $\left(\mathrm{CHCl}_{3} / \mathrm{MeOH}, 9: 1\right)$ Yield: $76 \%$ (yellow crystals). $\mathrm{Mp}=124-126^{\circ} \mathrm{C} .[\alpha]_{\mathrm{D}}^{20}=+22\left(c 0.52\right.$, DMSO). ${ }^{1} \mathrm{H}$ NMR $(360 \mathrm{MHz}$, $\left.\mathrm{CD}_{3} \mathrm{SOCD}_{3}\right): \delta=8.44(\mathrm{~d}, 2 \mathrm{H}, J=9.3 \mathrm{~Hz}, \mathrm{H}-\mathrm{ar}), 8.30(\mathrm{~d}, 2 \mathrm{H}$, $J=9.3 \mathrm{~Hz}, \mathrm{H}-\mathrm{ar}), 5.44(\mathrm{~d}, 1 \mathrm{H}, J=5.3 \mathrm{~Hz}, \mathrm{OH}), 5.24(\mathrm{~d}, 1 \mathrm{H}$, $J=4.0 \mathrm{~Hz}, \mathrm{OH}), 5.14(\mathrm{~d}, 1 \mathrm{H}, J=5.3 \mathrm{~Hz}, \mathrm{OH}), 4.63-4.58(\mathrm{~m}, 2 \mathrm{H}, \mathrm{H}-$ $\left.1^{\prime}, \mathrm{OH}\right), 3.74-3.37$ (m, 6H, H-2', H-3', H-4', H-5', H-6'a, H-6'b). ${ }^{13} \mathrm{C}$ NMR $\left(90 \mathrm{MHz}, \mathrm{CD}_{3} \mathrm{SOCD}_{3}\right): \delta=164.8,163.1$ (C-2oxa, C-5oxa), 149.3, 128.6, 128.1, 124.7, 81.9 (C-1'), 77.2, 72.7, 71.8, 69.9 (C-2', C-3', C-4', C-5'), 61.0 (C-6'). Anal. Calcd for $\mathrm{C}_{14} \mathrm{H}_{15} \mathrm{~N}_{3} \mathrm{O}_{8}$ (353.29): C, 47.60; H, 4.28; N, 11.89. Found: C, 47.69; H, 4.34; N, 11.80.

\subsubsection{2-(4-Aminophenyl)-5-( $\beta$-D-glucopyranosyl)-1,3,4- oxadiazole (6f)}

Compound $\mathbf{6 e}$ ( $60 \mathrm{mg}, 0.17 \mathrm{mmol})$ was dissolved in a mixture of abs. EtOAc $(2 \mathrm{~mL})$ and abs. $\mathrm{MeOH}(2 \mathrm{~mL})$, and reduced by $\mathrm{H}_{2}$ (1 atm) using Raney-Ni as catalyst at $60^{\circ} \mathrm{C}$ for $8 \mathrm{~h}$. After filtration 
and evaporation of the solvents the residue was purified by column chromatography $\left(\mathrm{CHCl}_{3} / \mathrm{MeOH}, 4: 1\right)$ Yield: $28 \mathrm{mg}, 51 \%$ (yellowish crystals). $\mathrm{Mp}=215-217^{\circ} \mathrm{C} .[\alpha]_{\mathrm{D}}^{20}=+16$ (c 0.12, DMSO). ${ }^{1} \mathrm{H}$ NMR (360 MHz, $\left.\mathrm{CD}_{3} \mathrm{SOCD}_{3}\right): \delta=7.68(\mathrm{~d}, 2 \mathrm{H}, J=7.9 \mathrm{~Hz}, \mathrm{H}-\mathrm{ar}), 6.70$ (d, $2 \mathrm{H}, J=7.9 \mathrm{~Hz}, \mathrm{H}-\mathrm{ar}), 5.98\left(\mathrm{~s}, 2 \mathrm{H}, \mathrm{NH}_{2}\right), 5.39(\mathrm{~d}, 1 \mathrm{H}, J=5.3 \mathrm{~Hz}$, $\mathrm{OH}), 5.21(\mathrm{~d}, 1 \mathrm{H}, J=5.3 \mathrm{~Hz}, \mathrm{OH}), 5.13(\mathrm{~d}, 1 \mathrm{H}, J=5.3 \mathrm{~Hz}, \mathrm{OH}), 4.64$ (dd, $1 \mathrm{H}, J=6.6 \mathrm{~Hz}, J=5.3 \mathrm{~Hz}, \mathrm{OH}), 4.47\left(\mathrm{~d}, 1 \mathrm{H}, J=9.3 \mathrm{~Hz}, \mathrm{H}-1^{\prime}\right)$, 3.74-2.20 (m, 6H, H-2', H-3', H-4', H-5', H-6'a, H-6'b). ${ }^{1} \mathrm{H}$ NMR $\left(360 \mathrm{MHz}, \mathrm{CD}_{3} \mathrm{OD}\right): \delta=7.74(\mathrm{~d}, 2 \mathrm{H}, J=9.3 \mathrm{~Hz}, \mathrm{H}-\mathrm{ar}), 6.74(\mathrm{~d}, 2 \mathrm{H}$, $J=9.3 \mathrm{~Hz}, \mathrm{H}-\mathrm{ar}$ ), 4.57 (d, $1 \mathrm{H}, J=9.3 \mathrm{~Hz}, \mathrm{H}-1^{\prime}$ ), 3.89 (pdd, $1 \mathrm{H}$, $\left.J<1 \mathrm{~Hz}, J=10.6 \mathrm{~Hz}, \mathrm{H}-6^{\prime} \mathrm{a}\right), 3.79$ (t, $1 \mathrm{H}, J=9.3 \mathrm{~Hz}, \mathrm{H}-2^{\prime}$ ), 3.70 (dd, $\left.1 \mathrm{H}, J=4.0 \mathrm{~Hz}, J=11.9 \mathrm{~Hz}, \mathrm{H}-6^{\prime} \mathrm{b}\right), 3.54-3.34\left(\mathrm{~m}, 3 \mathrm{H}, \mathrm{H}^{-3}{ }^{\prime}, \mathrm{H}-4^{\prime}\right.$, H-5 $).{ }^{13} \mathrm{C}$ NMR $\left(90 \mathrm{MHz}, \mathrm{CD}_{3} \mathrm{OD}\right): \delta=167.8,164.3$ (C-2oxa, C5oxa), 154.1, 129.7, 115.2, 111.7, $82.9\left(\mathrm{C}^{\prime} \mathbf{1}^{\prime}\right), 79.2,74.7,73.4$, $71.3\left(\mathrm{C}-2^{\prime}, \mathrm{C}-3^{\prime}, \mathrm{C}-4^{\prime}, \mathrm{C}-5^{\prime}\right), 62.7\left(\mathrm{C}-6^{\prime}\right)$. Anal. Calcd for $\mathrm{C}_{14} \mathrm{H}_{17} \mathrm{~N}_{3} \mathrm{O}_{6}$ (323.31): C, 52.01; H, 5.30; N, 13.00. Found: C, 50.94; H, 5.22; N, 13.10 .

\subsubsection{5-( $\beta$-D-Glucopyranosyl)-2-(4-hydroxyphenyl)-1,3,4- oxadiazole $(6 \mathrm{~g})$}

Prepared according to method G. Yield: $45 \%$ (yellowish amorphous solid). $[\alpha]_{\mathrm{D}}^{20}=+20($ c $0.2, \mathrm{MeOH}) .{ }^{1} \mathrm{H}$ NMR $\left(360 \mathrm{MHz}, \mathrm{D}_{2} \mathrm{O}\right)$ : $\delta=7.84$ (d, 2H, $J=7.9 \mathrm{~Hz}, \mathrm{H}-\mathrm{ar}$ ), 6.97 (d, 2H, $J=7.9 \mathrm{~Hz}, \mathrm{H}-\mathrm{ar}), 3.98$ (pdd, $\left.1 \mathrm{H}, J<1 \mathrm{~Hz}, J=11.9 \mathrm{~Hz}, \mathrm{H}-6^{\prime} \mathrm{a}\right), 3.91-3.79$ (m, 3H, H-1', $\mathrm{H}^{\prime} 2^{\prime}$, $\left.\mathrm{H}-6^{\prime} \mathrm{b}\right), 3.73-3.68$ ( $\left.\mathrm{m}, 2 \mathrm{H}, \mathrm{H}-3^{\prime}, \mathrm{H}-5^{\prime}\right), 3.60$ (t, $\left.1 \mathrm{H}, J=9.2 \mathrm{~Hz}, \mathrm{H}-4^{\prime}\right)$. ${ }^{13} \mathrm{C}$ NMR $\left(90 \mathrm{MHz}, \mathrm{D}_{2} \mathrm{O}\right): \delta=163.7,160.4$ (C-2oxa, C-5oxa), 129.9-

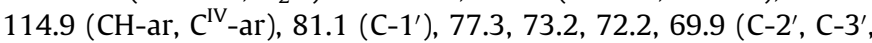
C-4', C-5'), $61.4\left(\mathrm{C}-6^{\prime}\right)$. Anal. Calcd for $\mathrm{C}_{14} \mathrm{H}_{16} \mathrm{~N}_{2} \mathrm{O}_{7}$ (324.29): C, 51.85; H, 4.97; N, 8.64. Found: C, 51.79; H, 4.91; N, 8.71.

\subsubsection{5-( $\beta$-D-Glucopyranosyl)-2-(1-naphthyl)-1,3,4-oxadiazole (6h)}

Prepared according to method G. Yield: $91 \%$ (colorless syrup). $[\alpha]_{\mathrm{D}}^{20}=+35(c 0.2, \mathrm{MeOH}) .{ }^{1} \mathrm{H}$ NMR $\left(360 \mathrm{MHz}, \mathrm{CD}_{3} \mathrm{OD}\right): \delta=8.96-$ $7.50(\mathrm{~m}, 7 \mathrm{H}, \mathrm{H}-\mathrm{ar}), 4.69$ (d, $\left.1 \mathrm{H}, J=10.6 \mathrm{~Hz}, \mathrm{H}-1^{\prime}\right), 3.91-3.8 \hat{2}(\mathrm{~m}$, $2 \mathrm{H}, \mathrm{H}-2^{\prime}$ or $\mathrm{H}-3^{\prime}$ or $\mathrm{H}-4^{\prime}$ and $\mathrm{H}-6^{\prime} \mathrm{a}$ ), 3.70 (dd, $1 \mathrm{H}, J=5.3 \mathrm{~Hz}$, $\left.J=11.9 \mathrm{~Hz}, \mathrm{H}-6^{\prime} \mathrm{b}\right), 3.57-3.44\left(\mathrm{~m}, 3 \mathrm{H}, \mathrm{H}-2^{\prime}\right.$ or $\mathrm{H}-3^{\prime}$ or $\mathrm{H}^{-} 4^{\prime}$ and $\mathrm{H}-$ $5^{\prime}$ ). ${ }^{13} \mathrm{C}$ NMR (90 MHz, $\mathrm{CD}_{3} \mathrm{OD}$ ): $\delta=166.7,165.3$ (C-2oxa, C-5oxa), $135.3,134.1,131.2,130.0,130.0,129.2,127.9,126.6,126.1$, 121.1, 82.9 (C-1'), 79.1, 74.7, 73.6, $71.3\left(\mathrm{C}-2^{\prime}, \mathrm{C}-3^{\prime}, \mathrm{C}-4^{\prime}, \mathrm{C}-5^{\prime}\right)$, $62.7\left(\mathrm{C}-6^{\prime}\right)$. Anal. Calcd for $\mathrm{C}_{18} \mathrm{H}_{18} \mathrm{~N}_{2} \mathrm{O}_{6}$ (358.35): C, 60.33; $\mathrm{H}$, 5.06; N, 7.82. Found: C, 60.22; H, 5.30; N, 7.98.

4.2.8. 5-( $\beta$-D-Glucopyranosyl)-2-(2-naphthyl)-1,3,4-oxadiazole (6i)

Prepared according to method G. Yield: $96 \%$ (white crystals). $\mathrm{Mp}=219-221^{\circ} \mathrm{C}$. $[\alpha]_{\mathrm{D}}^{20}=-5$ (c 0.1 , DMSO). ${ }^{1} \mathrm{H}$ NMR $(360 \mathrm{MHz}$, $\left.\mathrm{CD}_{3} \mathrm{SOCD}_{3}\right): \delta=8.66-7.66(\mathrm{~m}, 7 \mathrm{H}, \mathrm{H}-\mathrm{ar}), 5.49(\mathrm{~d}, 1 \mathrm{H}, J=9.2 \mathrm{~Hz}, \mathrm{H}-$ $\left.1^{\prime}\right)$, 3.72-3.16 (m, 6H, H-2', H-3', H-4', H-5', H-6'a, H-6'b). ${ }^{13} \mathrm{C}$ NMR $\left(90 \mathrm{MHz}, \mathrm{CD}_{3} \mathrm{SOCD}_{3}\right): \delta=164.6,164.0$ (C-2oxa, C-5oxa), $134.2,132.4,129.3,128.9,128.3,127.9,127.3,127.1,122.8$, 120.4, $81.9\left(\mathrm{C}-1^{\prime}\right), 77.3,72.7,71.7,69.9\left(\mathrm{C}-2^{\prime}, \mathrm{C}-3^{\prime}, \mathrm{C}-4^{\prime}, \mathrm{C}-5^{\prime}\right)$, $61.0\left(\mathrm{C}-6^{\prime}\right)$. Anal. Calcd for $\mathrm{C}_{18} \mathrm{H}_{18} \mathrm{~N}_{2} \mathrm{O}_{6}$ (358.35): C, 60.33; $\mathrm{H}$, 5.06; N, 7.82. Found: C, 60.23; H, 5.18; N, 7.65.

\subsection{Synthesis of 3-aryl-5-( $\beta$-D-glucopyranosyl)-1,3,4-oxadiazoles}

4.3.1. 5-( $\beta$-D-Glucopyranosyl)-3-phenyl-1,2,4-oxadiazole (8b) and 5-(2-deoxy-D-arabino-hex-1-enopyranosyl)-3-phenyl-1,2,4oxadiazole (18b)

A solution of 17b (155 mg, $0.21 \mathrm{mmol})$ was treated according to method $\mathrm{F}$. The residue was purified by flash silica gel column chromatography (PE/EtOAc, 3:2 then EtOAc then EtOAc/MeOH 9:1) to afford $\mathbf{8 b}(67 \mathrm{mg}, 92 \%)$ as a yellow solid and $\mathbf{1 8 b}(5 \mathrm{mg}, 8 \%)$ as a yellow solid. Analytical data for $\mathbf{8 b}: R_{\mathrm{f}}=0.41(\mathrm{EtOAc} / \mathrm{MeOH}, 9: 1)$. $\mathrm{Mp}=129-130{ }^{\circ} \mathrm{C}(\mathrm{MeOH} /$ hexane $) .[\alpha]_{\mathrm{D}}^{20}=+16(\mathrm{c} 1, \mathrm{MeOH}) .{ }^{1} \mathrm{H}$ NMR (300 MHz, $\left.\widehat{C D}_{3} \mathrm{OD}\right): \delta=8.10-8.06(\mathrm{~m}, 2 \mathrm{H}, \mathrm{H}-\mathrm{ar}), 7.55-7.50$ (m, 3H, H-ar), 4.66 (d, $\left.1 \mathrm{H}, J=\hat{9} .8 \mathrm{~Hz}, \mathrm{H}-1^{\prime}\right), 3.91$ (pdd, $1 \hat{\mathrm{H}}, J<1 \mathrm{~Hz}$,
$J=12.2 \mathrm{~Hz}, \mathrm{H}-6^{\prime} \mathrm{a}$ ), 3.80 (dd, $\left.1 \mathrm{H}, J=8.5 \mathrm{~Hz}, J=9.8 \mathrm{~Hz}, \mathrm{H}-2^{\prime}\right), 3.72$ (dd, $\left.1 \mathrm{H}, J=4.5 \mathrm{~Hz}, J=12.2 \mathrm{~Hz}, \mathrm{H}-6^{\prime} \mathrm{b}\right), 3.50-3.40\left(\mathrm{~m}, 3 \mathrm{H}, \mathrm{H}-3^{\prime}, \mathrm{H}-\right.$ $\left.4^{\prime}, \mathrm{H}-5^{\prime}\right) .{ }^{13} \mathrm{C}$ NMR (75 MHz, $\mathrm{CD}_{3} \mathrm{OD}$ ): $\delta=178.2$ (C-5oxa), 169.6 (C3oxa), 132.6, $130.1(2 \mathrm{C}), 128.4(2 \mathrm{C}), 127.8$ ( $\left.\mathrm{C}^{\mathrm{IV}}-\mathrm{ar}\right), 83.0\left(\mathrm{C}-5^{\prime}\right)$, $79.2\left(\mathrm{C}-3^{\prime}\right), 75.1\left(\mathrm{C}-1^{\prime}\right), 74.0\left(\mathrm{C}-2^{\prime}\right), 71.2\left(\mathrm{C}-4^{\prime}\right), 62.7\left(\mathrm{C}-6^{\prime}\right) . \mathrm{MS}$ (LSIMS, glycerol) $m / z=309[\mathrm{M}+\mathrm{H}]^{+}$. HRMS (LSIMS, glycerol) $\mathrm{m} /$ $z=\mathrm{C}_{14} \mathrm{H}_{17} \mathrm{~N}_{2} \mathrm{O}_{6}[\mathrm{M}+\mathrm{H}]^{+}$calcd 309.1087 , found 309.1088. Analytical data for 18b: $R_{\mathrm{f}}=0.51(\mathrm{EtOAc} / \mathrm{MeOH}, 9: 1) .{ }^{1} \mathrm{H} \mathrm{NMR}(300 \mathrm{MHz}$, $\mathrm{CD}_{3} \mathrm{OD}$ ): $\delta=8.10-7.96$ (m, 5H, H-ar), 6.13 (d, 1H, $J=2.8 \mathrm{~Hz}, \mathrm{H}-2^{\prime}$ ), $4.34\left(\mathrm{dd}, 1 \mathrm{H}, J=2.8 \mathrm{~Hz}, J=7.2 \mathrm{~Hz}, \mathrm{H}-3^{\prime}\right.$ ), 4.06 (ddd, $1 \mathrm{H}, J=2.3 \mathrm{~Hz}$, $\left.J=5.2 \mathrm{~Hz}, J=9.5 \mathrm{~Hz}, \mathrm{H}-5^{\prime}\right), 4.01(\mathrm{dd}, 1 \mathrm{H}, J=2.3 \mathrm{~Hz}, J=12.6 \mathrm{~Hz}, \mathrm{H}-$ 6'a), 3.93 (dd, $1 \mathrm{H}, J=5.2 \mathrm{~Hz}, J=12.6 \mathrm{~Hz}, \mathrm{H}-6^{\prime} \mathrm{b}$ ), 3.75 (dd, $\left.J=7.2 \mathrm{~Hz}, J=9.5 \mathrm{~Hz}, \mathrm{H}-4^{\prime}\right) .{ }^{13} \mathrm{C}$ NMR $\left(75 \mathrm{MHz}, \mathrm{CD}_{3} \mathrm{OD}\right): \delta=172.9$ (C-5oxa), 169.8 (C-3oxa), $141.1\left(\mathrm{C}-1^{\prime}\right), 132.7,130.7,128.4,127.7$ ( $\mathrm{C}^{\mathrm{IV}}$-ar), $112.9\left(\mathrm{C}-2^{\prime}\right), 82.3\left(\mathrm{C}-5^{\prime}\right), 70.2\left(\mathrm{C}-3^{\prime}\right), 69.7\left(\mathrm{C}-4^{\prime}\right), 61.9(\mathrm{C}-$ $6^{\prime}$ ). MS (LSIMS, glycerol) $m / z=291[\mathrm{M}+\mathrm{H}]^{+}$. HRMS (LSIMS, glycerol) $m / z=\mathrm{C}_{14} \mathrm{H}_{15} \mathrm{~N}_{2} \mathrm{O}_{5}[\mathrm{M}+\mathrm{H}]^{+}$calcd 291.0981, found 291.0981 .

4.3.2. 5-( $\beta$-D-Glucopyranosyl)-3-(4-methylphenyl)-1,2,4-oxadiazole (8c) and 5-(2-deoxy-D-D-arabino-hex-1-enopyranosyl)-3(4-methylphenyl)-1,2,4-oxadiazole (18c)

A solution of $17 \mathrm{c}$ ( $250 \mathrm{mg}, 0.38 \mathrm{mmol})$ was treated according to method $\mathrm{F}$. The residue was purified by flash silica gel column chromatography (PE/EtOAc, 3:2 then EtOAc then EtOAc/MeOH 9:1) to afford $8 \mathbf{c}(103 \mathrm{mg}, 92 \%)$ as a colorless oil and $\mathbf{1 8 c}(11 \mathrm{mg}, 8 \%)$ as a colorless oil. Analytical data for $8 \mathrm{c}$ : $R_{\mathrm{f}}=0.38$ (EtOAc/MeOH, 9:1). $[\alpha]_{\mathrm{D}}^{20}=+14($ c $1, \mathrm{MeOH}) .{ }^{1} \mathrm{H}$ NMR $\left(300 \mathrm{MHz}, \mathrm{CD}_{3} \mathrm{OD}\right)$ : $\delta=7.74(\mathrm{~d}, 2 \mathrm{H}, J=8.1 \mathrm{~Hz}, \mathrm{H}-\mathrm{ar}), 7.34$ (d, 2H, $J=8.1 \mathrm{~Hz}, \mathrm{H}-\mathrm{ar}), 4.64$ (d, $1 \mathrm{H}, J=9.8 \mathrm{~Hz}, \mathrm{H}-1^{\prime}$ ), 3.90 (pdd, $1 \mathrm{H}, J<1 \mathrm{~Hz}, J=12.3 \mathrm{~Hz}, \mathrm{H}-6^{\prime} \mathrm{a}$ ), $3.78\left(\mathrm{dd}, 1 \mathrm{H}, J=8.6 \mathrm{~Hz}, J=9.8 \mathrm{~Hz}, \mathrm{H}-2^{\prime}\right), 3.71$ (dd, $1 \mathrm{H}, J=5.3 \mathrm{~Hz}$, $\left.J=12.3 \mathrm{~Hz}, \mathrm{H}-6^{\prime} \mathrm{b}\right), 3.55-3.45$ (m, 3H, H-3', H-4', H-5'), 2.41 (s, 3H, $\mathrm{CH}_{3} \mathrm{Ph}$ ). ${ }^{13} \mathrm{C}$ NMR (75 MHz, CD $\mathrm{OD}$ ): $\delta=178.1$ (C-5oxa), 169.6 (C3oxa), 143.3 (C-1"), 130.8 (2C, C-2", C-6" $\left.6^{\prime \prime}\right), 128.4\left(2 \mathrm{C}, \mathrm{C}-3^{\prime \prime}, \mathrm{C}-5^{\prime \prime}\right)$, $125.0\left(\mathrm{C}-4^{\prime \prime}\right), 83.0\left(\mathrm{C}-5^{\prime}\right), 79.2\left(\mathrm{C}-3^{\prime}\right), 75.2\left(\mathrm{C}-1^{\prime}\right), 74.0\left(\mathrm{C}-2^{\prime}\right), 71.3$ (C-4'), $62.8\left(\mathrm{C}-6^{\prime}\right), 21.6\left(\mathrm{CH}_{3} \mathrm{Ph}\right) . \mathrm{MS}(\mathrm{ESI}) \mathrm{m} / z=323.0[\mathrm{M}+\mathrm{H}]^{+}$, $345.1[\mathrm{M}+\mathrm{Na}]^{+}, 666.9[2 \mathrm{M}+\mathrm{Na}]^{+}$. HRMS (ESI) $m / z=\mathrm{C}_{15} \mathrm{H}_{19} \mathrm{~N}_{2} \mathrm{O}_{6}$ $[\mathrm{M}+\mathrm{H}]^{+}$calcd 323.1243, found 323.1245. Analytical data for 18c: $R_{\mathrm{f}}=0.38$ (EtOAc/MeOH, 9:1). ${ }^{1} \mathrm{H}$ NMR (300 MHz, CD $\left.{ }_{3} \mathrm{OD}\right): \delta=7.94$ (d, $2 \mathrm{H}, J=8.1 \mathrm{~Hz}, \mathrm{H}-\mathrm{ar}), 7.34$ (d, $2 \mathrm{H}, J=8.1 \mathrm{~Hz}, \mathrm{H}-\mathrm{ar}), 6.12$ (d, $1 \mathrm{H}$, $\left.J=2.8 \mathrm{~Hz}, \mathrm{H}-2^{\prime}\right), 4.33\left(\mathrm{dd}, 1 \mathrm{H}, J=2.8 \mathrm{~Hz}, J=7.2 \mathrm{~Hz}, \mathrm{H}-3^{\prime}\right), 4.06$ (ddd, $\left.1 \mathrm{H}, J=2.6 \mathrm{~Hz}, J=5.4 \mathrm{~Hz}, J=9.5 \mathrm{~Hz}, \mathrm{H}-5^{\prime}\right), 4.01(\mathrm{~m}, 1 \mathrm{H}, \mathrm{H}-$ 6'a), 3.94 (dd, $1 \mathrm{H}, J=5.4 \mathrm{~Hz}, J=12.6 \mathrm{~Hz}, \mathrm{H}-6^{\prime} \mathrm{b}$ ), 3.75 (dd, $\left.J=7.2 \mathrm{~Hz}, J=9.5 \mathrm{~Hz}, \mathrm{H}-4^{\prime}\right), 2.41\left(\mathrm{~s}, 3 \mathrm{H}, \mathrm{CH}_{3} \mathrm{Ph}\right) .{ }^{13} \mathrm{C}$ NMR $(75 \mathrm{MHz}$, $\left.\mathrm{CD}_{3} \mathrm{OD}\right): \delta=172.8$ (C-5oxa), 169.9 (C-3oxa), $143.4\left(\mathrm{C}-1^{\prime}\right), 141.2$, 130.8 (2C), $128.4(2 \mathrm{C}), 124.9$ ( $\mathrm{C}^{\mathrm{IV}}$-ar), $112.8\left(\mathrm{C}-2^{\prime}\right), 82.3\left(\mathrm{C}-5^{\prime}\right)$, $70.3\left(\mathrm{C}-3^{\prime}\right), 69.8\left(\mathrm{C}-4^{\prime}\right), 62.0\left(\mathrm{C}-6^{\prime}\right), 21.6\left(\mathrm{CH}_{3} \mathrm{Ph}\right) . \mathrm{MS}(\mathrm{ESI}) \mathrm{m} /$ $z=304.8[\mathrm{M}+\mathrm{H}]^{+}, 327.0[\mathrm{M}+\mathrm{Na}]^{+}, 630.8[2 \mathrm{M}+\mathrm{Na}]^{+}$. HRMS (ESI) $\mathrm{m} /$ $z=\mathrm{C}_{15} \mathrm{H}_{17} \mathrm{~N}_{2} \mathrm{O}_{5}[\mathrm{M}+\mathrm{H}]^{+}$calcd 305.1137, found 305.1136 .

4.3.3. 5-( $\beta$-D-Glucopyranosyl)-3-(4-methoxyphenyl)-1,2,4-oxadiazole (8d) and 5-(2-deoxy-D-arabino-hex-1-enopyranosyl)-3-(4methoxyphenyl)-1,2,4-oxadiazole (18d)

A solution of 17d (187 mg, $0.25 \mathrm{mmol})$ was treated according to method $\mathrm{F}$. The residue was purified by flash silica gel column chromatography (PE/EtOAc, 3:2 then EtOAc then EtOAc/MeOH 9:1) to afford $8 d(62 \mathrm{mg}, 75 \%)$ as a white solid and $\mathbf{1 8 d}(3 \mathrm{mg}, 5 \%)$ as a pale yellow solid. Analytical data for 8d: $R_{\mathrm{f}}=0.08$ (EtOAc). $\mathrm{Mp}=152-$ $153{ }^{\circ} \mathrm{C}$ (MeOH/hexane). $[\alpha]_{\mathrm{D}}^{20}=+16$ (c $\left.0.75, \mathrm{MeOH}\right) .{ }^{\wedge} \mathrm{H}$ NMR $\left(300 \mathrm{MHz}, \mathrm{CD}_{3} \mathrm{OD}\right): \delta=8.00$ (d, $\left.2 \mathrm{H}, J=8.9 \mathrm{~Hz}, \mathrm{H}-\mathrm{ar}\right), 7.05$ (d, $2 \mathrm{H}$, $J=8.9 \mathrm{~Hz}, \mathrm{H}-\mathrm{ar}$ ), $4.63\left(\mathrm{~d}, 1 \mathrm{H}, J=9.6 \mathrm{~Hz}, \mathrm{H}-1^{\prime}\right), 3.91$ (pdd, $1 \mathrm{H}$, $\left.J<1 \mathrm{~Hz}, J=12.3 \mathrm{~Hz}, \mathrm{H}-6^{\prime} \mathrm{a}\right), 3.86\left(\mathrm{~s}, 3 \mathrm{H}, \mathrm{OCH}_{3}\right), 3.79$ (dd, $1 \mathrm{H}$, $\left.J=8.8 \mathrm{~Hz}, J=9.6 \mathrm{~Hz}, \mathrm{H}-2^{\prime}\right), 3.72(\mathrm{dd}, 1 \mathrm{H}, J=4.8 \mathrm{~Hz}, J=12.3 \mathrm{~Hz}, \mathrm{H}-$ $\left.6^{\prime} \mathrm{b}\right), 3.50-3.43$ ( $\left.\mathrm{m}, 3 \mathrm{H}, \mathrm{H}-3^{\prime}, \mathrm{H}-4^{\prime}, \mathrm{H}-5^{\prime}\right) .{ }^{13} \mathrm{C} \mathrm{NMR}$ (75 MHz, CD $\left.{ }_{3} \mathrm{OD}\right)$ : $\delta=177.9$ (C-5oxa), 169.3 (C-3oxa), 163.8 (C-4"), 130.1 (2C), 120.0 ( $\mathrm{C}^{\mathrm{IV}}$-ar), $115.2(2 \mathrm{C}), 83.0(\mathrm{C}-5), 79.2\left(\mathrm{C}-3^{\prime}\right), 75.2\left(\mathrm{C}-1^{\prime}\right), 74.0\left(\mathrm{C}-2^{\prime}\right)$, $71.2\left(\mathrm{C}-4^{\prime}\right), 62.8\left(\mathrm{C}-6^{\prime}\right), 56.0\left(\mathrm{OCH}_{3}\right)$. MS (LSIMS, glycerol) $\mathrm{m} / z=339$ 
$[\mathrm{M}+\mathrm{H}]^{+}$. HRMS (LSIMS, glycerol) $m / z=\mathrm{C}_{15} \mathrm{H}_{19} \mathrm{~N}_{2} \mathrm{O}_{7}[\mathrm{M}+\mathrm{H}]^{+}$calcd 339.1192, found 339.1191. Analytical data for 18d: $R_{\mathrm{f}}=0.17$ (EtOAc). ${ }^{1} \mathrm{H}$ NMR (500 MHz, CD $\left.{ }_{3} \mathrm{OD}\right): \delta=8.00$ (d, $2 \mathrm{H}, J=8.9 \mathrm{~Hz}, \mathrm{H}-$ ar), 7.07 (d, $2 \mathrm{H}, J=8.9 \mathrm{~Hz}, \mathrm{H}-\mathrm{ar}), 6.11$ (d, $1 \mathrm{H}, 1 \mathrm{H}, J=2.8 \mathrm{~Hz}, \mathrm{H}-2^{\prime}$ ), $4.34\left(\mathrm{dd}, 1 \mathrm{H}, J=2.8 \mathrm{~Hz}, J=7.3 \mathrm{~Hz}, \mathrm{H}-3^{\prime}\right), 4.06$ (ddd, $1 \mathrm{H}, J=2.3 \mathrm{~Hz}$, $\left.J=5.4 \mathrm{~Hz}, J=9.5 \mathrm{~Hz}, \mathrm{H}-5^{\prime}\right), 4.03(\mathrm{dd}, 1 \mathrm{H}, J=2.3 \mathrm{~Hz}, J=12.7 \mathrm{~Hz}, \mathrm{H}-$ 6'a), 3.93 (dd, $\left.1 \mathrm{H}, J=5.4 \mathrm{~Hz}, J=12.7 \mathrm{~Hz}, \mathrm{H}-6^{\prime} \mathrm{b}\right), 3.87$ (s, 3H, $\mathrm{OCH}_{3}$ ), $3.74\left(\mathrm{dd}, J=7.3 \mathrm{~Hz}, J=9.5 \mathrm{~Hz}, \mathrm{H}-4^{\prime}\right) .{ }^{13} \mathrm{C} \mathrm{NMR}\left(125 \mathrm{MHz}, \mathrm{CD}_{3} \mathrm{OD}\right)$ : $\delta=171.6(\mathrm{C}-50 x a), 168.5$ (C-3oxa), $162.9\left(\mathrm{C}-4^{\prime \prime}\right), 140.1\left(\mathrm{C}-1^{\prime}\right), 129.0$ (2C), $118.8\left(\mathrm{C}^{\mathrm{IV}}-\mathrm{ar}\right), 114.5(2 \mathrm{C}), 111.7\left(\mathrm{C}-2^{\prime}\right), 81.2\left(\mathrm{C}-5^{\prime}\right), 69.2\left(\mathrm{C}-3^{\prime}\right)$, $68.7\left(\mathrm{C}-4^{\prime}\right), 60.9\left(\mathrm{C}-6^{\prime}\right), 54.9\left(\mathrm{OCH}_{3}\right)$. MS (LSIMS, glycerol) $\mathrm{m} / z=321$ $[\mathrm{M}+\mathrm{H}]^{+}$. HRMS (LSIMS, glycerol) $m / z=\mathrm{C}_{15} \mathrm{H}_{17} \mathrm{~N}_{2} \mathrm{O}_{6}[\mathrm{M}+\mathrm{H}]^{+}$çalcd 321.1087, found 321.1087 .

4.3.4. 5-( $\beta$-D-Glucopyranosyl)-3-(4-nitrophenyl)-1,2,4-oxadiazole (8e) and 5-(2-deoxy-D-arabino-hex-1-enopyranosyl)-3-(4-nitrophenyl)-1,2,4-oxadiazole (18e)

A solution of $17 \mathrm{e}(258 \mathrm{mg}, 0.34 \mathrm{mmol})$ was treated according to method $\mathrm{F}$. The residue was purified by flash silica gel column chromatography (PE/EtOAc, 3:2 then EtOAc then EtOAc/MeOH 9:1) to afford $8 \mathbf{e}(89 \mathrm{mg}, 76 \%)$ as a yellow solid and $\mathbf{1 8 e}(4 \mathrm{mg}, 4 \%)$ as a yellow solid. Analytical data for 8e: $R_{\mathrm{f}}=0.08$ (EtOAc). $\mathrm{Mp}=141-$ $142{ }^{\circ} \mathrm{C}$ (MeOH/hexane). $[\alpha]_{\mathrm{D}}^{20}=+22(c \quad 0.5, \mathrm{MeOH}) .{ }^{1} \mathrm{H} \quad \mathrm{NMR}$ (300 MHz, CD $\left.\mathrm{CD}_{3} \mathrm{OD}\right): \delta=8.43-8.36(\mathrm{~m}, 2 \mathrm{H}, \mathrm{H}-\mathrm{ar}), 8.34-8.30(\mathrm{~m}$, $2 \mathrm{H}, \mathrm{H}-\mathrm{ar}$ ), 4.70 (d, $\left.1 \mathrm{H}, \hat{J}=9.8 \mathrm{~Hz}, \mathrm{H}-1^{\prime}\right), 3.92$ (dd, $1 \mathrm{H}, J=1.7 \mathrm{~Hz}$, $J=12.0 \mathrm{~Hz}, \mathrm{H}-6^{\prime} \mathrm{a}$ ), 3.81 (dd, $\left.1 \mathrm{H}, J=9.8 \mathrm{~Hz}, J=8.8 \mathrm{~Hz}, \mathrm{H}-2^{\prime}\right), 3.72$ (dd, $\left.1 \mathrm{H}, J=5.4 \mathrm{~Hz}, J=12.0 \mathrm{~Hz}, \mathrm{H}-6^{\prime} \mathrm{b}\right), 3.54(\mathrm{dd}, 1 \mathrm{H}, J=8.5 \mathrm{~Hz}$, $\left.J=8.8 \mathrm{~Hz}, \mathrm{H}-3^{\prime}\right), 3.49-3.42\left(\mathrm{~m}, 2 \mathrm{H}, \mathrm{H}-4^{\prime}, \mathrm{H}-5^{\prime}\right) .{ }^{13} \mathrm{C}$ NMR $(75 \mathrm{MHz}$, $\left.\mathrm{CD}_{3} \mathrm{OD}\right): \delta=178.9$ (C-5oxa), 168.3 (C-3oxa), 151.1 ( $\left.\mathrm{C}^{\mathrm{IV}}-\mathrm{ar}\right), 133.6$ $\left(\mathrm{C}^{\mathrm{IV}}\right.$-ar $), 129.6(2 \mathrm{C}), 125.3(2 \mathrm{C}), 83.1\left(\mathrm{C}-5^{\prime}\right), 79.1\left(\mathrm{C}-3^{\prime}\right), 75.1\left(\mathrm{C}-1^{\prime}\right)$, 73.9 (C-2'), 71.2 (C-4'), 62.8 (C-6'). MS (LSIMS, glycerol) $\mathrm{m} / z=354$ $[\mathrm{M}+\mathrm{H}]^{+}$. HRMS (LSIMS, glycerol) $m / z=\mathrm{C}_{14} \mathrm{H}_{16} \mathrm{~N}_{3} \mathrm{O}_{8}[\mathrm{M}+\mathrm{H}]^{+}$calcd 354.0937, found 354.0940. Analytical data for 18e: $R_{\mathrm{f}}=0.17$ (EtOAc). ${ }^{1} \mathrm{H}$ NMR (500 MHz, $\left.\mathrm{CD}_{3} \mathrm{OD}\right): \delta=8.43-8.37$ (m, 2H, H-ar), $8.34-8.30(\mathrm{~m}, 2 \mathrm{H}, \mathrm{H}-\mathrm{ar}), 6.18\left(\mathrm{~d}, 1 \mathrm{H}, J=2.8 \mathrm{~Hz}, \mathrm{H}-2^{\prime}\right), 4.35$ (dd, $\hat{1} \mathrm{H}, J=2.8 \mathrm{~Hz}, J=7.3 \mathrm{~Hz}, \mathrm{H}-3^{\prime}$ ), 4.07 (ddd, $1 \mathrm{H}, J=1.9 \mathrm{~Hz}, J=4.7 \mathrm{~Hz}$, $J=9.5 \mathrm{~Hz}, \mathrm{H}-5^{\prime}$ ), 4.03 (dd, $\left.1 \mathrm{H}, J=1.9 \mathrm{~Hz}, J=12.3 \mathrm{~Hz}, \mathrm{H}-6^{\prime} \mathrm{a}\right), 3.95$ (dd, $\left.1 \mathrm{H}, J=4.7 \mathrm{~Hz}, J=12.3 \mathrm{~Hz}, \mathrm{H}-6^{\prime} \mathrm{b}\right), 3.77(\mathrm{dd}, 1 \mathrm{H}, J=7.3 \mathrm{~Hz}$, $\left.J=9.5 \mathrm{~Hz}, \mathrm{H}-4^{\prime}\right) .{ }^{13} \mathrm{C}$ NMR (125 MHz, $\left.\mathrm{CD}_{3} \mathrm{OD}\right): \delta=173.6$ (C-5oxa), 168.5 (C-3oxa), 151.2 ( ( $\mathrm{IV}^{\mathrm{IV}}$-ar), $141.1\left(\mathrm{C}-1^{\prime}\right), 133.6\left(\mathrm{C}^{\mathrm{IV}}-\mathrm{ar}\right), 129.6$, 125.3 (2C), $113.4\left(\mathrm{C}-2^{\prime}\right), 82.3$ (C-5'), $70.2\left(\mathrm{C}-3^{\prime}\right), 69.6\left(\mathrm{C}-4^{\prime}\right), 61.8$ $\left(\mathrm{C}-6^{\prime}\right)$. MS (ESI) $m / z=692.7[2 \mathrm{M}+\mathrm{Na}]^{+}$. HRMS (ESI) $m / z=\mathrm{C}_{14} \mathrm{H}_{14^{-}}$ $\mathrm{N}_{3} \mathrm{O}_{7}[\mathrm{M}+\mathrm{H}]^{+}$calcd 336.0832, found 336.0836.

\subsubsection{3-(4-Aminophenyl)-5-( $\beta$-D-glucopyranosyl)-1,2,4- oxadiazole ( $8 f$ )}

A solution of $8 \mathbf{e}(30 \mathrm{mg}, 8.2 \mu \mathrm{mol})$ and $\mathrm{Pd}-\mathrm{C} 10 \%(5 \mathrm{mg})$ in $\mathrm{MeOH}(5 \mathrm{~mL})$ was stirred at $\mathrm{rt}$ under $\mathrm{H}_{2}$ ( $1 \widehat{\mathrm{atm}}$.). After $24 \mathrm{~h}$, the solution was filtered through a pad of Celite, washed with $\mathrm{MeOH}$ $(3 \times 10 \mathrm{~mL})$. The filtrate was evaporated under diminished pressure and the residue was purified by reversed-phase silica gel column chromatography (water) to afford $\mathbf{8 f}(30 \mathrm{mg}, 99 \%)$ as a pale brown foam. $[\alpha]_{\mathrm{D}}^{20}=-7.8$ (c $\left.0.95, \mathrm{MeOH}\right) .{ }^{1} \mathrm{H} \mathrm{NMR}(300 \mathrm{MHz}$, $\mathrm{CD}_{3} \mathrm{OD}$ ): $\delta=7.57$ (d, $\left.2 \mathrm{H}, J=9.2 \mathrm{~Hz}, \mathrm{H}-2^{\prime \prime}, \mathrm{H}-6^{\prime \prime}\right), 6.73$ (d, $2 \mathrm{H}$, $J=9.2 \mathrm{~Hz}, \mathrm{H}-3^{\prime \prime}, \mathrm{H}-5^{\prime \prime}$ ), 3.85 (m, 1H, H-6'a), 3.63 (m, 1H, H-6'b), $3.56\left(\mathrm{~m}, 1 \mathrm{H}, \mathrm{H}-1^{\prime}\right), 3.20-3.42\left(\mathrm{~m}, 4 \mathrm{H}, \mathrm{H}-2^{\prime}, \mathrm{H}-3^{\prime}, \mathrm{H}-4^{\prime}, \mathrm{H}-5^{\prime}\right) .{ }^{13} \mathrm{C}$ NMR (75 MHz, $\left.\mathrm{CD}_{3} \mathrm{OD}\right): \delta=176.8$ (C-5oxa), 166.1 (C-3oxa), 155.1 $\left(\mathrm{C}-4^{\prime \prime}\right), 129.8\left(\mathrm{C}-2^{\prime \prime}, \mathrm{C}-6^{\prime \prime}\right), 113.7\left(\mathrm{C}-3^{\prime \prime}, \mathrm{C}-5^{\prime \prime}\right), 113.5\left(\mathrm{C}-1^{\prime \prime}\right), 77.7$ (C$\left.1^{\prime}\right), 80.0,78.4,72.7,70.8\left(\mathrm{C}-2^{\prime}, \mathrm{C}-3^{\prime}, \mathrm{C}-4^{\prime}, \mathrm{C}-5^{\prime}\right), 62.0\left(\mathrm{C}-6^{\prime}\right)$.

\section{4.3.6. 5-( $\beta$-D-Glucopyranosyl)-3-(4-hydroxyphenyl)-1,2,4-} oxadiazole $(8 \mathrm{~g})$

A solution of $17 \mathrm{~g}(173 \mathrm{mg}, 0.27 \mathrm{mmol})$ and NaOMe (5 mg) in $\mathrm{MeOH} / \mathrm{CH}_{2} \mathrm{Cl}_{2}$ (10 mL, 9:1) was stirred at rt for $24 \mathrm{~h}$. The reaction was neutralized to $\mathrm{pH}$ 5-6 with Amberlite IR-120 resin $\left(\mathrm{H}^{+}\right.$form)

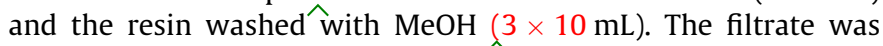

evaporated under diminished pressure and the residue was purified by flash silica gel column chromatography (PE/EtOAc, 1:1 then EtOAc then EtOAc/MeOH 95:5) to afford $\mathbf{8 g}$ (32 $\mathrm{mg}, 37 \%$ ) as a white gum. $R_{\mathrm{f}}=0.39(\mathrm{EtOAc} / \mathrm{MeOH}, 85: 15) \cdot[\alpha]_{\mathrm{D}}^{20}=+10.4(c 1, \mathrm{MeOH}) \cdot{ }^{1} \mathrm{H}$ NMR ( $300 \mathrm{MHz}, \mathrm{CD}_{3} \mathrm{OD}$ ): $\delta=7.88$ (d, $2 \mathrm{H}, J=8.7 \mathrm{~Hz}, \mathrm{H}-2^{\prime \prime}, \mathrm{H}-6^{\prime \prime}$ ), 6.88 (d, 2H, J=8.7 Hz, H-3", H-5"), 4.60 (d, $\left.1 \mathrm{H}, J=9.9 \mathrm{~Hz}, \mathrm{H}-1^{\prime}\right)$, 3.88 (pdd, $1 \mathrm{H}, J<1 \mathrm{~Hz}, J=11.7 \mathrm{~Hz}, \mathrm{H}-6^{\prime} \mathrm{a}$ ), 3.77 (dd, $1 \mathrm{H}, J=8.7 \mathrm{~Hz}$, $\left.J=9.9 \mathrm{~Hz}, \mathrm{H}-2^{\prime}\right), 3.70\left(\mathrm{~m}, 1 \mathrm{H}, \mathrm{H}-6^{\prime} \mathrm{b}\right), 3.54-3.44\left(\mathrm{~m}, 3 \mathrm{H}, \mathrm{H}-3^{\prime}, \mathrm{H}-4^{\prime}\right.$, $\mathrm{H}-5^{\prime}$ ). ${ }^{13} \mathrm{C}$ NMR (75 MHz, CD $\mathrm{OD}$ ): $\delta=176.7$ (C-5oxa), 168.4 (C3oxa), 160.8 (C-4"), 129.1 (C-2", C-6" $), 117.7\left(\mathrm{C}-1^{\prime \prime}\right), 115.8$ (C-3", C-5"'), $74.1\left(\mathrm{C}-1^{\prime}\right), 72.9\left(\mathrm{C}-2^{\prime}\right), 81.9,78.1,70.2\left(\mathrm{C}-3^{\prime}, \mathrm{C}-4^{\prime}, \mathrm{C}-5^{\prime}\right)$, $61.7\left(\mathrm{C}-6^{\prime}\right)$. MS (ESI) $m / z=347.0[\mathrm{M}+\mathrm{Na}]^{+}$. HRMS (ESI) $m / z=$ $\mathrm{C}_{14} \mathrm{H}_{16} \mathrm{~N}_{2} \mathrm{O}_{7}[\mathrm{M}+\mathrm{Na}]^{+}$calcd 347.0855, found 347.0857.

\subsubsection{5-( $\beta$-D-Glucopyranosyl)-3-(1-naphthyl)-1,2,4-oxadiazole ( $8 \mathrm{~h}$ )}

A solution of $17 \mathbf{h}(388 \mathrm{mg}, 0.43 \mathrm{mmol})$ and NaOMe $(5 \mathrm{mg})$ in $\mathrm{MeOH} / \mathrm{CH}_{2} \mathrm{Cl}_{2}(10 \mathrm{~mL}, 9: 1)$ was stirred at rt for $24 \mathrm{~h}$. The reaction was neutralized to $\mathrm{pH}$ 5-6 with Amberlite IR-120 resin ( $\mathrm{H}^{+}$form) and the resin washed with $\mathrm{MeOH}(3 \times 10 \mathrm{~mL})$. The filtrate was evaporated under diminished pressure and the residue was purified by flash silica gel column chromatography (PE/EtOAc, 1:1 then EtOAc then EtOAc/MeOH 95:5) to afford $\mathbf{8 h}(125 \mathrm{mg}, 79 \%)$ as a white solid. $R_{\mathrm{f}}=0.45 \quad(\mathrm{EtOAc} / \mathrm{MeOH}, \quad 9: 1) . \quad \mathrm{Mp}=182-183^{\circ} \mathrm{C}$. $[\alpha]_{\mathrm{D}}^{20}=+14.0(\mathrm{c} 1, \mathrm{MeOH}) .{ }^{1} \mathrm{H}$ NMR $\left(500 \mathrm{MHz}, \mathrm{CD}_{3} \mathrm{OD}\right): \delta=8.83$ $\left(\mathrm{d}, 1 \mathrm{H}, J=8.4 \mathrm{~Hz}, \mathrm{H}-8^{\prime \prime}\right), 8.24\left(\mathrm{~d}, 1 \mathrm{H}, J=7.1 \mathrm{~Hz}, \mathrm{H}-2^{\prime \prime}\right), 8.09(\mathrm{~d}, 1 \mathrm{H}$, $\left.J=8.2 \mathrm{~Hz}, \mathrm{H}-4^{\prime \prime}\right), 7.99\left(\mathrm{~d}, 1 \mathrm{H}, J=7.9 \mathrm{~Hz}, \mathrm{H}-5^{\prime \prime}\right), 7.65-7.58(\mathrm{~m}, 3 \mathrm{H}$, H-3", H-6", H-7"'), 4.73 (d, $\left.1 \mathrm{H}, J=9.8 \mathrm{~Hz}, \mathrm{H}-\hat{1}^{\prime}\right), 3.92$ (dd, $1 \mathrm{H}$, $\left.J<1 \mathrm{~Hz}, J=11.7 \mathrm{~Hz}, \mathrm{H}-6^{\prime} \mathrm{a}\right), 3.85$ (dd, $1 \mathrm{H}, J=9.2 \mathrm{~Hz}, J=9.8 \mathrm{~Hz}, \mathrm{H}-$ $2^{\prime}$ ), 3.74 (dd, $\left.1 \mathrm{H}, J=5.4 \mathrm{~Hz}, J=11.7 \mathrm{~Hz}, \mathrm{H}-6^{\prime} \mathrm{b}\right), 3.57-3.47(\mathrm{~m}, 3 \mathrm{H}$, $\left.\mathrm{H}-3^{\prime}, \mathrm{H}-4^{\prime}, \mathrm{H}-5^{\prime}\right) .{ }^{13} \mathrm{C}$ NMR (125 MHz, CD $\left.\mathrm{OD}\right): \hat{\delta}=176.4$ (C-5oxa), 168.9 (C-3oxa), $134.4\left(\mathrm{C}-1^{\prime \prime}\right), 132.1\left(\mathrm{C}-4^{\prime \prime}\right), 130.8\left(\mathrm{C}-8 \mathrm{a}^{\prime \prime}\right), 129.4(\mathrm{C}-$ $\left.2^{\prime \prime}\right), 128.8\left(\mathrm{C}-5^{\prime \prime}\right), 127.6\left(\mathrm{C}-6^{\prime \prime}\right), 126.5\left(\mathrm{C}-7^{\prime \prime}\right), 126.0\left(\mathrm{C}-8^{\prime \prime}\right), 125.1$ (C-3"), $123.7\left(\mathrm{C}-4 \mathrm{a}^{\prime \prime}\right), 82.0,78.2\left(\mathrm{C}-3^{\prime}, \mathrm{C}-5^{\prime}\right), 74.2\left(\mathrm{C}-1^{\prime}\right), 73.0(\mathrm{C}-$ $\left.2^{\prime}\right), 70.2\left(\mathrm{C}-4^{\prime}\right), 61.7\left(\mathrm{C}-6^{\prime}\right)$. MS (ESI) $m / z=381.2[\mathrm{M}+\mathrm{Na}]^{+}$. HRMS (ESI) $m / z=\mathrm{C}_{18} \mathrm{H}_{18} \mathrm{~N}_{2} \mathrm{O}_{6}[\mathrm{M}+\mathrm{Na}]^{+}$calcd 381.1062, found 381.1062.

4.3.8. 5-( $\beta$-D-Glucopyranosyl)-3-(2-naphthyl)-1,2,4-oxadiazole (8i) and 5-(2-deoxy-D-arabino-hex-1-enopyranosyl)-3-(2naphthyl)-1,2,4-oxadiazole (18i)

A solution of $17 \mathbf{i}$ ( $340 \mathrm{mg}, 0.44 \mathrm{mmol}$ ) was treated according to method $\mathrm{F}$. The residue was purified by flash silica gel column chromatography (PE/EtOAc, 3:2 then EtOAc then EtOAc/MeOH 9:1) to afford $\mathbf{8 i}$ (119 $\mathrm{mg}, 76 \%$ ) as a yellow foam and $\mathbf{1 8 i}$ ( $11 \mathrm{mg}, 8 \%$ ) as a white solid. Analytical data for $\mathbf{8 i}: R_{\mathrm{f}}=0.51(\mathrm{EtOAc} / \mathrm{MeOH}, 9: 1)$. $[\alpha]_{\mathrm{D}}^{20}=+14$ (c 1, MeOH). ${ }^{1} \mathrm{H}$ NMR (300 MHz, $\left.\mathrm{CD}_{3} \mathrm{OD}\right): \delta=8.62$ (s, 1H, H-ar), 8.99 (d, $1 \mathrm{H}, J=8.6 \mathrm{~Hz}, \mathrm{H}-\mathrm{ar}), 7.98-7.92$ (m, 3H, H-ar), 7.59-7-55 (m, 2H, $\mathrm{H}-\mathrm{ar}$ ), $4.70\left(\mathrm{~d}, 1 \mathrm{H}, J=9.8 \mathrm{~Hz}, \mathrm{H}-1^{\prime}\right), 3.93$ (pdd, $1 \mathrm{H}, J<1 \mathrm{~Hz}$, $J=12.2 \mathrm{~Hz}, \mathrm{H}-6^{\prime} \mathrm{a}$ ), $3.84\left(\mathrm{dd}, 1 \mathrm{H}, J=8.9 \mathrm{~Hz}, J=9.8 \mathrm{~Hz}, \mathrm{H}-2^{\prime}\right), 3.74$ (dd, $\left.1 \mathrm{H}, J=4.5 \mathrm{~Hz}, J=12.2 \mathrm{~Hz}, \mathrm{H}-6^{\prime} \mathrm{b}\right), 3.59-3.49$ (m, 3H, H-3', H-4', $\left.\mathrm{H}-5^{\prime}\right) .{ }^{13} \mathrm{C}$ NMR $\left(75 \mathrm{MHz}, \mathrm{CD}_{3} \mathrm{OD}\right): \delta=178.3$ (C-5oxa), 169.7 (C3oxa), 136.2 ( $\mathrm{C}^{\mathrm{IV}}$-ar), 134.5 ( ( $\mathrm{Cl}^{\mathrm{IV}}$-ar), 130.0, 129.9, 129.01, 128.98, 128.9, 128.1, 125.1 ( $\mathrm{C}^{\mathrm{IV}}$-ar), 124.6, $83.0\left(\mathrm{C}-5^{\prime}\right), 79.2\left(\mathrm{C}-3^{\prime}\right), 75.2(\mathrm{C}-$ $\left.1^{\prime}\right), 74.0\left(\mathrm{C}-2^{\prime}\right), 71.3\left(\mathrm{C}-4^{\prime}\right), 62.8\left(\mathrm{C}-6^{\prime}\right)$. MS (ESI) $m / z=359.0[\mathrm{M}+\mathrm{H}]^{+}$, $381.0[\mathrm{M}+\mathrm{Na}]^{+}, 738.9[2 \mathrm{M}+\mathrm{Na}]^{+}$. HRMS (ESI) $m / z=\mathrm{C}_{18} \mathrm{H}_{19} \mathrm{~N}_{2} \mathrm{O}_{6}$ $[\mathrm{M}+\mathrm{H}]^{+}$calcd 359.1243, found 359.1244. Analytical data for 18i: $R_{\mathrm{f}}=0.61$ (EtOAc/MeOH, 9:1). ${ }^{1} \mathrm{H}$ NMR $\left(300 \mathrm{MHz}, \mathrm{CD}_{3} \mathrm{OD}\right): \delta=8.61$ (s, 1H, H-ar), 8.10 (dd, $1 \mathrm{H}, J=1.6 \mathrm{~Hz}, J=8.6 \mathrm{~Hz}, \mathrm{H}-\mathrm{ar}$ ), $8.03-7.97$ (m, 3H H-ar), 7.61-7.57 (m, 2H, H-ar), 6.16 (d, 1H, J = 2.8 $\mathrm{Hz}, \mathrm{H}-2^{\prime}$ ), $4.36\left(\mathrm{dd}, 1 \mathrm{H}, \hat{J}=2.8 \mathrm{~Hz}, J=7.2 \mathrm{~Hz}, \mathrm{H}-3^{\prime}\right), 4.09-4.05\left(\mathrm{~m}, 2 \mathrm{H}, \mathrm{H}-5^{\prime}, \mathrm{H}-\right.$ 6'a), 3.95 (dd, $\left.1 \mathrm{H}, J=5.3 \mathrm{~Hz}, J=12.5 \hat{\mathrm{Hz}}, \mathrm{H}-6^{\prime} \mathrm{b}\right), 3.77$ (dd, $1 \mathrm{H}$, $\left.J=7.2 \mathrm{~Hz}, J=9.5 \mathrm{~Hz}, \mathrm{H}-4^{\prime}\right) .{ }^{13} \mathrm{C}$ NMR $\left(75 \mathrm{MHz}, \mathrm{CD}_{3} \mathrm{OD}\right): \delta=173.0$ (C-5oxa), 169.9 (C-3oxa), $141.2\left(\mathrm{C}-1^{\prime}\right), 136.3\left(\mathrm{C}^{\mathrm{IV}}-\mathrm{ar}\right), 134.5\left(\mathrm{C}^{\mathrm{IV}}-\mathrm{ar}\right)$, $130.1,129.9,129.02,128.96,128.2,125.0\left(\mathrm{C}^{\mathrm{IV}}\right.$-ar), 124.6, $113.0(\mathrm{C}-$ $\left.2^{\prime}\right), 82.3\left(\mathrm{C}-5^{\prime}\right), 70.3\left(\mathrm{C}-3^{\prime}\right), 69.8\left(\mathrm{C}-4^{\prime}\right), 62.0\left(\mathrm{C}-6^{\prime}\right) . \mathrm{MS}(\mathrm{ESI}) \mathrm{m} / z=$ $341.0[\mathrm{M}+\mathrm{H}]^{+}, 363.0[\mathrm{M}+\mathrm{Na}]^{+}, 702.9[2 \mathrm{M}+\mathrm{Na}]^{+}$. HRMS (ESI) $\mathrm{m} / z=$ $\mathrm{C}_{18} \mathrm{H}_{17} \mathrm{~N}_{2} \mathrm{O}_{5}[\mathrm{M}+\mathrm{H}]^{+}$calcd 341.1137, found 341.1136. 
700 4.3.9. 3-(4-Benzyloxyphenyl)-5-( $\beta$-D-glucopyranosyl)-1,2,4oxadiazole (8j)

A solution of $\mathbf{1 7 j}$ (205 $\mathrm{mg}, 0.25 \mathrm{mmol})$ and NaOMe (5 mg) in $\mathrm{MeOH} / \mathrm{CH}_{2} \mathrm{Cl}_{2}$ (5 mL, 9:1) was stirred at $x \mathrm{t}$ for $24 \mathrm{~h}$. The reaction was neutralized to $\mathrm{pH}$ 5-6 with Amberlite IR-120 resin ( $\mathrm{H}^{+}$form) and the resin washed with $\mathrm{MeOH}(3 \times 10 \mathrm{~mL})$. The filtrate was evaporated under diminished pressure and the residue was purified by flash silica gel column chromatography (PE/EtOAc, 1:1 then EtOAc then EtOAc/MeOH 95:5) to afford $8 \mathbf{j}$ (57 mg, 56\%) as a white foam. $R_{\mathrm{f}}=0.31$ (EtOAc/MeOH, 9:1). $[\alpha]_{\mathrm{D}}^{20}=+10.5$ (c 1.13, MeOH). ${ }^{1} \mathrm{H}$ NMR $\left(300 \mathrm{MHz}, \mathrm{CD}_{3} \mathrm{OD}\right): \delta=8.00\left(\mathrm{~d}, 2 \mathrm{H}, J=9.0 \mathrm{~Hz}, \mathrm{H}-2^{\prime \prime}, \mathrm{H}-\right.$ $\left.6^{\prime \prime}\right)$, Z.50-7.25 (m, 5H, CH 2 Ph), 7.13 (d, $2 \mathrm{H}, J=9.0 \mathrm{~Hz}, \mathrm{H}-3^{\prime \prime}, \mathrm{H}-5^{\prime \prime}$ ), 5.15 (s, 2H, CH $\left.\mathrm{CH}_{2} \mathrm{Ph}\right), 4.63$ (d, $1 \mathrm{H}, J=9.6 \mathrm{~Hz}, \mathrm{H}-1^{\prime}$ ), 3.91 (pdd, $1 \mathrm{H}$, $\left.J<1 \mathrm{~Hz}, J=11.4 \mathrm{~Hz}, \mathrm{H}-6^{\prime} \mathrm{a}\right), 3.80(\mathrm{dd}, 1 \mathrm{H}, J=8.7 \mathrm{~Hz}, J=9.6 \mathrm{~Hz}, \mathrm{H}-$ $2^{\prime}$ ), 3.72 (m, $\left.1 \mathrm{H}, \mathrm{H}-6^{\prime} \mathrm{b}\right), 3.47$ ( $\left.\mathrm{m}, 3 \mathrm{H}, \mathrm{H}-3^{\prime}, \mathrm{H}-4^{\prime}, \mathrm{H}-5^{\prime}\right) .{ }^{13} \mathrm{C} \mathrm{NMR}$ (75 MHz, CD ${ }_{3} \mathrm{OD}$ ): $\delta=177.9$ (C-5oxa), 169.3 (C-3oxa), 162.8 (C$\left.4^{\prime \prime}\right), 138.2\left(\mathrm{C}^{\mathrm{IV}}-\mathrm{ar}\right), 130.0\left(\mathrm{C}-2^{\prime \prime}, \mathrm{C}-6^{\prime \prime}\right), 129.6,129.0,128.6\left(\mathrm{CH}_{2} \mathrm{Ph}\right)$, 120.3 (C-1"), 116.4 (C-3", $\left.\mathrm{C}^{\prime \prime} 5^{\prime \prime}\right), 75.1\left(\mathrm{C}-1^{\prime}\right), 73.9\left(\mathrm{C}-2^{\prime}\right), 83.0,79.2$, $71.2\left(\mathrm{C}-3^{\prime}, \mathrm{C}-4^{\prime}, \mathrm{C}-5^{\prime}\right), 71.1\left(\mathrm{CH}_{2} \mathrm{Ph}\right), 62.7\left(\mathrm{C}-6^{\prime}\right) . \mathrm{MS}(\mathrm{ESI}) \mathrm{m} / \mathrm{z}=$ $437.2[\mathrm{M}+\mathrm{Na}]^{+}$. HRMS (ESI) $m / z=\mathrm{C}_{21} \mathrm{H}_{22} \mathrm{~N}_{2} \mathrm{O}_{7}[\mathrm{M}+\mathrm{Na}]^{+}$calcd 437.1325 , found 437.1325 .

\subsubsection{3-(1,3-Benzodioxol-5-yl)-5-( $\beta$-D-glucopyranosyl)-1,2,4- oxadiazole ( $8 \mathrm{k}$ )}

A solution of 17k (280 mg, $0.36 \mathrm{mmol})$ and NaOMe $(5 \mathrm{mg})$ in $\mathrm{MeOH} / \mathrm{CH}_{2} \mathrm{Cl}_{2}$ (15 mL, 2:1) was stirred at rt for $2 \mathrm{~h}$. The reaction was neutralized to $\mathrm{pH}$ 5-6 with Amberlite IR-120 resin ( $\mathrm{H}^{+}$form) and the resin washed with $\mathrm{MeOH}(2 \times 10 \mathrm{~mL})$. The filtrate was evaporated under diminished pressure and the residue was purified by flash silica gel column chromatography (PE/EtOAc, 1:1 then EtOAc then EtOAc/MeOH 85:15) to afford 8k (74 mg, 60\%) as a pale yellow foam. $R_{\mathrm{f}}=0.41$ (EtOAc/MeOH, 85:15). $[\alpha]_{\mathrm{D}}^{20}=+18.0$ (c 1, DMSO). ${ }^{1} \mathrm{H}$ NMR $\left(300 \mathrm{MHz}, \mathrm{CD}_{3} \mathrm{OD}\right): \delta=7.64$ (dd, $\left.1 \mathrm{H}, J=1.6 \mathrm{~Hz}, J=8.1 \mathrm{~Hz}, \mathrm{H}-5^{\prime \prime}\right), 7.48(\mathrm{~d}, 1 \mathrm{H}, J=1.6 \mathrm{~Hz}, \mathrm{H}$ $3^{\prime \prime}$ ), $6.95\left(\mathrm{~d}, 1 \mathrm{H}, J=8.1 \mathrm{~Hz}, \mathrm{H}-6^{\prime \prime}\right), 6.05\left(\mathrm{~s}, 2 \mathrm{H}, \mathrm{OCH}_{2} \mathrm{O}\right), 4.62$ (d, $\left.1 \mathrm{H}, J=9.8 \mathrm{~Hz}, \mathrm{H}-1^{\prime}\right), 3.91$ (dd, $1 \mathrm{H}, J=1.6 \mathrm{~Hz}, J=12.2 \mathrm{~Hz}, \mathrm{H}-6^{\prime} \mathrm{a}$ ), $3.78\left(\mathrm{t}, 1 \mathrm{H}, J=9.8 \mathrm{~Hz}, \mathrm{H}-2^{\prime}\right), 3.71(\mathrm{dd}, 1 \mathrm{H}, J=5.2 \mathrm{~Hz}, J=12.2 \mathrm{~Hz}$, $\left.\mathrm{H}-6^{\prime} \mathrm{b}\right), 3.56-3.40\left(\mathrm{~m}, 3 \mathrm{H}, \mathrm{H}-3^{\prime}, \mathrm{H}-4^{\prime}, \mathrm{H}-5^{\prime}\right) .{ }^{13} \mathrm{C} \mathrm{NMR}(75 \mathrm{MHz}$, $\left.\mathrm{CD}_{3} \mathrm{OD}\right): \delta=178.0$ (C-5oxa), 169.3 (C-3oxa), 152.0, 149.8 (C-1", $\left.\mathrm{C}-2^{\prime \prime}\right), 123.4\left(\mathrm{C}-5^{\prime \prime}\right), 121.5\left(\mathrm{C}^{\mathrm{IV}}-\mathrm{ar}\right), 109.7\left(\mathrm{C}-6^{\prime \prime}\right), 108.7\left(\mathrm{C}-3^{\prime \prime}\right)$, $103.3\left(\mathrm{OCH}_{2} \mathrm{O}\right), 75.2\left(\mathrm{C}-1^{\prime}\right), 74.0\left(\mathrm{C}-2^{\prime}\right), 83.0,79.2,71.2\left(\mathrm{C}-3^{\prime}, \mathrm{C}-\right.$ $\left.4^{\prime}, \mathrm{C}-5^{\prime}\right), 62.8\left(\mathrm{C}-6^{\prime}\right)$. MS (ESI) $m / z=353[\mathrm{M}+\mathrm{H}]^{+}, 375[\mathrm{M}+\mathrm{Na}]^{+}$, $727[2 \mathrm{M}+\mathrm{Na}]^{+}$. HRMS (ESI) $m / z=\mathrm{C}_{15} \mathrm{H}_{16} \mathrm{~N}_{2} \mathrm{NaO}_{8}[\mathrm{M}+\mathrm{Na}]^{+}$calcd 375.0804 , found 375.0802 .

\subsection{Zemplén deacylation of 1,3,4-oxadiazoles}

\subsubsection{2-Phenyl-5-(2,3,4,6-tetra-O-benzoyl- $\beta$-D-glucopyranosyl)-} 1,3,4-oxadiazole $(11 \mathrm{~b})$

Prepared according to method A. Yield: 78\% (white solid). Alternative preparation: To a solution of benzoic acid $(19 \mathrm{mg}$, $0.15 \mathrm{mmol}$ ) and DCC (32 $\mathrm{mg}, 0.15 \mathrm{mmol}$ ) in abs. toluene was added tetrazole $10(100 \mathrm{mg}, 0.15 \mathrm{mmol})$, and refluxed for $4 \mathrm{~h}$. After cooling to rt the mixture was filtered and evaporated. The product 11b was crystallized from EtOH (62 mg, 56\%) and obtained as white crystals. $\mathrm{Mp}=186-187^{\circ} \mathrm{C} . \quad[\alpha]_{\mathrm{D}}^{20}=-195(\mathrm{c}$ $\left.0.21, \mathrm{CHCl}_{3}\right) .{ }^{1} \mathrm{H}$ NMR $\left(360 \mathrm{MHz}, \mathrm{CDCl}_{3}\right): \delta=8.06-7.26(\mathrm{~m}, 25 \mathrm{H}$, $\mathrm{H}$-ar), 6.11, 6.01, $5.88\left(3 \times \mathrm{pt}, 3 \mathrm{H}, J \sim 9.3 \mathrm{~Hz}, \mathrm{H}-2^{\prime}, \mathrm{H}-3^{\prime}, \mathrm{H}-4^{\prime}\right)$, $5.29\left(\mathrm{~d}, 1 \mathrm{H}, J=9.3 \mathrm{~Hz}, \mathrm{H}-1^{\prime}\right), 4.71$ (dd, $1 \mathrm{H}, J=2.6 \mathrm{~Hz}, J=11.9 \mathrm{~Hz}$, H-6'a), 4.54 (dd, $1 \mathrm{H}, J=5.3 \mathrm{~Hz}, J=11.9 \mathrm{~Hz}, \mathrm{H}-6^{\prime} \mathrm{b}$ ), 4.40 (ddd, $\left.1 \mathrm{H}, J=2.6 \mathrm{~Hz}, J=5.3 \mathrm{~Hz}, J=9.3 \mathrm{~Hz}, \mathrm{H}-5^{\prime}\right) .{ }^{13} \mathrm{C}$ NMR $(90 \mathrm{MHz}$, $\left.\mathrm{CDCl}_{3}\right): \delta=166.0, \quad 165.9165 .6,165.1,164.8$ (C=0, C-5oxa), 162.0 (C-2oxa), 133.5-123.3 (CH-ar, $\left.\mathrm{C}^{\mathrm{IV}}-\mathrm{ar}\right), 77.1$ (C-1'), 73.6, 71.9, 70.3, 69.0 (C-2', C-3', C-4', C-5'), 63.0 (C-6'). Anal. Calcd for $\mathrm{C}_{42} \mathrm{H}_{32} \mathrm{~N}_{2} \mathrm{O}_{10}$ (724.73): C, 69.61; H, 4.45; N, 3.87. Found: $\mathrm{C}$, 69.52; H, 4.11; N, 3.99.

\subsubsection{2-(4-Methylphenyl)-5-(2,3,4,6-tetra-O-benzoyl- $\beta$-D- glucopyranosyl)-1,3,4-oxadiazole $(11 \mathrm{c})$}

To a solution of tetrazole $\mathbf{1 0}(500 \mathrm{mg}, 0.77 \mathrm{mmol})$ in abs. toluene $(5 \mathrm{~mL})$ was added 4-methyl-benzoyl chloride $(0.95 \mathrm{mmol})$. The reaction mixture was refluxed for $3 \mathrm{~h}$ then evaporated in vacuum. Crystallisation from EtOH gave 11c (379 mg, 70\%) as white crystals. Mp $=170-172{ }^{\circ} \mathrm{C} .[\alpha]_{\mathrm{D}}^{20}=-200\left(\right.$ c $\left.0.19, \mathrm{CHCl}_{3}\right) .{ }^{1} \mathrm{H}$ NMR $\left(360 \mathrm{MHz}, \mathrm{CDCl}_{3}\right): \delta=8.05-7.80(\mathrm{~m}, 10 \mathrm{H}, \mathrm{H}-\mathrm{ar}), 7.57-7.29(\mathrm{~m}$, $14 \mathrm{H}, \mathrm{H}-\mathrm{ar}$ ), 6.10 (t, $\left.1 \mathrm{H}, J=9.3 \mathrm{~Hz}, \mathrm{H}-2^{\prime}\right), 6.02(\mathrm{t}, 1 \mathrm{H}, J=9.3 \mathrm{~Hz}, \mathrm{H}-$ $3^{\prime}$ ), 5.87 (dd, $1 \mathrm{H}, J=9.3 \mathrm{~Hz}, J=10.6 \mathrm{~Hz}, \mathrm{H}-4^{\prime}$ ), 5.27 (d, $1 \mathrm{H}$, $\left.J=9.3 \mathrm{~Hz}, \mathrm{H}-1^{\prime}\right), 4.70\left(\mathrm{dd}, 1 \mathrm{H}, J<1 \mathrm{~Hz}, J=11.9 \mathrm{~Hz}, \mathrm{H}-6^{\prime} \mathrm{a}\right), 4.54$ (dd, $1 \mathrm{H}, J=5.3 \mathrm{~Hz}, J=11.9 \mathrm{~Hz}, \mathrm{H}-6^{\prime} \mathrm{b}$ ), 4.38 (ddd, $1 \mathrm{H}, J<1 \mathrm{~Hz}$, $\left.J=5.3 \mathrm{~Hz}, J=10.6 \mathrm{~Hz}, \mathrm{H}-5^{\prime}\right), 2.41$ (s, 3H, $\left.\mathrm{PhCH}_{3}\right) .{ }^{13} \mathrm{C}$ NMR $\left(90 \mathrm{MHz}, \mathrm{CDCl}_{3}\right): \delta=166.1,165.7,165.2,164.9(\mathrm{C}=0), 160.7$, 142.7 (C-2oxa, C-5oxa), 133.6-120.6 (CH-ar, C $\mathrm{C}^{\mathrm{IV}}$-ar), 77.0 (C-1'), 73.7, 71.9, 70.2, 69.1 (C-2', C-3', C-4', C-5'), $63.0\left(\mathrm{C}-6^{\prime}\right), 21.6$ $\left(\mathrm{PhCH}_{3}\right)$. Anal. Calcd for $\mathrm{C}_{43} \mathrm{H}_{34} \mathrm{~N}_{2} \mathrm{O}_{10}$ (738.76): C, 69.91; $\mathrm{H}, 4.64$; N, 3.79. Found: C, 69.99; H, 4.57; N, 3.72.

\subsubsection{2-(4-Methoxyphenyl)-5-(2,3,4,6-tetra-0-benzoyl- $\beta$-D- glucopyranosyl)-1,3,4-oxadiazole (11d)}

To a solution of tetrazole $\mathbf{1 0}(500 \mathrm{mg}, 0.77 \mathrm{mmol})$ in abs. toluene $(5 \mathrm{~mL})$ was added 4-methoxy-benzoyl chloride ( $1.54 \mathrm{mmol})$. The reaction mixture was refluxed for $1 \mathrm{~h}$. Then it was cooled to rt, washed with saturated aqueous $\mathrm{NaHCO}_{3}$ solution and water. The organic phase was dried $\left(\mathrm{MgSO}_{4}\right)$, concentrated under diminished pressure and purified by column chromatography (hexane/ EtOAc, $1: 1)$ to give 11d $(235 \mathrm{mg}, 40 \%)$ as a syrup. $[\alpha]_{\mathrm{D}}^{20}=-261(c$ $\left.0.19, \mathrm{CHCl}_{3}\right) .{ }^{1} \mathrm{H}$ NMR $\left(360 \mathrm{MHz}, \mathrm{CDCl}_{3}\right): \delta=8.05-7.80(\mathrm{~m}, 10 \mathrm{H}$, $\mathrm{H}$-ar), 7.36-7.27 (m, 12H, H-ar), 6.97-6.95 (d, 2H, J=9.3 Hz, Har), $6.12\left(\mathrm{dd}, 1 \mathrm{H}, J=9.3 \mathrm{~Hz}, J=10.6 \mathrm{~Hz}, \mathrm{H}-2^{\prime}\right), 6.04(\mathrm{dd}, 1 \mathrm{H}$, $\left.J=9.3 \mathrm{~Hz}, J=10.6 \mathrm{~Hz}, \mathrm{H}-3^{\prime}\right), 5.89\left(\mathrm{t}, 1 \mathrm{H}, J=9.3 \mathrm{~Hz}, \mathrm{H}-4^{\prime}\right), 5.28$ (d, $1 \mathrm{H}, J=9.3 \mathrm{~Hz}, \mathrm{H}-1^{\prime}$ ), 4.71 (pdd, $1 \mathrm{H}, J<1 \mathrm{~Hz}, J=11.9 \mathrm{~Hz}, \mathrm{H}-6^{\prime} \mathrm{a}$ ), 4.55 (dd, $1 \mathrm{H}, J=5.3 \mathrm{~Hz}, J=11.9 \mathrm{~Hz}, \mathrm{H}-6^{\prime} \mathrm{b}$ ), 4.40 (ddd, $1 \mathrm{H}$, $\left.J=2.6 \mathrm{~Hz}, J=5.3 \mathrm{~Hz}, J=9.3 \mathrm{~Hz}, \mathrm{H}-5^{\prime}\right), 3.80$ (s, 3H, OMe). ${ }^{13} \mathrm{C} \mathrm{NMR}$ $\left(90 \mathrm{MHz}, \mathrm{CDCl}_{3}\right): \delta=166.0,165.8,165.6,165.1(\mathrm{C}=0), 162.5$, 160.4 (C-2oxa, C-5oxa), 133.5-114.3 (CH-ar, $\left.\mathrm{C}^{\mathrm{IV}}-\mathrm{ar}\right), 77.0\left(\mathrm{C}-1^{\prime}\right)$, 73.6, 71.8, 70.2, $69.0\left(\hat{\mathrm{C}}^{-} 2^{\prime}, \mathrm{C}-3^{\prime}, \mathrm{C}-4^{\prime}, \mathrm{C}-5^{\prime}\right), 62.9\left(\mathrm{C}-6^{\prime}\right), 55.3$ (OMe). Anal. Calcd for $\mathrm{C}_{43} \mathrm{H}_{34} \mathrm{~N}_{2} \mathrm{O}_{11}$ (754.76): C, 68.43; $\mathrm{H}, 4.54 ; \mathrm{N}$, 3.71. Found: C, 68.34; H, 4.61; N, 3.63.

\subsubsection{2-(4-Nitrophenyl)-5-(2,3,4,6-tetra-0-benzoyl- $\beta$-D- glucopyranosyl)-1,3,4-oxadiazole (11e)}

To a solution of tetrazole $\mathbf{1 0}(850 \mathrm{mg}, 1.31 \mathrm{mmol})$ in abs. toluene $(9 \mathrm{~mL})$ was added 4-nitro-benzoyl chloride $(1.57 \mathrm{mmol})$. The reaction mixture was refluxed for $4.5 \mathrm{~h}$ then evaporated under diminished pressure. Crystallisation from EtOH gave 11e (635 mg, 63\%) as yellowish crystals. $\mathrm{Mp}=158-161{ }^{\circ} \mathrm{C}$. $[\alpha]_{\mathrm{D}}^{20}=>-297$ (c 0.17, $\left.\mathrm{CHCl}_{3}\right) .{ }^{1} \mathrm{H} \mathrm{NMR}\left(360 \mathrm{MHz}, \mathrm{CDCl}_{3}\right): \delta=8.36-7.29$ (m, 24H, H-ar), $6.13\left(\mathrm{t}, 1 \mathrm{H}, J=9.3 \mathrm{~Hz}, \mathrm{H}-2^{\prime}\right), 5.95(\mathrm{dd}, 1 \hat{\mathrm{H},} J=9.3 \mathrm{~Hz}, J=10.6 \mathrm{~Hz}, \mathrm{H}-$ 3'), 5.89 (dd, $\left.1 \mathrm{H}, J=9.3 \mathrm{~Hz}, J=10.6 \mathrm{~Hz}, \mathrm{H}-4^{\prime}\right), 5.29$ (d, $1 \mathrm{H}$, $\left.J=9.3 \mathrm{~Hz}, \mathrm{H}-1^{\prime}\right), 4.70\left(\mathrm{dd}, 1 \mathrm{H}, J<1 \mathrm{~Hz}, J=11.9 \mathrm{~Hz}, \mathrm{H}-6^{\prime} \mathrm{a}\right), 4.53$ (dd, $\left.1 \mathrm{H}, J=3.9 \mathrm{~Hz}, J=11.9 \mathrm{~Hz}, \mathrm{H}^{\prime} 6^{\prime} \mathrm{b}\right), 4.41$ (ddd, $1 \mathrm{H}, J<1 \mathrm{~Hz}, J=3.9 \mathrm{~Hz}$, $\left.J=9.3 \mathrm{~Hz}, \mathrm{H}-5^{\prime}\right) .{ }^{13} \mathrm{C} \mathrm{NMR}\left(90 \mathrm{MHz}, \mathrm{CDCl}_{3}\right): \delta=166.0,165.6,165.1$, 165.0 (C=O), 164.1, 162.0 (C-2oxa, C-5oxa), 149.7 (CH-ar, $\mathrm{C}^{\mathrm{IV}}-\mathrm{ar}$ ) 133.7-128.2 (CH-ar, C $\mathrm{C}^{\mathrm{IV}}$-ar), $77.2\left(\mathrm{C}-1^{\prime}\right), 73.3,71.8,70.4,68.9$ (C-2', C-3', C-4', C-5'), 62.8 (C-6'). Anal. Calcd for $\mathrm{C}_{42} \mathrm{H}_{31} \mathrm{~N}_{3} \mathrm{O}_{12}$ (769.73): C, 65.54; H, 4.06; N, 5.46. Found: C, 65.48; H, 4.12; $\mathrm{N}, 5.52$.

4.4.5. 2-(1-Naphthyl)-5-(2,3,4,6-tetra-O-benzoyl- $\beta$-D-glucopyranosyl)-1,3,4-oxadiazole (11h)

Prepared according to method A. Yield: $75 \%$ (white solid). $\mathrm{Mp}=172-174{ }^{\circ} \mathrm{C} .[\alpha]_{\mathrm{D}}^{20}=-162\left(c 0.21, \mathrm{CHCl}_{3}\right) .{ }^{1} \mathrm{H} \mathrm{NMR}(360 \mathrm{MHz}$, $\left.\mathrm{CDCl}_{3}\right): \delta=8.22-7.28(\mathrm{~m}, 27 \mathrm{H}, \mathrm{H}-\mathrm{ar}), 6.14,6.10,5.90(3 \times \mathrm{pt}, 3 \mathrm{H}$, $J \sim 9.3 \mathrm{~Hz}, \widehat{\mathrm{H}-2} 2^{\prime}, \mathrm{H}-3^{\prime}, \mathrm{H}-4^{\prime}$ ), $5.34\left(\mathrm{~d}, 1 \mathrm{H}, J=9.3 \mathrm{~Hz}, \mathrm{H}-1^{\prime}\right), 4.71(\mathrm{dd}$, 
$\left.1 \mathrm{H}, J=2.6 \mathrm{~Hz}, J=11.9 \mathrm{~Hz}, \mathrm{H}-6^{\prime} \mathrm{a}\right), 4.55(\mathrm{dd}, 1 \mathrm{H}, J=5.3 \mathrm{~Hz}, J=11.9 \mathrm{~Hz}$, $\mathrm{H}-6^{\prime} \mathrm{b}$ ), 4.42 (ddd, $\left.1 \mathrm{H}, J=2.6 \mathrm{~Hz}, J=5.3 \mathrm{~Hz}, J=9.3 \mathrm{~Hz}, \mathrm{H}-5^{\prime}\right) .{ }^{13} \mathrm{C} \mathrm{NMR}$ $\left.\left(90 \mathrm{MHz}, \mathrm{CDCl}_{3}\right): \delta=166.1,165.9165 .6,165.2,164.9{ }_{\mathrm{C}} \mathrm{C}=\mathrm{O}, \mathrm{C}-5 o x a\right)$, 160.7 (C-2oxa), 133.2-120.0 (CH-ar, $\left.\mathrm{C}^{\mathrm{IV}}-\mathrm{ar}\right), 77.1$ (C-1'), 73.6, 71.9, 70.4, 69.1 (C-2', C-3', C-4', C-5'), $63.0\left(\mathrm{C}-6^{\prime}\right)$. Anal. Calcd for $\mathrm{C}_{46} \mathrm{H}_{34} \mathrm{~N}_{2} \mathrm{O}_{10}$ (774.79): $\mathrm{C}, 71.31 ; \mathrm{H}, 4.42 ; \mathrm{N}, 3.62$. Found: $\mathrm{C}, 71.52$; $\mathrm{H}, 4.20 ; \mathrm{N}, 3.64$.

\subsubsection{2-(2-Naphthyl)-5-(2,3,4,6-tetra-O-benzoyl- $\beta$-D-glucopyr-} anosyl)-1,3,4-oxadiazole (11i)

Prepared according to method A. Yield: $62 \%$ (white solid). $\mathrm{Mp}=164-166^{\circ} \mathrm{C} . \quad[\alpha]_{\mathrm{D}}^{20}=-318 \quad\left(\mathrm{c} 0.21, \quad \mathrm{CHCl}_{3}\right) .{ }^{1} \mathrm{H} \quad \mathrm{NMR}$ $\left(360 \mathrm{MHz}, \mathrm{CDCl}_{3}\right): \delta=8.56-7.30(\mathrm{~m}, 27 \mathrm{H}, \mathrm{H}-\mathrm{ar}), 6.12,6.06,5.90$ $\left(3 \times \mathrm{pt}, 3 \mathrm{H}, J \sim 9.3 \mathrm{~Hz}, \mathrm{H}-2^{\prime}, \mathrm{H}-3^{\prime}, \mathrm{H}-4^{\prime}\right), 5.30(\mathrm{~d}, 1 \mathrm{H}, J=9.3 \mathrm{~Hz}, \mathrm{H}-$ $\left.1^{\prime}\right), 4.72\left(\mathrm{dd}, 1 \mathrm{H}, J=2.6 \mathrm{~Hz}, J=11.9 \mathrm{~Hz}, \mathrm{H}-6^{\prime} \mathrm{a}\right), 4.56$ (dd, $1 \mathrm{H}$, $J=5.3 \mathrm{~Hz}, J=11.9 \mathrm{~Hz}, \mathrm{H}-6^{\prime} \mathrm{b}$ ), 4.40 (ddd, $1 \mathrm{H}, J=2.6 \mathrm{~Hz}, J=5.3 \mathrm{~Hz}$, $\left.J=9.3 \mathrm{~Hz}, \mathrm{H}-5^{\prime}\right) .{ }^{13} \mathrm{C}$ NMR $\left(90 \mathrm{MHz}, \mathrm{CDCl}_{3}\right): \delta=166.5,166.1165 .7$, 165.2, 164.9 (C=O, C-5oxa), 163.2 (C-2oxa), 133.4-120.6 (CH-ar, $\mathrm{C}^{\mathrm{IV}}$-ar), $77.1\left(\mathrm{C}-1^{\prime}\right), 73.6,71.0,70.3,69.1\left(\mathrm{C}-2^{\prime}, \mathrm{C}-3^{\prime}, \mathrm{C}-4^{\prime}, \mathrm{C}-5^{\prime}\right)$, 63.1 (C-6'). Anal. Calcd for $\mathrm{C}_{46} \mathrm{H}_{34} \mathrm{~N}_{2} \mathrm{O}_{10}$ (774.79): C, 71.31; $\mathrm{H}$, 4.42; N, 3.62. Found: C, 71.55; H, 4.08; N, 3.54.

\subsubsection{2-(4-Acetoxyphenyl)-5-(2,3,4,6-tetra-O-benzoyl- $\beta$-D- glucopyranosyl)-1,3,4-oxadiazole $(111)$}

To a solution of 4-acetoxybenzoic acid ( $139 \mathrm{mg}, 0.77 \mathrm{mmol})$ and DCC (159 $\mathrm{mg}, 0.77 \mathrm{mmol})$ in abs. toluene $(5 \mathrm{~mL})$ was added tetrazole 10 ( $500 \mathrm{mg}, 0.77 \mathrm{mmol})$. The reaction was heated to reflux for $7 \mathrm{~h}$. After cooling to rt the mixture was filtered, evaporated and purified by column chromatography (hexane/EtOAc, 2:1) to give 111 (247 mg, 41\%) as a white amorphous product. $[\alpha]_{\mathrm{D}}^{20}=-174\left(\right.$ c $\left.0.17, \mathrm{CHCl}_{3}\right) .{ }^{1} \mathrm{H}$ NMR $\left(360 \mathrm{MHz}, \mathrm{CDCl}_{3}\right): \delta=8.09-$ $7.81(\mathrm{~m}, 10 \mathrm{H}, \mathrm{H}-\mathrm{ar}), 7.56-7.23(\mathrm{~m}, 14 \mathrm{H}, \mathrm{H}-\mathrm{ar}) 6.10(\mathrm{t}, 1 \mathrm{H}$, $\left.J=9.3 \mathrm{~Hz}, \mathrm{H}-2^{\prime}\right), 5.99\left(\mathrm{dd}, 1 \mathrm{H}, J=9.3 \mathrm{~Hz}, J=10.6 \mathrm{~Hz}, \mathrm{H}-3^{\prime}\right), 5.87$ (dd, $\left.1 \mathrm{H}, J=9.3 \mathrm{~Hz}, J=10.6 \mathrm{~Hz}, \mathrm{H}-4^{\prime}\right), 5.26\left(\mathrm{~d}, 1 \mathrm{H}, J=9.3 \mathrm{~Hz}, \mathrm{H}-1^{\prime}\right)$, 4.71 (dd, $1 \mathrm{H}, J=2.6 \mathrm{~Hz}, J=11.9 \mathrm{~Hz}, \mathrm{H}-6 \mathrm{a}), 4.53(\mathrm{dd}, 1 \mathrm{H}$, $J=11.9 \mathrm{~Hz}, J=5.3 \mathrm{~Hz}, \mathrm{H}-6^{\prime} \mathrm{b}$ ), 4.38 (ddd, $1 \mathrm{H}, J=2.6 \mathrm{~Hz}, J=5.3 \mathrm{~Hz}$, $\left.J=9.3 \mathrm{~Hz}, \mathrm{H}-5^{\prime}\right), 2.33$ (s, 3H, OAc). ${ }^{13} \mathrm{C} \mathrm{NMR}\left(90 \mathrm{MHz}, \mathrm{CDCl}_{3}\right)$ : $\delta=168.8\left(\mathrm{COCH}_{3}\right), 166.1,165.7,165.2,165.1(\mathrm{C}=\mathrm{O}), 164.8,161.0$ (C-2oxa, C-5oxa), 153.4, 133.6-120.8 (CH-ar, C $\left.\mathrm{C}^{\mathrm{IV}}-\mathrm{ar}\right), 77.0\left(\mathrm{C}-1^{\prime}\right)$, 73.5, 71.8, 70.2, $69.0\left(\widehat{C}-2^{\prime}, C-3^{\prime}, C^{\prime}-4^{\prime}, C-5^{\prime}\right), 62.9\left(\mathrm{C}-6^{\prime}\right), 21.1$ $\left(\mathrm{COCH}_{3}\right)$. Anal. Calcd for $\mathrm{C}_{44} \mathrm{H}_{34} \mathrm{~N}_{2} \mathrm{O}_{12}$ (782.77): $\mathrm{C}, 67.52 ; \mathrm{H}, 4.38$; $\mathrm{N}, 3.58$. Found: C, 67.58; H, 4.30; N, 3.64.

\subsubsection{2-Phenyl-5-(2,3,4,6-tetra-O-acetyl- $\beta$-D-galactopyranosyl)-} 1,3,4-oxadiazole (15a)

Prepared according to method C. Yield: $78 \%$ (colourless syrup). $[\alpha]_{\mathrm{D}}^{20}=-30\left(\right.$ c 1.06, $\left.\mathrm{CHCl}_{3}\right) .{ }^{1} \mathrm{H}$ NMR $\left(360 \mathrm{MHz}, \mathrm{CDCl}_{3}\right): \delta 8.11-$ $8.09(\mathrm{~m}, 2 \mathrm{H}, \mathrm{H}-\mathrm{ar}), 7.61-7.45(\mathrm{~m}, 3 \mathrm{H}, \mathrm{H}-\mathrm{ar}), 5.64(\mathrm{t}, 1 \mathrm{H}, J=9.9 \mathrm{~Hz}$, $\left.\mathrm{H}-2^{\prime}\right), 5.44\left(\mathrm{~d}, 1 \hat{\mathrm{H},} \mathrm{J}=3.0 \mathrm{~Hz}, \mathrm{H}-4^{\prime}\right), 5.23(\mathrm{dd}, 1 \mathrm{H}, J=3.0 \mathrm{~Hz}$, $\left.J=9.9 \mathrm{~Hz}, \mathrm{H}-3^{\prime}\right), 4.86\left(\mathrm{~d}, 1 \mathrm{H}, J=10.0 \mathrm{~Hz}, \mathrm{H}-1^{\prime}\right), 4.28-4.11(\mathrm{~m}, 3 \mathrm{H}$, $\left.\mathrm{H}^{\prime} 5^{\prime}, \mathrm{H}-6^{\prime} \mathrm{a}, \mathrm{H}-6^{\prime} \mathrm{b}\right), 2.24,2.06,2.02,1.95\left(4 \mathrm{~s}, 12 \hat{\mathrm{H}}, \mathrm{CH}_{3}\right) .{ }^{13} \mathrm{C} \mathrm{NMR}$ $\left(90 \mathrm{MHz}, \mathrm{CDCl}_{3}\right): \delta=170.5,170.3,170.0,169.4(\mathrm{C}=\mathrm{O}), 166.0$ 161.3 (C-2oxa, C-5oxa), 132.2, 129.1,127.4 (CH-ar), 123.5 ( $\mathrm{C}^{\mathrm{IV}}$-ar), $75.5,72.1,71.4,67.4,66.9$ (C-1', C-2', C-3', C-4', C-5'), 61.6 (C-6), 20.7, 20.6, $20.5\left(\mathrm{CH}_{3}\right)$. Anal. Calcd for $\mathrm{C}_{22} \mathrm{H}_{24} \mathrm{~N}_{2} \mathrm{O}_{10}$ (476.43): C, 55.46; H, 5.08; N, 5.88. Found: C, 55.28; H, 5.21; N, 5.67.

\subsubsection{2-Phenyl-5-(2,3,4-tri-O-acetyl- $\beta$-D-xylopyranosyl)-1,3,4- oxadiazole (15b)}

Prepared according to method C. Yield: $67 \%$ (colourless syrup). $[\alpha]_{\mathrm{D}}^{20}=-87\left(\mathrm{c} 1.05, \mathrm{CHCl}_{3}\right) .{ }^{1} \mathrm{H}$ NMR $\left(360 \mathrm{MHz}, \mathrm{CDCl}_{3}\right): \delta=8.09-$ $8.06(\mathrm{~m}, 2 \mathrm{H}, \mathrm{H}-\mathrm{ar}), 7.56-7.49(\mathrm{~m}, 3 \mathrm{H}, \mathrm{H}-\mathrm{ar}), 5.43(\mathrm{pt}, 1 \mathrm{H}$, $J=9.2 \mathrm{~Hz}, \mathrm{H}-2$ or $\mathrm{H}-3), 5.39(\mathrm{t}, 1 \mathrm{H}, J=9.2 \mathrm{~Hz}, \mathrm{H}-2$ or $\mathrm{H}-3), 5.22$ $5.13\left(\mathrm{~m}, 1 \mathrm{H}, \mathrm{H}-4^{\prime}\right), 4.81\left(\mathrm{~d}, 1 \mathrm{H}, J=9.5 \mathrm{~Hz}, \mathrm{H}-1^{\prime}\right), 4.31$ (d) $1 \mathrm{H}$, $J=5.6 \mathrm{~Hz}, J=11.5 \mathrm{~Hz}, \mathrm{H}-5^{\prime}{ }_{\mathrm{eq}}$ ), 3.53 (dd, $1 \mathrm{H}, J=10.7 \mathrm{~Hz}, J=11.5 \mathrm{~Hz}$, $\left.\mathrm{H}^{-5^{\prime}}{ }_{\mathrm{ax}}\right), 2.08,2.06,1.95\left(3 \mathrm{~s}, 9 \mathrm{H}, \mathrm{CH}_{3}\right) .{ }^{13} \mathrm{C} \mathrm{NMR}\left(90 \mathrm{MHz}, \mathrm{CDCl}_{3}\right)$ : $\delta=170.0,169.7$ 169.2, $(\mathrm{C}=0), 165.7,161.2$ (C-2oxa, C-5oxa), 132.1, 129.0, 127.1 (CH-ar), 123.2 ( ( $\mathrm{IV}_{-\mathrm{ar}}$ ), 72.5, 71.9, 69.5, 68.5 $\left(\mathrm{C}-1^{\prime}, \mathrm{C}-2^{\prime}, \mathrm{C}-3^{\prime}, \mathrm{C}-4^{\prime}\right), 67.1\left(\mathrm{C}-5^{\prime}\right), 20.3,20.6\left(\mathrm{CH}_{3}\right)$. Anal. Calcd for $\mathrm{C}_{19} \mathrm{H}_{20} \mathrm{~N}_{2} \mathrm{O}_{8}$ (404.37): C, 56.43; H, 4.99; N, 6.93. Found: C, 56.25; $\mathrm{H}, 5.10 ; \mathrm{N}, 6.80$.

\subsubsection{2-Phenyl-5-(2,3,4-tri-O-acetyl- $\alpha$-D-arabinopyranosyl)- 1,3,4-oxadiazole $(15 \mathrm{c})$}

Prepared according to method C. Yield: 57\% (colourless syrup). $[\alpha]_{\mathrm{D}}^{20}=+48\left(c \lambda .188, \mathrm{CHCl}_{3}\right) .{ }^{1} \mathrm{H} \mathrm{NMR}\left(360 \mathrm{MHz}, \mathrm{CDCl}_{3}\right): \delta=8.11-$ $8.01(\mathrm{~m}, 2 \mathrm{H}, \mathrm{H}-\mathrm{ar}), 2.56-7.49(\mathrm{~m}, 3 \mathrm{H}, \mathrm{H}-\mathrm{ar}), 5.66(\mathrm{pt}, 1 \mathrm{H}$, $\left.J=10.0 \mathrm{~Hz}, \mathrm{H}-2^{\prime}\right), 5.46-5.44\left(\mathrm{~m}, 1 \mathrm{H}, \mathrm{H}-4^{\prime}\right), 5.24(\mathrm{dd}, 1 \mathrm{H}, J=3.3 \mathrm{~Hz}$, $\left.J=10.0 \mathrm{~Hz}, \mathrm{H}-3^{\prime}\right), 4.80\left(\mathrm{~d}, 1 \mathrm{H}, J=9.5 \mathrm{~Hz}, \mathrm{H}-1^{\prime}\right), 4.21(\mathrm{dd}, 1 \mathrm{H}$, $\left.J=2.3 \mathrm{~Hz}, J=13.2 \mathrm{~Hz},{\mathrm{H}-5^{\prime}}_{\mathrm{ax}}\right), 3.90(\mathrm{dd}, 1 \mathrm{H}, J=1.2 \mathrm{~Hz}, J=13.2 \mathrm{~Hz}$, $\mathrm{H}-5^{\prime}{ }_{\text {eq }}$ ), 2.24, 2.04, 1.97 (3s, 9H, $\left.\mathrm{CH}_{3}\right) .{ }^{13} \mathrm{C} \mathrm{NMR}\left(90 \mathrm{MHz}, \mathrm{CDCl}_{3}\right)$ : $\delta=170.3169 .9,169.3, \quad(\mathrm{C}=0), 165.7,161.4$ (C-2oxa, C-5oxa), 132.0, 129.0, 127.1 (CH-ar), 123.3 ( $\mathrm{C}^{\mathrm{IV}}$-ar), 72.2, 70.8, 68.0, 67.0 $\left(\mathrm{C}-1^{\prime}, \mathrm{C}-2^{\prime}, \mathrm{C}-3^{\prime}, \mathrm{C}-4^{\prime}\right), 68.5\left(\mathrm{C}-5^{\prime}\right), 20.9,20.6,20.4\left(\mathrm{CH}_{3}\right)$. Anal. Calcd for $\mathrm{C}_{19} \mathrm{H}_{20} \mathrm{~N}_{2} \mathrm{O}_{8}$ (404.37): C, 56.43; H, 4.99; N, 6.93. Found: C, 56.38; $\mathrm{H}, 4.91 ; \mathrm{N}, 6.70$.

\subsection{Synthesis of hydroximoyl chlorides}

4.5.1. $N$-Hydroxy-benzenecarboximidoyl chloride $(16 b)^{46}$ Prepared according to method D from benzaldehyde (1.76 g, $16.6 \mathrm{mmol})$ to afford $\mathbf{1 6 b}(2.51 \mathrm{~g}, 98 \%)$ as a pale yellow amorphous solid. $R_{\mathrm{f}}=0.69(\mathrm{PE} / \mathrm{EtOAc}, 3 / 1)$.

4.5.2. $N$-Hydroxy-4-methyl-benzenecarboximidoyl chloride $(16 c)^{46}$ Prepared according to method D from 4-methyl-benzaldehyde (3.6 g, $30 \mathrm{mmol})$ to afford $\mathbf{1 6 c}(3.85 \mathrm{~g}, 76 \%)$ as a yellow oil. $\mathrm{R}_{f}=0.37\left(\mathrm{CH}_{2} \mathrm{Cl}_{2}\right) .{ }^{1} \mathrm{H} \mathrm{NMR}\left(300 \mathrm{MHz}, \mathrm{CDCl}_{3}\right): \delta=9.15(\mathrm{~s}, 1 \mathrm{H}, \mathrm{OH})$, 7.70 (d, $2 \mathrm{H}, J=9.0 \mathrm{~Hz}, \mathrm{H}-\mathrm{ar}), 7.18$ (d, 2H, $J=9.0 \mathrm{~Hz}, \mathrm{H}-\mathrm{ar}), 2.36$ (s, $3 \mathrm{H}, \mathrm{PhMe}) .{ }^{13} \mathrm{C}$ NMR $\left(75 \mathrm{MHz}, \mathrm{CDCl}_{3}\right): \delta=144.1,140.3,131.8$, 129.1, 127.0, 21.2.

\subsection{3. $\mathrm{N}$-Hydroxy-4-methoxy-benzenecarboximidoyl chloride $(16 \mathrm{~d})^{47}$}

Prepared according to method D from 4-methoxy-benzaldehyde $(2 \mathrm{~g}, 14.7 \mathrm{mmol})$ to afford $\mathbf{1 6 d}(2.12 \mathrm{~g}, 78 \%)$ as a pale yellow amorphous solid.

4.5.4. $N$-Hydroxy-4-nitro-benzenecarboximidoyl chloride (16e) Prepared according to method D from 4-nitro-benzaldehyde $(2 \mathrm{~g}, 14.1 \mathrm{mmol})$ to afford $\mathbf{1 6 e}(1.61 \mathrm{~g}, 91 \%)$ as a yellow solid. $R_{\mathrm{f}}=0.75\left(\mathrm{CH}_{2} \mathrm{Cl}_{2}\right) . \mathrm{Mp}=101-103{ }^{\circ} \mathrm{C} .{ }^{1} \mathrm{H} \mathrm{NMR}\left(300 \mathrm{MHz}, \mathrm{CDCl}_{3}\right)$ : $\delta=8.05(\mathrm{~d}, 2 \mathrm{H}, J=9.0 \mathrm{~Hz}, \mathrm{H}-3, \mathrm{H}-5), 8.27(\mathrm{~d}, 2 \mathrm{H}, J=9.0 \mathrm{~Hz}, \mathrm{H}-2$, $\mathrm{H}-6), 8.63$ (s, $1 \mathrm{H}, \mathrm{OH}) .{ }^{13} \mathrm{C}$ NMR $\left(75 \mathrm{MHz}, \mathrm{CDCl}_{3}\right): \delta=123.6(\mathrm{C}-3$, C-5), 127.9 (C-2, C-6), 137.9 (C-1), 138.1 (ClCNOH), 148.8 (C-4).

\subsection{5. $\mathrm{N}$-Hydroxy-4-hydroxy-benzenecarboximidoyl chloride} $(16 \mathrm{~g})$

Prepared according to method D from 4-hydroxy-benzaldehyde $(1.71 \mathrm{~g}, 14.0 \mathrm{mmol})$ to afford $\mathbf{1 6 g}(933 \mathrm{mg}, 39 \%)$ as a pale orange oil. $R_{\mathrm{f}}=0.73$ (PE/EtOAc, 3/2). ${ }^{1} \mathrm{H}$ NMR (300 MHz, $\mathrm{CD}_{3} \mathrm{SOCD}_{3}$ ): $\delta=6.83(\mathrm{~d}, 2 \mathrm{H}, J=8.8 \mathrm{~Hz}, \mathrm{H}-2, \mathrm{H}-6), 7.61$ (d, $2 \mathrm{H}, J=8.8 \mathrm{~Hz}, \mathrm{H}-3$, $\mathrm{H}-5), 7.95$ (s, 1H, PhOH), 12.01 (s, $1 \mathrm{H}, \mathrm{NOH}) .{ }^{13} \mathrm{C}$ NMR $(75 \mathrm{MHz}$, $\left.\mathrm{CD}_{3} \mathrm{SOCD}_{3}\right): \delta=116.3(\mathrm{C}-3, \mathrm{C}-5), 123.5(\mathrm{C}-1), 133.7$ (C-2, C-6), 147.3 (ClCNOH), 158.0 (C-4). MS (CI, isobutene) $\mathrm{m} / z=172.0$ $[\mathrm{M}+\mathrm{H}]^{+}$. HRMS (CI, isobutene) $m / z=\mathrm{C}_{7} \mathrm{H}_{6} \mathrm{ClNO}[\mathrm{M}+\mathrm{Na}]^{+}$calcd 172.0165 , found 172.0169 .

4.5.6. $\mathrm{N}$-Hydroxy-1-naphthalenecarboximidoyl chloride $(16 \mathrm{~h})^{46}$ Prepared according to method D from 1-naphthaldehyde $(2 \hat{\mathrm{g}}$, $12.8 \mathrm{mmol})$ to afford $\mathbf{1 6 h}(1.56 \mathrm{~g}, 91 \%)$ as a brown oil. $R_{\mathrm{f}}=0.84$ $\left(\mathrm{CH}_{2} \mathrm{Cl}_{2}\right) .{ }^{1} \mathrm{H}$ NMR $\left(300 \mathrm{MHz}, \mathrm{CD}_{3} \mathrm{SOCD}_{3}\right): \delta=7.48-7.55(\mathrm{~m}, 3 \mathrm{H}, \mathrm{H}-$ 
3, H-6, H-7), 7.66 (dd, 1H, J = 5.1 Hz, J = 7.2 Hz, H-8), Z.91-7.99 (m, $1 \mathrm{H}, \mathrm{H}-4, \mathrm{H}-5), 8,07(\mathrm{~m}, 1 \mathrm{H}, \mathrm{H}-2) .{ }^{13} \mathrm{C}$ NMR $\left(75 \mathrm{MHz}, \mathrm{CD}_{3} \mathrm{SOCD}_{3}\right)$ : $\delta=124.0,124.7,126.0,126.8,127.6,128.0,129.4,130.1,130,4$, $132.7,132.8$. MS (CI, isobutene) $\mathrm{m} / z=206.0[\mathrm{M}+\mathrm{H}]^{+}$. HRMS (CI, isobutene) $m / z=\mathrm{C}_{11} \mathrm{H}_{8} \mathrm{ClNO}[\mathrm{M}+\mathrm{Na}]^{+}$calcd 206.0373, found 206.0370 .

\subsection{7. $N$-Hydroxy-2-naphthalenecarboximidoyl chloride $(16 i)_{\wedge}^{46,48}$}

Prepared according to method D from 2-naphthaldehyde (3.4 g $21.6 \mathrm{mmol})$ to afford $42(2.84 \mathrm{~g}, 64 \%)$ as a pale orange amorphous solid. $R_{\mathrm{f}}=0.66\left(\mathrm{CH}_{2} \mathrm{Cl}_{2}\right) .{ }^{1} \mathrm{H} \mathrm{NMR}\left(300 \mathrm{MHz}, \mathrm{CDCl}_{3}\right): \delta=8.81(\mathrm{~s}, 1 \mathrm{H}$, $\mathrm{OH}), 8.30$ (s, 1H, H-ar), Z.2-7.93 ( $\mathrm{m}, 4 \mathrm{H}, \mathrm{H}-\mathrm{ar}), \mathrm{Z} .43-7.58(\mathrm{~m}, 2 \mathrm{H}, \mathrm{H}-$ ar). ${ }^{13} \mathrm{C}$ NMR ( $\left.75 \mathrm{MHz}, \mathrm{CDCl}_{3}\right): \delta=140.5,134.2,132.6,129.5,128.8$, $128.2,128.1,127.6,127.5,126.8,123.2$.

\subsubsection{4-Benzyloxy- $N$-hydroxy-benzenecarboximidoyl chloride} (16j)

Prepared according to method D from 4-benzyloxy-benzaldehyde $(3 \mathrm{~g}, 14.1 \mathrm{mmol})$ to afford $\mathbf{1 6 j}(1.87 \mathrm{~g}, 51 \%)$ as a pale orange solid. $\quad R_{\mathrm{f}}=0.88 \quad(\mathrm{PE} / \mathrm{EtOAc}, \quad 9 / 1) . \quad \mathrm{Mp}=83-84{ }^{\circ} \mathrm{C} .{ }^{1} \mathrm{H} \quad \mathrm{NMR}$ $\left(300 \mathrm{MHz}, \mathrm{CD}_{3} \mathrm{SOCD}_{3}\right): \delta=5.07\left(\mathrm{~s}, 2 \mathrm{H}, \mathrm{OCH}_{2} \mathrm{Ph}\right), 7.01(\mathrm{~d}, 2 \mathrm{H}$, $J=9.0 \mathrm{~Hz}, \mathrm{H}-3, \mathrm{H}-5), \mathrm{Z} .31-7.36\left(\mathrm{~m}, 5 \mathrm{H}, \mathrm{OCH}_{2} \mathrm{Ph}\right), 7.63(\mathrm{~d}, 2 \mathrm{H}$, $J=9.0 \mathrm{~Hz}, \mathrm{H}-2, \mathrm{H}-6), 12.09$ (s, $1 \mathrm{H}, \mathrm{OH}) .{ }^{13} \mathrm{C}$ NMR $(75 \mathrm{MHz}$, $\left.\mathrm{CD}_{3} \mathrm{SOCD}_{3}\right): \delta=68.7\left(\mathrm{OCH}_{2} \mathrm{Ph}\right), 114.3(\mathrm{C}-3, \mathrm{C}-5), 124.5(\mathrm{C}-1)$, 126.1, 126.9, 127.0, 127.3, 127.9, 127.5 (C-2, C-6), 135.9, 159.3 (ClCNOH), 178.7 (C-4). MS (CI, isobutene) $\mathrm{m} / z=262.0[\mathrm{M}+\mathrm{H}]^{+}$. HRMS (CI, isobutene) $m / z=\mathrm{C}_{14} \mathrm{H}_{12} \mathrm{ClNO}_{2}[\mathrm{M}+\mathrm{Na}]^{+}$calcd 262.0635, found 262.0637 .

\subsection{9. $N$-Hydroxy-benzo[1,3]dioxole-5-carboximidoyl chloride (16k)}

Prepared according to method $\mathrm{D}$ from benzo[1,3]dioxole-5carbaldehyde $(4.5 \mathrm{~g}, 30 \mathrm{mmol})$ to afford $\mathbf{1 6 k}(4.87 \mathrm{~g}, 81 \%)$ as a pale brown amorphous solid. $R_{\mathrm{f}}=0.76\left(\mathrm{PE} / \mathrm{CH}_{2} \mathrm{Cl}_{2}, 3 / 7\right) .{ }^{1} \mathrm{H}$ NMR $\left(300 \mathrm{MHz}, \mathrm{CD}_{3} \mathrm{SOCD}_{3}\right): \delta=12.2(\mathrm{~s}, 1 \mathrm{H}, \mathrm{OH}), 7.32(\mathrm{dd}, 1 \mathrm{H}$, $J=8.2 \mathrm{~Hz}, J=1.8 \mathrm{~Hz}, \mathrm{H}-4), 7.27$ (d, $1 \mathrm{H}, J=1.8 \mathrm{~Hz}, \mathrm{H}-6), 7.00$ (d, $1 \mathrm{H}, J=8.2 \mathrm{~Hz}, \mathrm{H}-3), 6.10\left(\mathrm{~s}, 2 \mathrm{H}, \mathrm{OCH}_{2} \mathrm{O}\right) .{ }^{13} \mathrm{C} \mathrm{NMR}(75 \mathrm{MHz}$, $\mathrm{CD}_{3} \mathrm{SOCD}_{3}$ ): $\delta=149.1,147.6,135.0,126.5,121.5$ (C-4), 108.2 (C3), 106.1 (C-6), $101.8\left(\mathrm{OCH}_{2} \mathrm{O}\right)$.

\section{6. $[3+2]$ Cycloaddition reactions}

4.6.1. 3-Phenyl-5-(2,3,4,6-tetra-O-benzoyl- $\beta$-D-glucopyranosyl)1,2,4-oxadiazole (17b)

A solution composed of $\mathbf{9}$ (350 mg, $0.58 \mathrm{mmol}), \mathbf{1 6 b}(450 \mathrm{mg}$, $2.89 \mathrm{mmol})$ and $\mathrm{Et}_{3} \mathrm{~N}(600 \mu \mathrm{L}, 4.33 \mathrm{mmol})$ was treated according to method $\mathrm{E}$. The residue was purified by flash silica gel column chromatography (PE/EtOAc, 4:1) to afford 17b (400 mg, 94\%) as a yellow solid. $R_{\mathrm{f}}=0.34(\mathrm{PE} /$ EtOAc, $4: 1) . \mathrm{Mp}=71-72{ }^{\circ} \mathrm{C}\left(\mathrm{CH}_{2} \mathrm{Cl}_{2} / \mathrm{PE}\right)$. $[\alpha]_{\mathrm{D}}^{20}=+5\left(c(c), \mathrm{CHCl}_{3}\right) .{ }^{1} \mathrm{H}$ NMR $\left(300 \mathrm{MHz}, \mathrm{CDCl}_{3}\right): \delta=8.05-$ 7.84 (m, 10H, H-ar), 7.53-7.24 (m, 15H, H-ar), 6.12 (m, 2H, H-2', $\left.\mathrm{H}-3^{\prime}\right), 5.92\left(\mathrm{t}, 1 \mathrm{H}, J=9.5 \mathrm{~Hz}, \mathrm{H}-4^{\prime}\right), 5.30\left(\mathrm{~d}, 1 \mathrm{H}, J=9.5 \mathrm{~Hz}, \mathrm{H}-1^{\prime}\right)$, $4.73\left(\mathrm{dd}, 1 \mathrm{H}, J=2.2 \mathrm{~Hz}, J=12.4 \mathrm{~Hz}, \mathrm{H}-6^{\prime} \mathrm{a}\right), 4.59$ (dd, $1 \mathrm{H}, J=4.9 \mathrm{~Hz}$, $\left.J=12.4 \mathrm{~Hz}, \mathrm{H}-6^{\prime} \mathrm{b}\right), 4.43\left(\mathrm{~m}, 1 \mathrm{H}, \mathrm{H}-5^{\prime}\right) .{ }^{13} \mathrm{C} \mathrm{NMR}\left(75 \mathrm{MHz}, \mathrm{CDCl}_{3}\right)$ : $\delta=173.3$ (C-5oxa), 168.3 (C-3oxa), 166.0, 165.7, 165.0, 164.7 $(C=0), 133.4,133.3,133.2,133.0,131.2,129.7$ (2C), 129.6 (3C), 129.3 ( ( $\left.\mathrm{C}^{\mathrm{IV}}-\mathrm{ar}\right), 128.6(2 \mathrm{C}), 128.5\left(2 \mathrm{C}^{\mathrm{IV}}-\mathrm{ar}\right), 128.4\left(\mathrm{C}^{\mathrm{IV}}-\mathrm{ar}\right), 128.3$ (2C), 128.2 (3C), 127.4 (2C), $125.9\left(\mathrm{C}-1^{\prime \prime}\right), 77.2\left(\mathrm{C}-5^{\prime}\right), 73.6\left(\mathrm{C}-3^{\prime}\right)$, $72.4\left(\mathrm{C}-1^{\prime}\right), 70.6\left(\mathrm{C}-2^{\prime}\right), 69.0\left(\mathrm{C}-4^{\prime}\right), 62.9\left(\mathrm{C}-6^{\prime}\right)$. MS (LSIMS, NBA) $m / z=725[\mathrm{M}+\mathrm{H}]^{+}$. HRMS (LSIMS, NBA) $m / z=\mathrm{C}_{42} \mathrm{H}_{33} \mathrm{~N}_{2} \mathrm{O}_{10}[\mathrm{M}+\mathrm{H}]^{+}$ calcd 725.2135 , found 725.2132 .

\subsubsection{3-(4-Methylphenyl)-5-(2,3,4,6-tetra-O-benzoyl- $\beta$-D-} glucopyranosyl)-1,2,4-oxadiazole (17c)

A solution composed of $\mathbf{9}(385 \mathrm{mg}, 0.64 \mathrm{mmol}), \mathbf{1 6 c}(540 \mathrm{mg}$, $3.18 \mathrm{mmol})$ and $\mathrm{Et}_{3} \mathrm{~N}(665 \mu \mathrm{L}, 4.77 \mathrm{mmol})$ was treated according to method $\mathrm{E}$. The residue was purified by flash silica gel column chromatography (PE/EtOAc, 7:3) to afford 17c (250 mg, 53\%) as a pale yellow foam. $R_{\mathrm{f}}=0.40$ (PE/EtOAc, 7:3). $[\alpha]_{\mathrm{D}}^{20}=-3\left(c 1, \mathrm{CH}_{2} \mathrm{Cl}_{2}\right)$. ${ }^{1} \mathrm{H}$ NMR (300 MHz, $\mathrm{CDCl}_{3}$ ): $\delta=8.04(\mathrm{~m}, 2 \mathrm{H}, \mathrm{H}-\mathrm{ar}), 7.94(\mathrm{~m}, 2 \mathrm{H}, \mathrm{H}-$ ar), Z.88-7.81 (m, 6H, H-ar), Z.55-7.24 (m, 12H, H-ar), 7.18 (d, $2 \mathrm{H}, J=8.0 \mathrm{~Hz}, \mathrm{H}-\mathrm{ar}), 6.08\left(\mathrm{~m}, 2 \mathrm{H}, \mathrm{H}-2^{\prime}, \mathrm{H}-3^{\prime}\right), 5.88(\mathrm{t}, 1 \mathrm{H}$, $\left.J=9.7 \mathrm{~Hz}, \mathrm{H}-4^{\prime}\right), 5.26\left(\mathrm{~d}, 1 \mathrm{H}, J=9.7 \mathrm{~Hz}, \mathrm{H}-1^{\prime}\right), 4.70$ (dd, $1 \mathrm{H}$, $\left.J=2.9 \mathrm{~Hz}, J=12.5 \mathrm{~Hz}, \mathrm{H}-6^{\prime} \mathrm{a}\right), 4.56$ (dd, $1 \mathrm{H}, J=5.0 \mathrm{~Hz}, J=12.5 \mathrm{~Hz}$, H-6'b), 4.40 (ddd, $1 \mathrm{H}, J=9.7 \mathrm{~Hz}, J=5.0 \mathrm{~Hz}, J=2.9 \mathrm{~Hz}, \mathrm{H}-5^{\prime}$ ), 2.34 (s, 3H, $\left.\mathrm{CH}_{3} \mathrm{Ph}\right) .{ }^{13} \mathrm{C}$ NMR (75 MHz, $\left.\mathrm{CDCl}_{3}\right): \delta=173.1$ (C-5oxa), 168.4 (C-3oxa), 166.0, 165.7, 165.0, $164.7(\mathrm{C}=0), 141.7\left(\mathrm{C}-1^{\prime \prime}\right)$, 133.5, 133.4, 133.3, 133.1, 129.8, 129.7 (2C), 129.4, 129.3 ( $\left.\mathrm{C}^{\mathrm{IV}}-\mathrm{ar}\right)$, 128.5 ( ( $\mathrm{C}^{\mathrm{IV}}$-ar), 128.4, $128.3(2 \mathrm{C}), 127.3,123.2\left(\mathrm{C}-4^{\prime \prime}\right), 77.1\left(\mathrm{C}-5^{\prime}\right)$, $73.7\left(\mathrm{C}-3^{\prime}\right), 72.4\left(\mathrm{C}-1^{\prime}\right), 70.6\left(\mathrm{C}-2^{\prime}\right), 69.0\left(\mathrm{C}-4^{\prime}\right), 62.9\left(\mathrm{C}-6^{\prime}\right), 21.5$ $\left(\mathrm{CH}_{3} \mathrm{Ph}\right)$. MS (ESI) $m / z=739.0[\mathrm{M}+\mathrm{H}]^{+}, 740.0[\mathrm{M}+\mathrm{Na}]^{+}, 1476.6$ $[2 \mathrm{M}+\mathrm{H}]^{+}, 1498.8[2 \mathrm{M}+\mathrm{Na}]^{+}$. HRMS (ESI) $m / z=\mathrm{C}_{43} \mathrm{H}_{35} \mathrm{~N}_{2} \mathrm{O}_{10}$ $[\mathrm{M}+\mathrm{H}]^{+}$calcd 739.2292, found 739.2293.

\subsubsection{3-(4-Methoxyphenyl)-5-(2,3,4,6-tetra-0-benzoyl- $\beta$-D- glucopyranosyl)-1,2,4-oxadiazole (17d)}

A solution composed of $\mathbf{9}(300 \mathrm{mg}, 0.5 \mathrm{mmol}), \mathbf{1 6 d}(460 \mathrm{mg}$, $2.48 \mathrm{mmol})$ and $\mathrm{Et}_{3} \mathrm{~N}(520 \mu \mathrm{L}, 3.71 \mathrm{mmol})$ was treated according to method $\mathrm{E}$. The residue was purified by flash silica gel column chromatography (PE/EtOAc, 4:1) to afford 17d (336 mg, 90\%) as a white solid. $R_{\mathrm{f}}=0.17$ (PE/EtOAc, 4:1). $\mathrm{Mp}=75-76{ }^{\circ} \mathrm{C}\left(\mathrm{CH}_{2} \mathrm{Cl}_{2} / \mathrm{PE}\right.$ ). $[\alpha]_{\mathrm{D}}^{20}=-9\left(c 1, \mathrm{CHCl}_{3}\right) .{ }^{1} \mathrm{H}$ NMR $\left(300 \widehat{\mathrm{MHz}}, \mathrm{CDCl}_{3}\right): \delta=8.05-7.85$ (m, 10H, H-ar), 7.55-7.28 (m, 12H, H-ar), 6.89 (d, $2 \mathrm{H}, J=8.7 \mathrm{~Hz}$, $\mathrm{H}$-ar), 6.06 (m, 2H, H-2', H-3'), $5.86\left(\mathrm{~m}, 1 \mathrm{H}, \mathrm{H}-4^{\prime}\right), 5.24(\mathrm{~m}, 1 \mathrm{H}, \mathrm{H}-$ $\left.1^{\prime}\right), 4.70\left(\mathrm{dd}, 1 \mathrm{H}, J=1.9 \mathrm{~Hz}, J=12.3 \mathrm{~Hz}, \mathrm{H}-6^{\prime} \mathrm{a}\right), 4.56$ (dd, $1 \mathrm{H}$, $\left.J=4.8 \mathrm{~Hz}, J=12.3 \mathrm{~Hz}, \mathrm{H}-6^{\prime} \mathrm{b}\right), 4.38\left(\mathrm{~m}, 1 \mathrm{H}, \mathrm{H}-5^{\prime}\right), 3.81(\mathrm{~s}, 3 \mathrm{H}$, $\left.\mathrm{OCH}_{3}\right) .{ }^{13} \mathrm{C}$ NMR $\left(75 \mathrm{MHz}, \mathrm{CDCl}_{3}\right): \delta=173.5$ (C-5oxa), $168.6(\mathrm{C}-$ 3oxa), 166.6, 166.2, 165.6 (C=O), $165.2\left(\mathrm{C}-4^{\prime \prime}\right), 162.5,134.0,133.9$, 133.8, 133.6, 130.3, 130.2, 129.9 ( ( $\left.\mathrm{C}^{\mathrm{IV}}-\mathrm{ar}\right), 129.6,129.1$ ( $\left.\mathrm{C}^{\mathrm{IV}}-\mathrm{ar}\right)$, 129.0 ( ( $\mathrm{Cl}^{\mathrm{IV}}$-ar), 128.9, 128.8, 128.8, $119.0\left(\mathrm{C}-1^{\prime \prime}\right), 114.6\left(\mathrm{C}-3^{\prime \prime}\right), 77.6$ $\left(\mathrm{C}-5^{\prime}\right), 74.2\left(\mathrm{C}-2^{\prime}\right.$ or $\left.\mathrm{C}-3^{\prime}\right), 72.9\left(\mathrm{C}-1^{\prime}\right), 71.1\left(\mathrm{C}-2^{\prime}\right.$ or $\left.\mathrm{C}-3^{\prime}\right), 69.5(\mathrm{C}-$ $\left.4^{\prime}\right), 63.4\left(\mathrm{C}-6^{\prime}\right), 55.8\left(\mathrm{OCH}_{3}\right)$. MS (LSIMS, NBA) $m / z=755[\mathrm{M}+\mathrm{H}]^{+}$. HRMS (LSIMS, NBA) $m / z=\mathrm{C}_{43} \mathrm{H}_{35} \mathrm{~N}_{2} \mathrm{O}_{11}[\mathrm{M}+\mathrm{H}]^{+}$calcd 755.2241, found 755.2242 .

\subsubsection{3-(4-Nitrophenyl)-5-(2,3,4,6-tetra-O-benzoyl- $\beta$-D- glucopyranosyl)-1,2,4-oxadiazole (17e)}

A solution composed of $\mathbf{9}(378 \mathrm{mg}, 0.62 \mathrm{mmol}), \mathbf{1 6 e}(630 \mathrm{mg}$, $3.12 \mathrm{mmol})$ and $\mathrm{Et}_{3} \mathrm{~N}(610 \mu \mathrm{L}, 4.86 \mathrm{mmol})$ was treated according to method $\mathrm{E}$. The residue was purified by flash silica gel column chromatography (PE/EtOAc, 4:1) to afford 17e (480 mg, 99\%) as

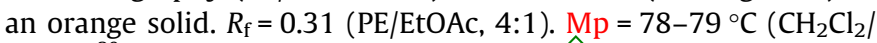
$\mathrm{PE}) .[\alpha]_{\mathrm{D}}^{20}=-9\left(\right.$ c $\left.1, \mathrm{CHCl}_{3}\right) .{ }^{1} \mathrm{H}$ NMR $\left(300 \widehat{\mathrm{MHz}}, \mathrm{CDCl}_{3}\right): \delta=8.21-$ $7.86(\mathrm{~m}, 14 \mathrm{H}, \mathrm{H}-\mathrm{ar}), 7.53-7.25(\mathrm{~m}, 10 \mathrm{H}, \mathrm{H}-\mathrm{ar}), 6.21(\mathrm{t}, 1 \mathrm{H}$, $\left.J=9.4 \mathrm{~Hz}, \mathrm{H}-3^{\prime}\right), 6.09$ t, $\left.1 \mathrm{H}, J=9.4 \mathrm{~Hz}, \mathrm{H}-2^{\prime}\right), 5.96(\mathrm{t}, 1 \mathrm{H}$, $\left.J=9.4 \mathrm{~Hz}, \mathrm{H}-4^{\prime}\right), 5.37$ (d, $\left.1 \mathrm{H}, J=9.4 \mathrm{~Hz}, \mathrm{H}-1^{\prime}\right), 4.77$ (dd, $1 \mathrm{H}$, $\left.J<1 \mathrm{~Hz}, J=12.3 \mathrm{~Hz}, \mathrm{H}-6^{\prime} \mathrm{a}\right), 4.62(\mathrm{dd}, 1 \mathrm{H}, J=4.4 \mathrm{~Hz}, J=12.3 \mathrm{~Hz}, \mathrm{H}-$ 6 b), $4.51\left(\mathrm{~m}, 1 \mathrm{H}, \mathrm{H}-5^{\prime}\right) .{ }^{13} \mathrm{C}$ NMR $\left(75 \mathrm{MHz}, \mathrm{CDCl}_{3}\right): \delta=174.8(\mathrm{C}-$ 5oxa), 167.3 (C-3oxa), 166.5, 166.2, 165.6, 165.4 (C=0), 149.9 (C$\left.1^{\prime \prime}\right), 134.1,133.9,133.7,132.3\left(\mathrm{C}-4^{\prime \prime}\right), 130.3,130.2$ (3C), 129.8 ( $\mathrm{Cl}^{\mathrm{V}}$-ar), 129.0 ( ( $\left.\mathrm{C}^{\mathrm{IV}}-\mathrm{ar}\right), 128.9(3 \mathrm{C}), 128.8(2 \mathrm{C}), 124.4,77.7\left(\mathrm{C}-5^{\prime}\right)$, $74.0\left(\mathrm{C}-3^{\prime}\right), 72.9\left(\mathrm{C}-1^{\prime}\right), 71.2\left(\mathrm{C}-2^{\prime}\right), 69.5\left(\mathrm{C}-4^{\prime}\right), 63.4\left(\mathrm{C}-6^{\prime}\right)$. MS (LSIMS, NBA) $m / z=770 \quad[\mathrm{M}+\mathrm{H}]^{+}$. HRMS (LSIMS, NBA) $\mathrm{m} /$ $z=\mathrm{C}_{42} \mathrm{H}_{32} \mathrm{~N}_{3} \mathrm{O}_{12}[\mathrm{M}+\mathrm{H}]^{+}$calcd 770.1986 , found 770.1983 .

\subsubsection{3-(4-Hydroxyphenyl)-5-(2,3,4,6-tetra-O-benzoyl- $\beta$-D- glucopyranosyl)-1,2,4-oxadiazole $(17 \mathrm{~g})$}

A solution composed of $\mathbf{9}(500 \mathrm{mg}, 0.82 \mathrm{mmol}), \mathbf{1 6 g}(700 \mathrm{mg}$, $4.13 \mathrm{mmol})$ and $\mathrm{Et}_{3} \mathrm{~N}(861 \mu \mathrm{L}, 5.29 \mathrm{mmol})$ was treated according to method $\mathrm{E}$. The residue was purified by flash silica gel column chromatography (PE then PE/EtOAc, 7:3) to afford $\mathbf{1 7} \mathbf{g}$ (250 mg, $41 \%)$ as a white gum. $R_{\mathrm{f}}=0.73(\mathrm{PE} /$ EtOAc, $1: 1) \cdot[\alpha]_{\mathrm{D}}^{20}=-11.7(\mathrm{c}$ 
1.05, $\left.\mathrm{CH}_{2} \mathrm{Cl}_{2}\right) .{ }^{1} \mathrm{H}$ NMR (500 MHz, $\left.\mathrm{CDCl}_{3}\right): \delta=8.07-7.82(\mathrm{~m}, 10 \mathrm{H}, \mathrm{H}-$ ar), Z.57-7.28 (m, 12H, H-ar), 6.85 (d, $\left.2 \mathrm{H}, J=8.7 \mathrm{~Hz}, \mathrm{H}-3^{\prime \prime}, \mathrm{H}-5^{\prime \prime}\right)$, 6.09-6.00 (m, 2H, H-2', H-3'), 5.86 (t, 1H, J = 9.9 Hz, H-4'), 5.24 (d, $1 \mathrm{H}, J=8.8 \mathrm{~Hz}, \mathrm{H}-1^{\prime}$ ), 4.72 (pdd, $1 \mathrm{H}, J<1 \mathrm{~Hz}, J=12.2 \mathrm{~Hz}, \mathrm{H}-6^{\prime} \mathrm{a}$ ), 4.57 (dd, $\left.J=5.1 \mathrm{~Hz}, J=12.2 \mathrm{~Hz}, \mathrm{H}-6^{\prime} \mathrm{b}\right), 4.43-4.36\left(\mathrm{~m}, 1 \mathrm{H}, \mathrm{H}-5^{\prime}\right)$. ${ }^{13} \mathrm{C}$ NMR $\left(125 \mathrm{MHz}, \mathrm{CDCl}_{3}\right): \delta=174.8$ (C-5oxa), 173.0 (C-3oxa), $168.1,166.2,165.8,165.1(\mathrm{C}=\mathrm{A}), 164.8,158.3\left(\mathrm{C}-4^{\prime \prime}\right), 133.6\left(\mathrm{C}^{\mathrm{IV}}-\right.$ ar), $133.8,133.5,133.2,129.9,129.8$ (C-2", C-6"), 129.4, 128.6, 128.56, 128.46, 128.38, $118.7\left(\mathrm{C}-1^{\prime \prime}\right), 115.7\left(\mathrm{C}-3^{\prime \prime}, \mathrm{C}-5^{\prime \prime}\right), 77.2$ (C5'), $73.7\left(\mathrm{C}-3^{\prime}\right), 72.5\left(\mathrm{C}-1^{\prime}\right), 70.6\left(\mathrm{C}-2^{\prime}\right), 69.0\left(\mathrm{C}-4^{\prime}\right), 63.0\left(\mathrm{C}-6^{\prime}\right)$. MS (ESI) $m / z=741.0 \quad[\mathrm{M}+\mathrm{H}]^{+}, \quad 763.0 \quad[\mathrm{M}+\mathrm{Na}]^{+}$. HRMS (ESI) $\mathrm{m} /$ $z=\mathrm{C}_{42} \mathrm{H}_{32} \mathrm{~N}_{2} \mathrm{O}_{11}[\mathrm{M}+\mathrm{H}]^{+}$calcd 741.2084, found 741.2082.

\subsubsection{3-(1-Naphthyl)-5-(2,3,4,6-tetra-O-benzoyl- $\beta$-D- glucopyranosyl)-1,2,4-oxadiazole (17h)}

A solution composed of $\mathbf{9}(600 \mathrm{mg}, 0.99 \mathrm{mmol}), \mathbf{1 6 h}(1.02 \mathrm{~g}$, $4.96 \mathrm{mmol})$ and $\mathrm{Et}_{3} \mathrm{~N}(1.03 \mathrm{~mL}, 7.43 \mathrm{mmol})$ was treated according to method $\mathrm{E}$. The residue was purified by flash silica gel column chromatography (PE then PE/EtOAc, 7:3) to afford 17h $(424 \mathrm{mg}$, $55 \%)$ as a dark red foam. $R_{\mathrm{f}}=0.65(\mathrm{PE} /$ EtOAc, $7: 3) .[\alpha]_{\mathrm{D}}^{20}=+3.0(\mathrm{c}$ 1, $\mathrm{CH}_{2} \mathrm{Cl}_{2}$ ). ${ }^{1} \mathrm{H}$ NMR $\left(300 \mathrm{MHz}, \mathrm{CDCl}_{3}\right): \delta=8.73$ (dd, $J=1.4 \mathrm{~Hz}$, $\left.J=15.8 \mathrm{~Hz}, \mathrm{H}-8^{\prime \prime}\right), 8.06-7.85(\mathrm{~m}, 10 \mathrm{H}, \mathrm{H}-\mathrm{ar}), 7.54-7.25(\mathrm{~m}, 16 \mathrm{H}$, $\mathrm{H}$-ar), $6.10\left(\mathrm{~m}, 2 \mathrm{H}, \mathrm{H}-2^{\prime}, \mathrm{H}-3^{\prime}\right), 5.88\left(\mathrm{t}, 1 \mathrm{H}, J=9.9 \mathrm{~Hz}, \mathrm{H}-4^{\prime}\right), 5.30$ (d, $\left.1 \mathrm{H}, J=9.0 \mathrm{~Hz}, \mathrm{H}-1^{\prime}\right), 4.73$ (dd, $1 \mathrm{H}, J=2.9 \mathrm{~Hz}, J=12.5 \mathrm{~Hz}, \mathrm{H}-6^{\prime} \mathrm{a}$ ), 4.58 (dd, $1 \mathrm{H}, J=5.2 \mathrm{~Hz}, J=12.5 \mathrm{~Hz}, \mathrm{H}-6^{\prime} \mathrm{b}$ ), 4.42 (ddd, $1 \mathrm{H}$, $\left.J=2.9 \mathrm{~Hz}, J=5.2 \mathrm{~Hz}, J=9.9 \mathrm{~Hz}, \mathrm{H}-5^{\prime}\right) .{ }^{13} \mathrm{C} \mathrm{NMR}\left(75 \mathrm{MHz}, \mathrm{CDCl}_{3}\right)$ : $\delta=172.4$ (C-5oxa), 168.8 (C-3oxa), 166.1, 165.7, 165.1, 164.8 $(\mathrm{C}=0), 133.7\left(\mathrm{C}^{\mathrm{IV}}-\mathrm{ar}\right), 133.6,133.5,133.3,131.1,130.4\left(\mathrm{C}^{\mathrm{IV}}-\mathrm{ar}\right)$, $129.8,129.7,129.5,129.4$ ( $\mathrm{C}^{\mathrm{IV}}$-ar), 128.6, 128.53 ( $\mathrm{C}^{\mathrm{IV}}$-ar), 128.5, $128.4,128.3,127.5,126.2,126.0,124.9,123.0$ ( ( $\mathrm{IV}^{\mathrm{V}}$-ar $), 77.2\left(\mathrm{C}-5^{\prime}\right)$, $73.6\left(\mathrm{C}-3^{\prime}\right), 72.5\left(\mathrm{C}-1^{\prime}\right), 70.7\left(\mathrm{C}-2^{\prime}\right), 69.0\left(\mathrm{C}-4^{\prime}\right), 62.9\left(\mathrm{C}-6^{\prime}\right)$. MS (ESI) $m / z=775.1 \quad[\mathrm{M}+\mathrm{H}]^{+}, \quad 797.1 \quad[\mathrm{M}+\mathrm{Na}]^{+}$. HRMS (ESI) $\mathrm{m} /$ $z=\mathrm{C}_{46} \mathrm{H}_{34} \mathrm{~N}_{2} \mathrm{O}_{10}[\mathrm{M}+\mathrm{Na}]^{+}$calcd 797.2111, found 770.2114.

\subsubsection{3-(2-Naphthyl)-5-(2,3,4,6-tetra-0-benzoyl-p-D-glucopyr-} anosyl)-1,2,4-oxadiazole (17i)

A solution composed of $\mathbf{9}(345 \mathrm{mg}, 0.57 \mathrm{mmol}), \mathbf{1 6 i}(586 \mathrm{mg}$, $2.85 \mathrm{mmol})$ and $\mathrm{Et}_{3} \mathrm{~N}(595 \mu \mathrm{L}, 4.86 \mathrm{mmol})$ was treated according to method $\mathrm{E}$. The residue was purified by flash silica gel column chromatography (PE/EtOAc, 4:1) to afford 17i (342 mg, 77\%) as a pale yellow foam. $R_{\mathrm{f}}=0.24$ (PE/EtOAc, 4:1). $[\alpha]_{\mathrm{D}}^{20}=-10$ (c 1 , $\mathrm{CH}_{2} \mathrm{Cl}_{2}$ ). ${ }^{1} \mathrm{H}$ NMR (300 MHz, $\mathrm{CDCl}_{3}$ ): $\delta=8.42$ (s, $\left.1 \mathrm{H}, \mathrm{H}-\mathrm{ar}\right), 8.00-$ $7.90(\mathrm{~m}, 12 \mathrm{H}, \mathrm{H}-\mathrm{ar}), 7.25-7.15(\mathrm{~m}, 14 \mathrm{H}, \mathrm{H}-\mathrm{ar}), 6.10-6.00(\mathrm{~m}, 2 \mathrm{H}$, $\left.\mathrm{H}-2^{\prime}, \mathrm{H}-3^{\prime}\right), 5.88\left(\mathrm{t}, 1 \hat{\mathrm{H}}, J=9.8 \mathrm{~Hz}, \mathrm{H}-4^{\prime}\right), 5.28(\mathrm{~d}, 1 \mathrm{H}, J=9.4 \mathrm{~Hz}, \mathrm{H}-$ $\left.1^{\prime}\right), 4.73\left(\mathrm{dd}, 1 \mathrm{H}, J=2.8 \mathrm{~Hz}, J=12.5 \mathrm{~Hz}, \mathrm{H}-6^{\prime} \mathrm{a}\right), 4.58$ (dd, $1 \mathrm{H}$, $J=5.0 \mathrm{~Hz}, J=12.5 \mathrm{~Hz}, \mathrm{H}-6^{\prime} \mathrm{b}$ ), 4.41 (ddd, $1 \mathrm{H}, J=2.8 \mathrm{~Hz}, J=5.0 \mathrm{~Hz}$, $\left.J=9.8 \mathrm{~Hz}, \mathrm{H}-5^{\prime}\right) .{ }^{13} \mathrm{C}$ NMR $\left(75 \mathrm{MHz}, \mathrm{CDCl}_{3}\right): \delta=173.4$ (C-5oxa), 168.5 (C-3oxa), 166.1, 165.8, 165.1, $164.8(\mathrm{C}=0), 134.6\left(\mathrm{C}^{\mathrm{IV}}-\mathrm{ar}\right)$, $133.6,133.5,133.4,133.2,132.8$ ( $\mathrm{C}^{\mathrm{IV}}-\mathrm{ar}$ ), 129.8, 129.7, 129.4, $128.8,128.6,128.5$ ( $\mathrm{C}^{\mathrm{IV}}$-ar), 128.4, 128.3, 128.2, 127.8, 127.5, 126.7, 123.7, $123.4\left(\mathrm{C}^{\mathrm{IV}}-\right.$ ar $), 77.2\left(\mathrm{C}-5^{\prime}\right), 73.6\left(\mathrm{C}-3^{\prime}\right), 72.6\left(\mathrm{C}-1^{\prime}\right)$, $70.6\left(\mathrm{C}-2^{\prime}\right), 69.0\left(\mathrm{C}-4^{\prime}\right), 63.0\left(\mathrm{C}-6^{\prime}\right)$. MS (ESI) $m / z=775.0[\mathrm{M}+\mathrm{H}]^{+}$, $1549.7[2 \mathrm{M}+\mathrm{H}]^{+}, 1570.8[2 \mathrm{M}+\mathrm{Na}]^{+}$. HRMS (ESI) $m / z=\mathrm{C}_{46} \mathrm{H}_{35} \mathrm{~N}_{2} \mathrm{O}_{10}$ $[\mathrm{M}+\mathrm{H}]^{+}$calcd 775.2292 , found 775.2293 .

\subsubsection{3-(4-Benzyloxyphenyl)-5-(2,3,4,6-tetra-O-benzoyl- $\beta$-D- glucopyranosyl)-1,2,4-oxadiazole $(17 \mathbf{j})$}

A solution composed of $\mathbf{9}(222 \mathrm{mg}, 0.37 \mathrm{mmol}), \mathbf{1 6 j}(482 \mathrm{mg}$, $1.83 \mathrm{mmol})$ and $\mathrm{Et}_{3} \mathrm{~N}(383 \mu \mathrm{L}, 2.75 \mathrm{mmol})$ was treated according to method $\mathrm{E}$. The residue was purified by flash silica gel column chromatography (PE then PE/EtOAc, 7:3) to afford 17j $(211 \mathrm{mg}$, $69 \%$ ) as a deep red foam. $R_{\mathrm{f}}=0.40(\mathrm{PE} / \mathrm{EtOAc}, 7: 3) \cdot[\alpha]_{\mathrm{D}}^{20}=-14.0$ (c $1, \mathrm{CH}_{2} \mathrm{Cl}_{2}$ ). ${ }^{1} \mathrm{H}$ NMR (500 MHz, $\left.\mathrm{CDCl}_{3}\right): \delta=8.09-8.03(\mathrm{~m}, 2 \mathrm{H}, \mathrm{H}-$ ar), 7.95 (d, $\left.2 \mathrm{H}, J=7.0 \mathrm{~Hz}, \mathrm{H}-2^{\prime \prime}, \mathrm{H}-6^{\prime \prime}\right), 7.92-7.87$ (m, 6H, H-ar), 7.58-7.31 (m, 17H, H-ar), 7.00 (d, 2H, J =8.5 Hz, H-3", H-5"), 6.07 (m, 2H, H-3', H-4') $5.87\left(\mathrm{t}, 1 \mathrm{H}, J=9.5 \mathrm{~Hz}, \mathrm{H}-2^{\prime}\right), 5.23(\mathrm{~d}, 1 \mathrm{H}$,
$\left.J=9.5 \mathrm{~Hz}, \mathrm{H}-1^{\prime}\right), 5.12\left(\mathrm{~s}, 2 \mathrm{H}, \mathrm{OCH}_{2} \mathrm{Ph}\right), 4.72(\mathrm{dd}, 1 \mathrm{H}, J=3.0 \mathrm{~Hz}$, $\left.J=17.5 \mathrm{~Hz}, \mathrm{H}-6^{\prime} \mathrm{a}\right), 4.58\left(\mathrm{dd}, 1 \mathrm{H}, J=5.0 \mathrm{~Hz}, J=17.5 \mathrm{~Hz}, \mathrm{H}-6^{\prime} \mathrm{b}\right)$, 4.40 (ddd, $1 \mathrm{H}, J=3.0 \mathrm{~Hz}, J=5.0 \mathrm{~Hz}, J=10.0 \mathrm{~Hz}, \mathrm{H}-5^{\prime}$ ). ${ }^{13} \mathrm{C} \mathrm{NMR}$ $\left(125 \mathrm{MHz}, \mathrm{CDCl}_{3}\right): \delta=173.0$ (C-5oxa), 168.1 (C-3oxa), 166.1, 165.8, 165.1, $164.7(\mathrm{C}=\mathrm{O}), 161.2\left(\mathrm{C}-4^{\prime \prime}\right), 136.3\left(\mathrm{C}^{\mathrm{IV}}-\mathrm{ar}\right), 133.6$, $133.4,133.3,133.2,129.9,129.8\left(\mathrm{C}^{\mathrm{IV}}-\mathrm{ar}\right), 129.4,129.2,128.6\left(\mathrm{C}^{\mathrm{IV}}\right.$ ar), $128.4,128.3\left(\mathrm{OCH}_{2} \mathrm{Ph}\right), 128.1,127.5,118.8\left(\mathrm{C}-1^{\prime}\right), 115.0\left(\mathrm{C}-3^{\prime \prime}\right.$, $\left.\mathrm{C}-5^{\prime \prime}\right), 77.2\left(\mathrm{C}-5^{\prime}\right), 73.7\left(\mathrm{C}-2^{\prime}\right), 72.5\left(\mathrm{C}-1^{\prime}\right), 70.6\left(\mathrm{C}-3^{\prime}\right), 70.0\left(\mathrm{OCH}_{2} \mathrm{Ph}\right)$, $69.0\left(\mathrm{C}-4^{\prime}\right), 63.0\left(\mathrm{C}-6^{\prime}\right)$. MS (ESI) $m / z=831.1[\mathrm{M}+\mathrm{H}]^{+}, \quad 853.2$ $[\mathrm{M}+\mathrm{Na}]^{+}$. HRMS (ESI) $m / z=\mathrm{C}_{49} \mathrm{H}_{38} \mathrm{~N}_{2} \mathrm{O}_{11}[\mathrm{M}+\mathrm{Na}]^{+}$calcd 853.2373, found 853.2375 .

4.6.9. 3-(1,3-Benzodioxol-5-yl)-5-(2,3,4,6-tetra-O-benzoyl- $\beta$-Dglucopyranosyl)-1,2,4-oxadiazole (17k)

A solution composed of $\mathbf{9}$ (300 $\mathrm{mg}, 0.49 \mathrm{mmol}), \mathbf{1 6 k}$ (494 mg, $2.48 \mathrm{mmol}$ ) and $\mathrm{Et}_{3} \mathrm{~N}(518 \mu \mathrm{L}, 3.72 \mathrm{mmol})$ was treated according to method $\mathrm{E}$. The residue was purified by flash silica gel column chromatography (PE/EtOAc, 4:1) to afford 17k (282 mg, 74\%) as a white foam. $R_{\mathrm{f}}=0.18(\mathrm{PE} / \mathrm{EtOAc}, 4: 1) .[\alpha]_{\mathrm{D}}^{20}=-11.0\left(c 1, \mathrm{CH}_{2} \mathrm{Cl}_{2}\right) .{ }^{1} \mathrm{H} \mathrm{NMR}$ (300 MHz, $\left.\mathrm{CDCl}_{3}\right): \delta=8.06-7.82(\mathrm{~m}, 8 \mathrm{H}, \mathrm{H}-\mathrm{ar}), 7.57-7.23(\mathrm{~m}, 14 \mathrm{H}$, $\mathrm{H}-\mathrm{ar}), 6.79(\mathrm{~d}, 1 \mathrm{H}, J=8.1 \mathrm{~Hz}, \mathrm{H}-\mathrm{ar}), 6.08\left(\mathrm{t}, 1 \mathrm{H}, J=9.5 \mathrm{~Hz}, \mathrm{H}-2^{\prime}\right)$, $6.03\left(\mathrm{t}, 1 \mathrm{H}, J=9.5 \mathrm{~Hz}, \mathrm{H}-3^{\prime}\right), 5.97\left(\mathrm{~s}, 2 \mathrm{H}, \mathrm{OCH}_{2} \mathrm{O}\right), 5.86(\mathrm{t}, 1 \mathrm{H}$, $\left.J=9.5 \mathrm{~Hz}, \mathrm{H}-4^{\prime}\right), 5.22$ (d, $\left.1 \mathrm{H}, J=9.5 \mathrm{~Hz}, \mathrm{H}-1^{\prime}\right), 4.70$ (dd, $1 \mathrm{H}$, $J=2.9 \mathrm{~Hz}, J=12.4 \mathrm{~Hz}, \mathrm{H}-6^{\prime} \mathrm{a}$ ), 4.55 (dd, $1 \mathrm{H}, J=5.2 \mathrm{~Hz}, J=12.4 \mathrm{~Hz}, \mathrm{H}-$ $\left.6^{\prime} \mathrm{b}\right), 4.38$ (ddd, $\left.1 \mathrm{H}, J=2.9 \mathrm{~Hz}, J=5.2 \mathrm{~Hz}, J=9.5 \mathrm{~Hz}, \mathrm{H}-5^{\prime}\right) .{ }^{13} \mathrm{C} \mathrm{NMR}$ $\left(75 \mathrm{MHz}, \mathrm{CDCl}_{3}\right.$ ): $\delta=173.1$ (C-5oxa), 168.1 (C-3oxa), 166.1, 165.7, 165.0, $164.7(\mathrm{C}=0), 150.2$ ( $\left.\mathrm{C}^{\mathrm{IV}}-\mathrm{ar}\right), 148.0$ ( $\left.\mathrm{C}^{\mathrm{IV}}-\mathrm{ar}\right), 133.5,133.4$, 133.3, 133.1, 129.8, 129.7, 129.4 ( ( $\mathrm{IV}^{\mathrm{V}}$-ar), 128.5 ( ( $\mathrm{C}^{\mathrm{IV}}$-ar), 128.4, 128.3, 122.5, 119.8 ( ( $\mathrm{IV}^{\mathrm{V}}$-ar), 108.5, 107.4, $101.5\left(\mathrm{OCH}_{2} \mathrm{O}\right), 77.1$ (C$\left.5^{\prime}\right), 73.6\left(\mathrm{C}-2^{\prime}\right), 72.4\left(\mathrm{C}-1^{\prime}\right), 70.6\left(\mathrm{C}-3^{\prime}\right), 69.0\left(\mathrm{C}-4^{\prime}\right), 62.9\left(\mathrm{C}-6^{\prime}\right)$. MS (ESI) $m / z=769[\mathrm{M}+\mathrm{H}]^{+}, 1537[2 \mathrm{M}+\mathrm{H}]^{+}, 1559[2 \mathrm{M}+\mathrm{Na}]^{+}$. HRMS (ESI) $m / z=\mathrm{C}_{43} \mathrm{H}_{33} \mathrm{~N}_{2} \mathrm{O}_{12}[\mathrm{M}+\mathrm{H}]^{+}$calcd 769.2033, found 769.2035.

\subsection{Enzymology}

Glycogen phosphorylase $b$ was prepared from rabbit skeletal muscle according to the method of Fischer and Krebs, ${ }^{42}$ using dithiothreitol instead of L-cysteine, and recrystallized at least three times before use. Kinetic experiments were performed in the direction of glycogen synthesis as described previously. ${ }^{43}$ Kinetic data for the inhibition of rabbit skeletal muscle glycogen phosphorylase were collected using different concentrations of $\alpha$-D-glucose-1phosphate $(2-20 \mathrm{mM})$, constant concentrations of glycogen $(1 \%$ $\mathrm{w} / \mathrm{v})$ and AMP $(1 \mathrm{mM})$, and various concentrations of inhibitors. Inhibitors were dissolved in dimethyl sulfoxide (DMSO) and diluted in the assay buffer ( $50 \mathrm{mM}$ triethanolamine, $1 \mathrm{mM}$ EDTA and $1 \mathrm{mM}$ dithiothreitol) so that the DMSO concentration in the assay should be lower than $1 \%$. The enzymatic activities were presented in the form of double-reciprocal plots (Lineweaver-Burk) applying a nonlinear data analysis program. The inhibitor constants $\left(K_{\mathrm{i}}\right)$ were determined by Dixon plots, by replotting the slopes from the Lineweaver-Burk plots against the inhibitor concentrations. ${ }^{17,44}$ The means of standard errors for all calculated kinetic parameters averaged to less than $10 \%$.

\section{Acknowledgments}

Financial support was received from the Hungarian Scientific Research Fund (Grants: OTKA 45927, 60620 and 61336) and the Hungarian National Office for Research and Technology (Öveges József Programme: HEF_06_3-T2DMDEBR). The authors thank the Hungarian Academy of Sciences and CNRS for supporting their cooperation in the frame of a Projet International de Coopération Scientifique (PICS 4576). Authors are also grateful to University Lyon 1 and the Région Rhône-Alpes for financial support (MIRA Recherche 2006) and a PhD stipend to MB. 


\section{References and notes}

1. Moller, D. E. Nature 2001, 414, 821.

2. Cheng, A. Y. Y.; Fantus, I. G. CMAJ 2005, 172, 213.

3. Krentz, A. J.; Bailey, C. J. Drugs 2005, 65, 385.

4. Padwal, R.; Majumdar, S. R.; Johnson, J. A.; Varney, J.; McAlister, F. A. Diabetes Care 2005, 28, 736 .

5. van de Laar, F. A.; Lucassen, P. L.; Akkermans, R. P.; van de Lisdonk, F. H.; Rutten G. E.; van Weel, C. Diabetes Care 2005, 28, 154.

6. Murata, G. H.; Duckworth, W. C.; Hoffman, R. M.; Wendel, C. S.; Mohler, M. J.; Shah, J. H. Biomed. Pharmacother. 2004, 58, 551.

7. Wagman, A. S.; Nuss, J. M. Curr. Pharm. Des. 2001, 7, 417.

8. Alberti, G.; Zimmet, P.; Shaw, J.; Bloomgarden, Z.; Kaufman, F.; Silink, M. Diabetes Care 2004, 27, 1798.

9. Bloomgarden, Z. T. Diabetes Care 2004, 27, 998

10. Ehtisham, S.; Barrett, T. G. Ann. Clin. Biochem. 2004, 41, 10

11. Agius, L. Best Pract. Res. Clin. Endocrinol. Metab. 2007, 21, 587.

12. Morral, N. Trends Endocrinol. Metab. 2003, 14, 169.

13. Nourparvar, A.; Bulotta, A.; Di Mario, U.; Perfetti, R. Trends Pharmacol. Sci. 2004 25,86

14. Oikonomakos, N. G. Curr. Protein Pept. Sci. 2002, 3, 561.

15. Treadway, J. L.; Mendys, P.; Hoover, D. J. Exp. Opin. Invest. Drugs 2001, 10, 439.

16. Watson, K. A.; Mitchell, E. P.; Johnson, L. N.; Cruciani, G.; Son, J. C.; Bichard, C. J. F.; Fleet, G. W. J.; Oikonomakos, N. G.; Kontou, M.; Zographos, S. E. Acto Crystallogr., Sect. D. 1995, 51, 458.

17. Somsák, L.; Kovács, L.; Tóth, M.; Ősz, E.; Szilágyi, L.; Györgydeák, Z.; Dinya, Z.; Docsa, T.; Tóth, B.; Gergely, P. J. Med. Chem. 2001, 44, 2843.

18. Györgydeák, Z.; Hadady, Z.; Felföldi, N.; Krakomperger, A.; Nagy, V.; Tóth, M.; Brunyánszky, A.; Docsa, T.; Gergely, P.; Somsák, L. Bioorg. Med. Chem. 2004, 12, 4861.

19. Oikonomakos, N. G.; Kosmopolou, M.; Zographos, S. E.; Leonidas, D. D.; Somsák L.; Nagy, V.; Praly, J.-P.; Docsa, T.; Tóth, B.; Gergely, P. Eur. J. Biochem. 2002, 269, 1684.

20. Somsák, L.; Czifrák, K.; Tóth, M.; Bokor, É.; Chrysina, E. D.; Alexacou, K. M.; Hayes, J. M.; Tiraidis, C.; Lazoura, E.; Leonidas, D. D.; Zographos, S. E. Oikonomakos, N. G. Curr. Med. Chem. 2008, 15, 2933.

21. Hadady, Z.; Tóth, M.; Somsák, L. Arkivoc 2004, 140.
22. Chrysina, E. D.; Kosmopolou, M. N.; Tiraidis, C.; Kardarakis, R.; Bischler, N.; Leonidas, D. D.; Hadady, Z.; Somsák, L.; Docsa, T.; Gergely, P.; Oikonomakos, N. G. Protein Sci. 2005, 14, 873.

23. Benltifa, M.; Vidal, S.; Fenet, B.; Msaddek, M.; Goekjian, P. G.; Praly, J.-P.; Brunyánszki, A.; Docsa, T.; Gergely, P. Eur. J. Org. Chem. 2006, 4242.

24. Benltifa, M.; Vidal, S.; Gueyrard, D.; Goekjian, P. G.; Msaddek, M.; Praly, J.-P. Tetrahedron Lett. 2006, 47, 6143.

25. Oikonomakos, N. G.; Somsák, L. Curr. Opin. Invest. Drugs 2008, 9, 379.

26. He, L.; Zhang, Y. Z.; Tanoh, M.; Chen, G. R.; Praly, J. P.; Chrysina, E. D.; Tiraidis, C.; Kosmopoulou, M.; Leonidas, D. D.; Oikonomakos, N. G. Eur. J. Org. Chem. 2007, 596.

27. Farkas, I.; Szabó, I. F.; Bognár, R. Carbohydr. Res. 1977, 56, 404.

28. Farkas, I.; Szabó, I. F.; Bognár, R.; Szilágyi, L. Khim. Geterotsikl. Soedin. 1978, 893.

29. Mahmoud, S. H.; Somsák, L.; Farkas, I. Carbohydr. Res. 1994, 254, 91.

30. Povazanec, F.; Kovac, J.; Svoboda, J. Collect. Czech. Chem. Commun. 1980, 45, 1299.

31. Narayana, B.; Ashalatha, B. V.; Vijaya Raj, K. K.; Fernandes, J.; Sarojini, B. K. Bioorg. Med. Chem. 2005, 13, 4638.

32. Chang, H.-T.; Chiang, K.-C.; Wong, F. F.; Yeh, M.-Y. Heterocycles 2006, 68, 1585.

33. Rao, V. S.; Sekhar, K. V. G. C. Synth. Commun. 2004, 34, 2153.

34. Li, Z.; Xing, Y.; Xuelin; Xiao, S.; Lu, Z. Synth. Commun. 2006, 36, 3287.

35. Shang, Z. Synth. Commun. 2006, 36, 2927.

36. Dabiri, M.; Salehi, P.; Baghbanzadeh, M.; Bahramnejad, M. Tetrahedron Lett. 2006, 47, 6983.

37. Tóth, M.; Somsák, L. Carbohydr. Res. 2003, 338, 1319.

38. Jung, M. E.; Trufinovich, I. D.; Gardiner, J. M.; Clevenger, G. L. J. Chem. Soc., Chem. Commun. 1990, 84

39. Delany, J. J.; Padykula, R. E.; Berchtold, G. A. J. Am. Chem. Soc. 1992, 114, 1394.

40. Buchanan, J. G.; Clelland, A. P. W.; Johnson, T.; Rennie, R. A. C.; Wightman, R. H. J. Chem. Soc., Perkin Trans. 1 1992, 2593.

41. Ősz, E.; Czifrák, K.; Deim, T.; Szilágyi, L.; Bényei, A.; Somsák, L. Tetrahedron 2001, 57, 5429.

42. Fischer, E. H.; Krebs, E. G. Meth. Enzymol. 1962, 5, 369.

43. Oikonomakos, N. G.; Skamnaki, V. T.; Ősz, E.; Szilágyi, L.; Somsák, L.; Docsa, T.; Tóth, B.; Gergely, P. Bioorg. Med. Chem. 2002, 10, 261.

44. Osz, E.; Somsák, L.; Szilágyi, L.; Kovács, L.; Docsa, T.; Tóth, B.; Gergely, P. Bioorg. Med. Chem. Lett. 1999, 9, 1385. 